\title{
Apathy in Alzheimer's and Parkinson's disease : assessment, pathophysiology and treatment
}

Citation for published version (APA):

Drijgers, R. L. (2012). Apathy in Alzheimer's and Parkinson's disease : assessment, pathophysiology and treatment. [Doctoral Thesis, Maastricht University]. NeuroPsych Publishers.

https://doi.org/10.26481/dis.20121011rd

Document status and date:

Published: 01/01/2012

DOI:

10.26481/dis.20121011rd

Document Version:

Publisher's PDF, also known as Version of record

\section{Please check the document version of this publication:}

- A submitted manuscript is the version of the article upon submission and before peer-review. There can be important differences between the submitted version and the official published version of record.

People interested in the research are advised to contact the author for the final version of the publication, or visit the DOI to the publisher's website.

- The final author version and the galley proof are versions of the publication after peer review.

- The final published version features the final layout of the paper including the volume, issue and page numbers.

Link to publication

\footnotetext{
General rights rights.

- You may freely distribute the URL identifying the publication in the public portal. please follow below link for the End User Agreement:

www.umlib.nl/taverne-license

Take down policy

If you believe that this document breaches copyright please contact us at:

repository@maastrichtuniversity.nl

providing details and we will investigate your claim.
}

Copyright and moral rights for the publications made accessible in the public portal are retained by the authors and/or other copyright owners and it is a condition of accessing publications that users recognise and abide by the legal requirements associated with these

- Users may download and print one copy of any publication from the public portal for the purpose of private study or research.

- You may not further distribute the material or use it for any profit-making activity or commercial gain

If the publication is distributed under the terms of Article $25 \mathrm{fa}$ of the Dutch Copyright Act, indicated by the "Taverne" license above, 
Apathy in Alzheimer's and Parkinson's disease Assessment, pathophysiology and treatment 
C copyright R. L. Drijgers, Maastricht 2012

Cover design: Renée Prevoo

Cover photography: Juliette Tellier

Cover model: Mevr. Johanna Swinkels-van Wekberg

Layout: Ivo Bleylevens

Printing: Datawyse BV, Maastricht

Publisher: NeuroPsych Publishers

ISBN: $\quad$ 978-90-75579-57-4

NeuroPsych Publishers is a non-profit organization, which aims at promoting the science of 'Brain and Behaviour' and improving the application of the products of this science in health care and education. NeuroPsych Publishers accomplishes these aims by publishing books, dissertations and other products of scientific activity, by disseminating educational material and publication of tests, assessment scales and other psychometric instruments in the field of Neuropsychology, Neuropsychiatry and other areas within the domain of Brain and Behaviour.

NeuroPsych Publisher

Department of Psychiatry \& Neuropsychology

Maastricht University

P.O. Box 616

6200 MD Maastricht

www.np.unimaas.nl 


\title{
Apathy in Alzheimer's and Parkinson's disease
}

\section{Assessment, pathophysiology and treatment}

\author{
PROEFSCHRIFT \\ Ter verkrijging van de graad van doctor aan de Universiteit Maastricht, \\ op gezag van de Rector Magnificus, Prof. dr. L.L.G. Soete, \\ volgens het besluit van het College van Decanen, \\ in het openbaar te verdedigen op \\ donderdag 11 oktober 2012 om 12.00 uur
}

door

Roosje Leontine Drijgers

Geboren op 24 december 1982 te Middelburg 


\title{
Promotor:
}

Prof. dr. F.R.J. Verhey

\section{Co-promotores:}

\author{
Dr. P. Aalten \\ Dr. A.F.G. Leentjens
}

\section{Beoordelingscommissie:}

Prof. dr. E. Griez (voorzitter)

Prof. dr. R.C. van der Mast (Leids Universitair Medisch Centrum)

Prof. P. Robert (Université de Nice Sophia Antipolis)

Prof. dr. Y. Temel

Dr. W. Weber

The research described in this thesis was performed at the department of Psychiatry \& Neuropsychology, School for Mental Health and Neuroscience, Maastricht University, The Netherlands.

The Internationale Stichting Alzheimer Onderzoek (ISAO) and Internationaal Parkinson Fonds (IPF) sponsored the research presented in Chapter 5 and 6.

Financial support for publication of this thesis was kindly provided by: Alzheimer Nederland, Boehringer Ingelheim B.V., Internationale Stichting Alzheimer Onderzoek (ISAO), Lundbeck B.V., Novartis B.V., Nutricia Advanced Medical Nutrition, Parkinson Vereniging, Servier, Stichting van Alkemade-Keuls, Teva Pharma Nederland,Van Leersumfonds KNAW, UCB Pharma B.V. 
Prologue

Chapter 1 General introduction

Chapter 2 Apathy: from symptom to syndrome

Tijdschrift voor Psychiatrie, 2010, 52, 397-405

Chapter 3 Validation of diagnostic criteria for apathy in Parkinson's disease Parkinsonism \& Related Disorders, 2010, 16, 656-60

Chapter 4 Neuropsychological correlates of apathy in mild cognitive impairment and Alzheimer's disease: the role of executive functioning International Psychogeriatrics, 2011, 23, 1327-1333

Chapter 5 Methylphenidate and the pathogenesis of apathy in Alzheimer's disease: a randomized controlled trial

Submitted

Chapter 6 The role of the dopaminergic system in mood, motivation and cognition in Parkinson's disease: a placebo-controlled double blind randomized experimental challenge with pramipexole and methylphenidate Journal of Neurological Sciences, 2012, 320, 121-126

Chapter 7 Pharmacological treatment of apathy in neurodegenerative diseases: a systematic review Dementia and Geriatric Cognitive Disorders, 2009, 28, 13-22

Chapter 8 General discussion

Appendix: Systematic observation of apathy

Summary

Samenvatting

Curriculum vitae

Publications

Dankwoord 

PROLOGUE 
This thesis deals with questions about the assessment, neuropathology and treatment of apathy. The following case illustrates the burden of apathy and the issues that arise in the care and management of apathy.

Two years ago, Mr. A, a 78-year old man, was diagnosed with Alzheimer's disease (AD). Before his diagnosis his wife already noticed that he became more and more inactive and withdrew from social activities. For example, he did not feel going to his weekly bridge night anymore, which he always really enjoyed. For a while, his wife thought he might be depressed.

At the memory clinic of the academic hospital Mr. A underwent an extensive physical and cognitive examination, which made clear he suffered from $A D$ in an early stage. $A$ depression questionnaire indicated no signs of depression. Since then, the inactivity of Mr. A. only increased. He can sit in his chair for hours, staring out of the window or watching television. His behaviour annoys his wife; she often feels that he is just lazy. Her social contacts are reduced as well, as she is afraid of leaving her husband alone and he does not want to go anywhere. In addition, she misses their conversations together. Before she could discuss everything with him, but lately he barely reacts. As a result, she feels lonely and sad.

Mrs. A expresses her frustration with her general practitioner and he refers her to the elderly care of the regional mental health service. There, a psychologist provides her with information about $A D$ and how to handle the problems they experience in daily life. His apathetic behaviour is also extensively discussed and she now realizes that not laziness but the disease causes his behaviour.

In consultation with the psychologist a suitable day care for Mr. A is arranged: two days a week he can visit a care farm nearby. At first, he does not want to go, but after two months he goes without complaining and seems to enjoy it. For two days a week Mrs. A can do what she wants to do again and she rapidly regains her energy. Because she understands her husband's behaviour better and she has more free time of herself, she is able to handle the situation much better now. She hopes her husband can stay at home for as long as possible. 
This case illustrates the situation of an apathetic AD patient, living at home with his spouse. Several questions arise from this case report:

- How do we diagnose apathy and what is the difference with depression?

- Is apathy always related to cognitive impairment?

- What are the biological mechanisms of apathy and what can we do to treat it?

- Is apathy a problem for the patient, or just for the caregiver?

These clinical questions show the issues that exist around apathy and formed the basis for the research described in this thesis. 



\section{CHAPTER 1 \\ General introduction}




\subsection{Introduction}

This thesis focuses on one of the most prevalent and burdensome neuropsychiatric syndromes in Alzheimer's disease (AD) and Parkinson's disease (PD): apathy. Apathy is a disorder of motivation, characterized by reduced goal-directed behaviour and cognition, and emotional indifference. Apathy is a major problem in both AD and PD; it has a serious negative impact on everyday functioning, cognitive and motor performance, and quality of life of both patients and caregivers (Barone et al., 2009; Lechowski et al., 2009), as illustrated in the prologue. The impact of apathy in neurodegenerative diseases, and in particular AD and PD is increasingly recognized. This is also reflected in the increase of scientific studies into apathy. Nevertheless, the etiology and effective treatment of apathy are still unclear (Chase, 2011). In this respect, the main aim of this thesis was to get more insight into the diagnosis, underlying pathology and treatment options of apathy in AD and PD. This first chapter will provide a short theoretical background on $A D, P D$ and apathy, and will describe the specific aims and questions of this thesis.

\subsection{Alzheimer's disease and Parkinson's disease}

Due to aging of our population, the number of people suffering from neurodegenerative diseases is expected to increase dramatically in the upcoming years. The two most prevalent neurodegenerative diseases are AD and PD (Nussbaum \& Ellis, 2003).

In Western Europe, approximately $5.4 \%$ of the people above 60 years have dementia, of which the majority is thought to have AD. In 2000 it concerned about 4.9 million people, and this number is expected to rise to almost 10 million in 2040 (Ballard et al., 2011). AD has a gradual but progressive course, which normally starts with a decline in episodic memory and, as the disease progresses, affects other cognitive domains, such as language, praxis, recognition, and executive functioning (Castellani et al., 2010). Microscopically, $A D$ is hallmarked by a significant loss of neurons in the cerebral cortex and certain subcortical regions, together with increased concentrations of amyloid plaques and neurofibrillary tangles. Although methods to improve diagnosis have been moving forward, the causes of $A D$ remain unclear. As a consequence available treatments at this moment can alleviate symptoms but not cure the disease (Ballard et al., 2011).

The second most common neurodegenerative disease is PD, affecting around $1.5 \%$ of the population aged 60 years and above. As with $A D$, the number of patients with $P D$ is expected to double over the next 20 years (Dorsey et al., 2007). PD is characterized by a gradual, progressive depletion of neurons in the substantia nigra pars compacta, which causes a dopamine deficiency in the striatum. The four main motor symptoms upon which the diagnosis of PD is currently based include resting tremor, muscle 
rigidity, bradykinesia or akinesia (slowness or complete lack of movement), and postural instability (Bogart, 2011). Besides motor symptoms many PD patients also experience non-motor symptoms, such as cognitive impairment, olfactory disturbances, and mood and motivational disorders.

\subsection{Apathy}

Although $A D$ is traditionally regarded as a disorder primarily characterized by cognitive impairment and PD is considered as a movement disorder, in both diseases it is increasingly recognized that neuropsychiatric symptoms, such as apathy, depression, agitation and psychosis, are an intrinsic part of the disease. Apathy is the most common neuropsychiatric symptom in $A D$, with prevalences ranging from 42 to $92 \%$ (Drijgers et al., 2009). In PD, apathy is reported in 17 to 70\% (Aarsland et al., 2009). The wide variation in prevalences is due to differences in study populations and used rating scales.

The assessment and treatment of apathy are essential components of the management and care of patients with $A D$ and PD. Because symptoms of apathy are closely related to symptoms of depression, differentiation between the two syndromes requires attention. A range of instruments is currently used to measure apathy, of which the most important ones are described more extensively in chapter 2 . These rating scales are used for assessing the severity of apathy, for which each scale uses its own cut-off scores. Just recently diagnostic criteria for apathy have been proposed and validated in different neuropsychiatric diseases (Mulin et al., 2011; Robert et al., 2009). A consensus on assessment and diagnosis of apathy is important for both clinical practice and research.

Apathy seems to be largely explained by neurobiological factors, in particular frontal-subcortical circuits (van Reekum et al., 2005). In both structural and functional imaging studies apathy has been associated with the anterior cingulate cortex and orbito-frontal cortex in AD as well as in PD (Guimaraes et al., 2008; Reijnders et al., 2010). Furthermore, several studies have suggested that apathy is related to dysfunction in the dopaminergic system, as the dopaminergic system is closely related to the brain reward system (Chaudhuri \& Schapira, 2009; Mitchell et al., 2010). However, knowledge about the pathophysiology of apathy is still limited. Given the lack of an evidenced based pharmacological treatment for apathy, in clinical care the focus is yet primarily on psychosocial therapies, such as multisensory stimulation (snoezelen) or music therapy (Raglio et al., 2010; Staal et al., 2007). More insight into the neuroanatomical and neurochemical correlates of apathy might provide better treatment options. 


\subsection{Aims of this thesis}

The overall aim of this thesis is to gain more insight into the assessment, the pathophysiology and treatment of apathy in neurodegenerative diseases and in particular in $A D$ and $P D$. The following research questions are addressed:

\section{Are the clinical diagnostic criteria for apathy valid compared to existing apathy assessments?}

To begin with, in chapter $\mathbf{2}$ an overview of the development of the concept of apathy is given. Through the years the concept of apathy has been changed and adapted till recently a consensus of diagnostic criteria for apathy as a syndrome was proposed. Our purpose was to describe the evolution of apathy and discuss the importance of diagnostic criteria for clinical practice. Following on chapter 2, chapter 3 describes a validation study of the proposed diagnostic criteria for apathy in a population of patients with PD.

\section{What are the neuropsychological correlates of apathy?}

In chapter $\mathbf{4}$ we investigate the neuropsychological correlates of apathy in patients with Mild Cognitive Impairment $(\mathrm{MCl})$ and $A D$. Studying the possible impact of apathy on cognitive status in $\mathrm{MCl}$ and comparing this with $\mathrm{AD}$ may provide better insight into the underlying pathology and may lead to new options for early diagnosis and treatment.

3. What is the role of the dopaminergic system in apathy?

Towards finding suitable treatment options, getting more insight into the pathophysiology of apathy, mood and motivational symptoms is of high importance. Therefore, in chapter $\mathbf{5}$ we explore the relationship between dopaminergic mechanisms in apathy, mood and cognition in $A D$ patients with an acute pharmacological challenge with methylphenidate. In addition, in chapter 6 we investigate the role of the dopaminergic neurotransmitter system in mood, motivation and cognition in patients with PD through the use of an acute pharmacological challenge with methylphenidate and pramipexole.

\section{What is the evidence base of pharmacological treatment of apathy?}

Chapter 7 provides a systematic review of the evidence base of pharmacological treatment of apathy in neurodegenerative diseases. Till now no specific treatment for apathy is available. We carried out a systematic literature search and evaluated the efficacy of pharmacological treatment of apathy in neurodegenerative diseases.

Finally, in chapter $\mathbf{8}$ the main findings of this thesis are summarized and discussed. Clinical implications and suggestions for further research are given. 


\section{References}

Aarsland, D., Marsh, L., \& Schrag, A. (2009). Neuropsychiatric symptoms in Parkinson's disease. Movement Disorders, 24(15), 2175-2186.

Ballard, C., Gauthier, S., Corbett, A., Brayne, C., Aarsland, D., \& Jones, E. (2011). Alzheimer's disease. Lancet, 377(9770), 1019-1031.

Barone, P., Antonini, A., Colosimo, C., Marconi, R., Morgante, L., Avarello, T., et al. (2009). The PRIAMO study: a multicenter assessment of nonmotor symptoms and their impact on quality of life in Parkinson's disease. Movement Disorders, 24(11), 1641-1649.

Bogart, K. R. (2011). Is apathy a valid and meaningful symptom or syndrome in Parkinson's disease? A critical review. Health Psychology, 30(4), 386-400.

Castellani, R. J., Rolston, R. K., \& Smith, M. A. (2010). Alzheimer disease. Disease-a-Month, 56(9), 484-546.

Chase,T. N. (2011). Apathy in Neuropsychiatric Disease: Diagnosis, Pathophysiology and Treatment. Neurotoxicity Research, 19(2), 266-278.

Chaudhuri, K., \& Schapira, A. (2009). Non-motor symptoms of Parkinson's disease: dopaminergic pathophysiology and treatment. Lancet Neurology, 8(5), 464-474.

Dorsey, E. R., Constantinescu, R., Thompson, J. P., Biglan, K. M., Holloway, R. G., Kieburtz, K., et al. (2007). Projected number of people with Parkinson disease in the most populous nations, 2005 through 2030. Neurology, 68(5), 384-386.

Drijgers, R. L., Aalten, P., Winogrodzka, A., Verhey, F. R. J., \& Leentjens, A. F. G. (2009). Pharmacological treatment of apathy in neurodegenerative diseases: a systematic review. Dementia and Geriatric Cognitive Disorders, 28(1), 13-22.

Guimaraes, H. C., Levy, R., Teixeira, A. L., Beato, R. G., \& Caramelli, P. (2008). Neurobiology of apathy. Arquivos de Neuro-Psiquiatria, 66(2b), 436-443.

Lechowski, L., Benoit, M., Chassagne, P., Vedel, I., Tortrat, D., Teillet, L., et al. (2009). Persistent apathy in Alzheimer's disease as an independent factor of rapid functional decline: the REAL longitudinal cohort study. International Journal of Geriatric Psychiatry, 24(4), 341-346.

Mitchell, R. A., Herrmann, N., \& Lanctôt, K. L. (2011). The role of dopamine in symptoms and treatment of apathy in Alzheimer's Disease. CNS Neuroscience and Therapeutics, 17(5), 411-427.

Mulin, E., Leone, E., Dujardin, K., Delliaux, M., Leentjens, A. F. G., Nobili, F., et al. (2011). Diagnostic criteria for apathy in clinical practice. International Journal Geriatric Psychiatry, 26(2), 158-165.

Nussbaum, R. L., \& Ellis, C. E. (2003). Alzheimer's Disease and Parkinson's Disease. The New England Journal of Medicine, 348(14) , 1356-1364.

Raglio, A., Bellelli, G., Traficante, D., Gianotti, M., Ubezio, M. C., Gentile, S., et al. (2010). Effect of music therapy treatment based on cycles of sessions: a randomised controlled trial. Aging and Mental Health, 14(8), 900-904.

Reijnders, J. S. A. M., Scholtissen, B., Weber, W. E. J., Aalten, P., Verhey, F. R. J., \& Leentjens, A. F. G. (2010). Neuroanatomical correlates of apathy in Parkinson's disease: a magnetic resonance imaging study using voxel-based morphometry. Movement Disorders, 25(14), 2318-2325.

Robert, P. H., Onyike, C. U., Leentjens, A. F. G., Dujardin, K., Aalten, P., Starkstein, S. E., et al. (2009). Proposed diagnostic criteria for apathy in alzheimer's disease and other neuropsychiatric disorders. European Psychiatry, 24(2), 98-104.

Staal, J. A., Sacks, A., Matheis, R., Collier, L., Calia, T., Hanif, H., et al. (2007). The effects of Snoezelen (multisensory behavior therapy) and psychiatric care on agitation, apathy, and activities of daily living in dementia patients on a short term geriatric psychiatric inpatient unit. International Journal of Psychiatry in Medicine, 37(4), 357-370.

van Reekum, R., Stuss, D. T., \& Ostrander, L. (2005). Apathy: why care? Journal of Neuropsychiatry and Clinical Neurosciences, 17(1), 7-19. 



\section{CHAPTER 2 Apathy: from symptom to syndrome}

Drijgers, R.L., Aalten, P., Leentjens, A.F.G., Verhey, F.R.J., 2010. Tijdschrift voor Psychiatrie, 52, 397-405. 


\section{Abstract}

Background: Apathy is an important behavioural problem of dementia and other neuropsychiatric diseases.

Aim: To give an overview of the development of the concept of apathy and its importance to clinical practice.

Methods: Literature research.

Results: There is evidence that apathy should be regarded as a syndrome instead of a symptom. Apathy is a construct that consists of several aspects. In addition, apathy can occur in the same manner across various diseases. Apathy can occur together with, or separate from, depressive disorder or cognitive decline. Recently diagnostic criteria for the diagnosis of the syndrome of apathy have been formulated on the base of an international consensus.

Conclusion: These diagnostic criteria that have been recently formulated facilitate the validation of measurement instruments as well as the research on the epidemiology, aetiology, pathophysiology and treatment of apathy to a great extent. 


\subsection{Introduction}

Apathy is characterized by a loss of initiative, loss of interest and emotional indifference. It is the most common neuropsychiatric problem in Alzheimer's disease (AD) (Aalten et al., 2005; Onyike et al., 2007) and prevalent in other neurological and psychiatric diseases such as frontotemporal dementia, Parkinson's disease (PD), traumatic brain injury and schizophrenia (van Reekum et al., 2005). Apathy often manifests in the early stages of dementia, and its prevalence and severity increases with the progress of the disease (Aalten et al., 2005). Apathy decreases the quality of life of patients and caregivers (Chaudhuri et al., 2009; Yeager et al., 2008). Moreover, apathy is associated with accelerated cognitive decline, increased risk of hospitalisation, and caregiver stress (de Vugt et al., 2003; Starkstein, Jorge, \& Mizrahi, 2006).

The interest in apathy is increasing in clinical practice and research; therefore reliably identifying and measuring apathy is important. Although there are numerous apathy assessment tools, there are still no accepted diagnostic criteria. Apathy studies often report widely varying results; for instance, the prevalence of apathy varies from $42 \%$ to $92 \%$ in patients with dementia and from $17 \%$ to $70 \%$ in patients with PD (Drijgers et al., 2009). Thus, there is a great need for diagnostic criteria. This paper reviews the recent literature to describe the development of apathy as a concept and its importance for clinical practice. Furthermore, we present the translation of the recently developed consensus criteria for apathy.

\subsection{Historical development}

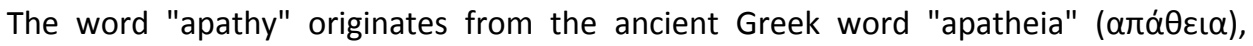
meaning "without sense". The Stoics used this term to indicate people who were free from passion and emotions such as pain, fear, desire and pleasure. Because emotions preclude rationality, the most important human quality, the Stoics believed that feelings and passion should be eliminated. They regarded apathy as a peaceful state that led to a virtuous and happy life (Starkstein et al., 2008).

Today, the Dutch-English Van Dale Dictionary describes apathy as psychic numbness, listlessness or indifference. In contrast to Ancient Greece, the current definition of apathy has negative connotations; however, a clear definition of apathy does not exist. The current psychiatric classification systems do not define apathy. The Diagnostic and Statistical Manual of Mental Disorders, 4th Edition (DSM-IV; American Psychiatric Association, 1994) mentions apathy as only a type of personality change due to a medical condition. The International Classification of Diseases (ICD-10; World Health Organisation, 1993) does not mention apathy. 


\subsection{Symptom or syndrome?}

Although, in the past, apathy has been often viewed as a symptom, it is increasingly considered a syndrome; meaning a fixed set of symptoms that can occur in combination. The arguments to support this latter position are as follows.

First, apathy is a complex construct that can be divided into different symptoms. Marin, and later Starkstein, composed diagnostic criteria for apathy that included three symptom dimensions: loss of motivation, loss of initiative and interest, and blunted emotions (Marin, 1991; Starkstein et al., 2001).

In addition, a number of studies have grouped the neuropsychiatric symptoms of dementia using factor analysis (Aalten et al., 2008; Zuidema et al., 2007). Almost all of these studies identified apathy as a distinct syndrome (i.e., factor). The largest study was that of the European Alzheimer's Disease Consortium (EADC), who distinguished different syndromes using the Neuropsychiatric Inventory (NPI) in 2,354 patients with $A D$ : hyperactivity, psychosis, affective symptoms and apathy. An additional analysis of the same data demonstrated that this finding was robust across other neuropsychiatric disorders, including vascular dementia, Lewy body dementia and frontotemporal dementia (Aalten et al., 2008). In addition, a recent Dutch study of 1,437 patients with dementia living in a nursing home showed that apathy was an independent syndrome; furthermore, apathy was stable across different stages of dementia (Zuidema et al., 2007). Finally, imaging studies have shown that apathy has the same pathophysiological correlates across different neuropsychiatric diseases. Various imaging studies as well as postmortem studies indicate that frontal-subcortical circuits, especially the anterior cingulate gyrus and dorsolateral prefrontal cortex, are involved in apathy (Lavretsky et al., 2007; van Reekum et al., 2005). These findings strongly suggest that apathy is a syndrome that has its own course and biological correlates and may have its own treatment.

\subsection{Apathy, depression and cognitive decline}

Despite the high prevalence of apathy, in the literature, more attention is given to depression. Much research focuses on the extent to which apathy and depression differ. Indeed, depression and apathy have several symptoms in common such as flattened affect, loss of initiative and motivation, loss of interest, and inertia (Landes et al., 2005), which makes distinguishing between the two syndromes difficult. However, both syndromes have their own core symptoms. Sad mood is a core symptom of depression but not of apathy. Anhedonia, the inability to experience pleasure in activities, another core symptom of depression, is often difficult to assess in apathy. Therefore, studies have focused on externally observable behaviours, such as the lack of emotional response to positive and negative stimuli or events. A lack of motivation and initiative 
are the most important symptoms of apathy (Boyle et al., 2004). Several studies have recently shown that apathy can occur in combination with depression but that these syndromes can also exist separately. The Cache County study used the Neuropsychiatric Inventory (NPI) to measure neuropsychiatric symptoms and found that the prevalence of apathy in patients with AD was $27.3 \%$. This epidemiological study also reported that more than $40 \%$ of patients with $A D$ and apathy had comorbid depression; conversely, $56.4 \%$ of the patients with depression and AD had comorbid apathy. These results show that nearly half of the patients with apathy were not depressed (Lyketsos et al., 2000). Starkstein, Jorge, and Mizrahi et al. (2006) diagnosed apathy using the Apathy Scale (AS) in 45 of 195 patients with AD without depression (23\%). In addition, several studies in patients with PD found that apathy exists without depression. Isella and colleagues (2002) also used the AS and found that 33\% of patients with PD and apathy did not have depression. Kirsch-Darrow et al. (2006) used the Apathy Evaluation Scale (AES) and found a prevalence rate of $28.8 \%$ in this same group of patients. Additional studies have found that apathy is different from depression because they respond differently to antidepressant treatments. Selective serotonin reuptake inhibitors (SSRIs) normally improve the moods of depressed patients; however, they do not improve the severity of apathy and may even increase it (Barnhart et al., 2004). For example, symptoms of apathy of elderly patients with depression who were treated with an SSRI increased despite improvements of their depressive symptoms (Wongpakaran et al., 2007). Conversely, drugs that affect dopaminergic mechanisms, such as psychostimulants, dopamine agonists and antidepressants with dopamine re-uptake activity, seem to improve apathy (Corcoran et al., 2004; Drijgers et al., 2009; Leentjens et al., 2009; Levy, 1998). Padala and colleagues $(2005 ; 2007)$ reported that apathy, but not depressive symptoms, improved in a patient with depression who was treated with methylphenidate as well as a patient with dementia and depression who was treated with modafinil. These results support the idea that apathy can occur independently of depression.

Like depression, apathy is sometimes seen as a consequence of cognitive decline. Indeed, apathy is related to faster cognitive decline (Kuzis et al., 1999). Onyike et al. (2007) found that the severity of apathy is positively correlated with the severity of cognitive decline. Moreover, patients with apathy often have lower scores on the Mini Mental State Examination (MMSE; Folstein et al., 1975; van Reekum et al., 2005), and apathy increases with disease severity (Aalten et al., 2005; Starkstein, Jorge, Mizrahi et al., 2006). However, approximately half of patients with dementia do not develop apathy (Starkstein et al., 2001); thus, cognitive decline is not a sufficient causation of apathy.

Apathy is associated with executive dysfunction: specifically, disturbances in abstract thinking, planning and executing complex tasks. Like apathy, executive dysfunction is associated with frontal-subcortical circuit damage. McPherson et al. (2002) confirmed Kuzis et al 's (1999) earlier findings that patients with AD and apathy perform 
worse on executive tasks compared to patients without apathy, and that this result is independent of mood.

In summary, apathy can occur independently or in combination with syndromes such as depression and dementia. Figure 1 demonstrates this relationship.

Figure 1. The relationship among depression, dementia and apathy

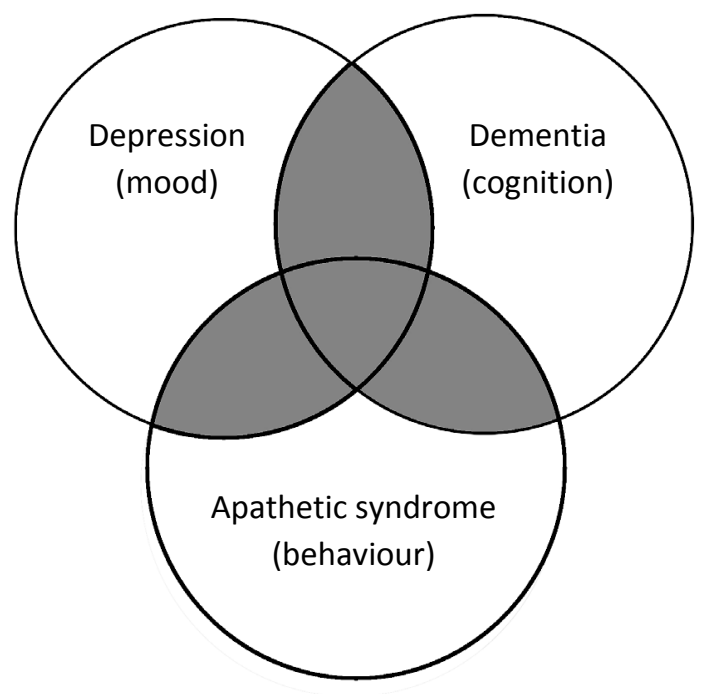

\subsection{The diagnostic criteria for apathy as a syndrome}

Apathy as a concept has only existed for two decades (Starkstein et al., 2008). In 1991, Marin created diagnostic criteria for apathy, thereby providing the first operational definition of apathy as a distinct syndrome. He characterized apathy by a lack of goaldirected behaviour as well as a reduction of its associated cognitions and emotions. Marin defined motivation as "the direction, intensity and persistence of goal-directed behaviour". The primary symptom of apathy was the loss of motivation. Marin structured the clinical definition of apathy on three pillars: reduced goal-directed behaviour (e.g., initiative and productivity), reduced goal-directed cognitions (e.g., interest or plans), and reduced emotions (e.g., flat affect and emotional indifference). In addition, he argued that these symptoms could not be attributed to a decreased level of consciousness or cognitive/emotional problems alone (Marin, 1991). Hence, Marin formulated a syndrome of "pure apathy" for patients who did not demonstrate cognitive or affective comorbidities; however, many patients with apathy suffer from other neuropsychiatric syndromes such as depression or cognitive decline. This finding limited the usefulness of Marin's criteria. A few years later, Starkstein and colleagues 
broadened these criteria by omitting the criterion that apathy should not be comorbid with depression or cognitive impairment. Moreover, the symptoms should cause a clinically relevant reduction in personal, social, occupational, or other important areas of functioning (Starkstein et al., 2001). Henceforth, these modified criteria have been widely used in scientific research. Starkstein and Leentjens (2008) added a time criterion: Apathy symptoms must be present during a majority of the day for at least 4 weeks (Starkstein et al., 2008). Thus, this criterion excluded brief episodes of apathy such as "off periods" in patients with PD, hypokinetic periods during delirium, and acute grief reactions from being considered apathy syndrome.

A limitation is that scientific and professional organisations do not support the above-mentioned criteria and that they are not included in diagnostic classification systems; therefore, they have no significant support. In 2008, a consensus conference of three professional organisations (the Association Française de Psychiatrie Biologique [AFPB], the European Psychiatric Association [EPA], and the European Alzheimer's Disease Consortium [EADC]), together with content experts from Europe, Australia and North America was held in Nice to address this issue. During this meeting, scientists used the latest revision of the diagnostic criteria for apathy (Starkstein et al., 2008) as the basis of a new consensus. The revised criteria have the same structure as those of Starkstein et al. (2001): Criterion A indicates that the core symptom of apathy is reduced motivation; Criterion B identifies the three domains of apathy (behaviour, cognition and affect), each of which is composed of both self-initiated actions (e.g., cognitions and emotions) and responses to external stimuli; Criterion $C$ provides the functional restrictions of apathy; and Criterion D excludes a number of causes (Table 1 ). Given that different expressions, and thus sub domains, of apathy exist (e.g., flat emotions as well as lack of initiative and interest), not all domains must be met for a diagnosis of apathy. The primary adjustment is made under Criterion B in which at least one symptom within two of the three domains must be fulfilled. This amended procedure is in contrast to Starkstein who proposed that a symptom must be present in each of the three domains. Attendees of the consensus conference were aware that apathy is a feature of other psychiatric disorders including major depression and schizophrenia. Another adjustment was made to Criterion D, which states that the symptoms cannot be solely explained by, or the result of, physical and motor impairments (Robert et al., 2009). Table 1 shows the criteria.

\subsection{The assessment of apathy}

In addition to these diagnostic criteria, using reliable and valid measures to diagnose and assess apathy is important. Validated scales are necessary for reliable research on the epidemiology, phenomenology, pathophysiology and treatment of apathy. 
Currently, several instruments assess the presence and severity of apathy in neurological and psychiatric diseases.

The Neuropsychiatric Inventory (NPI) is one of the most common assessments of apathy. This broad and valid scale measures the neuropsychiatric functioning of patients by determining the presence of 12 different neuropsychiatric symptoms, including apathy (Cummings, 1994). The NPI indicates the frequency (0-4) and severity (0-3) of these symptoms via a semi-structured interview with the patient's caregiver. Because the NPI does not distinguish between the different domains of apathy, it may be a weak instrument to diagnose apathy syndrome; however, from the numerous studies described above, the NPI seems well suited to distinguish among different syndromes, including apathy and depression. Marin and colleagues were the first group to develop a scale to specifically measure apathy (the AES; Marin et al., 1991). The AES is an 18-item survey that uses 4-point Likert scales to measure apathy symptoms. It has three different versions for the patient, caregiver or clinician. The AES has been validated in patients with $A D$, stroke, depression, or other types of dementia. Starkstein et al. (1995) developed the AS, a derivative of the AES, which consists of 14 items and has been validated in patients with PD. Robert et al. developed the Inventoire Apathy (IA), the first instrument to distinguish among different dimensions of apathy. The IA evaluates emotional flattening, lack of initiative and loss of interest. Like the AES, there are three versions of the IA for the patient, caregiver or clinician. The IA has been validated in patients $A D$, mild cognitive impairment (MCI) and PD (Robert et al., 2002). The Lille Apathy Rating Scale (LARS) is the most recently developed scale. Patient and caregiver versions of the LARS exist. The LARS has been validated in patients with PD. The LARS is an extensive 33-item questionnaire that consists of a structured interview to eventually measure four domains of apathy: intellectual curiosity, emotion, action initiation and self-awareness (Sockeel et al., 2006).

Given its applicability in clinical practice, we currently support the AES. However, because of a lack of diagnostic criteria clinimetric support for all scales remained limited to reliability and internal consistency. The newly formulated criteria can serve as gold standard, which makes further validation possible (Leentjens et al., 2008).

\subsection{Conclusion}

Apathy is a common phenomenon in various neuropsychiatric diseases. There is convincing evidence that apathy should be considered not only as a symptom but also as an independent syndrome. Apathy negatively affects the quality of life patients and their environment. Therefore, more research should focus on apathy and its treatment. The recently published consensus on the diagnostic criteria for apathy will facilitate such research. 
Table 1. Diagnostic criteria for apathy (Robert et al., 2009)

For a diagnosis of apathy the patient should fulfil the criteria A, B, C and D

A. Loss of or diminished motivation in comparison to the patient's previous level of functioning and which is not consistent with his age or culture. These changes in motivation may be reported by the patient himself or by the observations of others.

B. Presence of at least one symptom in at least two of the three following domains for a period of at least four weeks and present most of the time.

\section{Domain B1- Behaviour:}

Loss of, or diminished, goal-directed behaviour as evidenced by at least one of the following:

- Initiation symptom: loss of self-initiated behaviour (for example: starting conversation, doing basic tasks of day-to-day living, seeking social activities, communicating choices).

- Responsiveness symptom: loss of environment-stimulated behaviour (for example: responding to conversation, participating in social activities).

\section{Domain B2 - Cognition:}

Loss of, or diminished, goal-directed cognitive activity as evidenced by at least one of the following:

- Initiation symptom: loss of spontaneous ideas and curiosity for routine and new events (i.e., challenging tasks, recent news, social opportunities, personal/family and social affairs).

- Responsiveness symptom: loss of environment-stimulated ideas and curiosity for routine and new events (i.e., in the person's residence, neighbourhood or community).

\section{Domain B3 - Emotion:}

Loss of, or diminished, emotion as evidenced by at least one of the following:

- Initiation symptom: loss of spontaneous emotion, observed or self-reported (for example, subjective feeling of weak or absent emotions, or observation by others of a blunted affect).

- Responsiveness symptom: loss of emotional responsiveness to positive or negative stimuli or events (for example, observer-reports of unchanging affect, or of little emotional reaction to exciting events, personal loss, serious illness, emotional-laden news).

C. These symptoms (A - B) cause clinically significant impairment in personal, social, occupational, or other important areas of functioning.

D. The symptoms (A - B) are not exclusively explained or due to physical disabilities (e.g. blindness and loss of hearing), to motor disabilities, to diminished level of consciousness or to the direct physiological effects of a substance (e.g. drug of abuse, a medication). 


\section{References}

Aalten, P., de Vugt, M. E., Jaspers, N., Jolles, J., \& Verhey, F. R. J. (2005). The course of neuropsychiatric symptoms in dementia. Part I: findings from the two-year longitudinal Maasbed study. International Journal of Geriatric Psychiatry, 20(6), 523-530.

Aalten, P., Verhey, F. R., Boziki, M., Bullock, R., Byrne, E. J., Camus, V., et al. (2008). Consistency of Neuropsychiatric Syndromes across Dementias: Results from the European Alzheimer Disease Consortium. Dementia and Geriatric Cognitive Disorders, 25(1), 1-8.

American Psychiatric Association. (1994). Diagnostic and statistical manual of mental disorders, 4th Edn. Washington, DC: American Psychiatric Press.

Barnhart, W., Makela, E., \& Latocha, M. (2004). SSRI-induced apathy syndrome: a clinical review. Journal of Psychiatry Practice, 10(3), 196-199.

Boyle, P. A., \& Malloy, P. F. (2004). Treating apathy in Alzheimer's disease. Dementia and Geriatric Cognitive Disorders, 17(1-2), 91-99.

Chaudhuri, K., \& Schapira, A. (2009). Non-motor symptoms of Parkinson's disease: dopaminergic pathophysiology and treatment. Lancet Neurology, 8(5), 464-474.

Corcoran, C., Wong, M., \& O'Keane, V. (2004). Bupropion in the management of apathy. Journal of Psychopharmacology, 18(1), 133-135.

Cummings, J. L., Mega, M., Gray, K., Rosenberg-Thompson, S., Carusi, D.A., Gornbein, J. (1994). The Neuropsychiatric Inventory: Comprehensive assessment of psychopathology in dementia. Neurology, 44(12), 2308-2314.

de Vugt, M. E., Stevens, F., Aalten, P., Lousberg, R., Jaspers, N., Winkers, I., et al. (2003). Behavioural disturbances in dementia patients and quality of the marital relationship. International Journal of Geriatric Psychiatry, 18(2), 149-154.

Drijgers, R. L., Aalten, P., Winogrodzka, A., Verhey, F. R. J., \& Leentjens, A. F. G. (2009). Pharmacological treatment of apathy in neurodegenerative diseases: a systematic review. Dementia and Geriatric Cognitive Disorders, 28(1), 13-22.

Folstein, M. F., Folstein, S. E., \& McHugh, P. R. (1975). "Mini-mental state". A practical method for grading the cognitive state of patients for the clinician. Journal of Psychiatric Research, 12(3), 189-198.

Isella, V., Melzi, P., Grimaldi, M., Iurlaro, S., Piolti, R., Ferrarese, C., et al. (2002). Clinical, neuropsychological, and morphometric correlates of apathy in Parkinson's disease. Movement Disorders, 17(2), 366-371.

Kirsch-Darrow, L., Fernandez, H. H., Marsiske, M., Okun, M. S., \& Bowers, D. (2006). Dissociating apathy and depression in Parkinson disease. Neurology, 67(1), 33-38.

Kuzis, G., Sabe, L., Tiberti, C., Dorrego, F., \& Starkstein, S. E. (1999). Neuropsychological correlates of apathy and depression in patients with dementia. Neurology, 52(7), 1403-1407.

Lavretsky, H., Ballmaier, M., Pham, D., Toga, A., \& Kumar, A. (2007). Neuroanatomical characteristics of geriatric apathy and depression: a magnetic resonance imaging study. American Journal of Geriatric Psychiatry, 15(5), 386-394.

Landes, A.M., Sperry, S.D., Strauss, M.W. (2005). Prevalence of apathy, dysphoria, and depression in relation to dementia severity in Alzheimer's disease. Journal of Neuropsychiatry and Clinical Neuroscience, 17(3), 342-9.

Leentjens, A. F. G., Dujardin, K., Marsh, L., Martinez-Martin, P., Richard, I. H., Starkstein, S. E., et al. (2008). Apathy and anhedonia rating scales in Parkinson's disease: critique and recommendations. Movement Disorders, 23(14), 2004-2014.

Leentjens, A. F. G., Koester, J., Fruh, B., Shephard, D. T. S., Barone, P., \& Houben, J. J. G. (2009). The effect of pramipexole on mood and motivational symptoms in Parkinson's disease: a meta-analysis of placebo controlled studies. Clinical Therapeutics, 31(1), 89-98.

Levy, M., Cummings, J., Fairbanks, L., Masterman, D., Miller, B., Craig, A., et al. (1998). Apathy is not depression. Journal of Neuropsychiatry and Clinical Neurosciences, 10(3), 314-319. 
Lyketsos, C. G., Steinberg, M., Tschanz, J. T., Norton, M. C., Steffens, D. C., \& Breitner, J. C. (2000). Mental and behavioral disturbances in dementia: findings from the Cache County Study on Memory in Aging. American Journal of Psychiatry, 157(5), 708-714.

Marin, R. S. (1991). Apathy: a neuropsychiatric syndrome. Journal of Neuropsychiatry and Clinical Neurosciences, 3(3), 243-254.

McPherson, S., Fairbanks, L., Tiken, S., Cummings, J. L., \& Back-Madruga. (2002). Apathy and executive function in Alzheimer's disease. Journal of the International Neuropsychological Society, 8(3), 373-381.

Onyike, C. U., Sheppard, J. M., Tschanz, J. T., Norton, M. C., Green, R. C., Steinberg, M., et al. (2007). Epidemiology of apathy in older adults: the Cache County Study. American Journal of Geriatric Psychiatry, 15(5), 365-375.

Padala, P., Burke, W., \& Bhatia, S. (2007). Modafinil therapy for apathy in an elderly patient. The Annals of Pharmacotherapy, 41(2), 346-349.

Padala, P., Petty, F., \& Bhatia, S. C. (2005). Methylphenidate may treat apathy independent of depression. The Annals of Pharmacotherapy, 39(11), 1947-1949.

Robert, P. H., Clairet, S., Benoit, M., Koutaich, J., Bertogliati, C., Tible, O., et al. (2002). The apathy inventory: assessment of apathy and awareness in Alzheimer's disease, Parkinson's disease and mild cognitive impairment. International Journal of Geriatric Psychiatry, 17(12), 1099-1105.

Robert, P. H., Onyike, C. U., Leentjens, A. F. G., Dujardin, K., Aalten, P., Starkstein, S. E., et al. (2009). Proposed diagnostic criteria for apathy in Alzheimer's disease and other neuropsychiatric disorders. European Psychiatry, 24(2), 98-104.

Starkstein, S. E., Jorge, R., \& Mizrahi, R. (2006). The prevalence, clinical correlates and treatment of apathy in Alzheimer's disease. European Journal of Psychiatry, 20(2), 96-106.

Starkstein, S. E., Jorge, R., Mizrahi, R., \& Robinson, R. G. (2006). A prospective longitudinal study of apathy in Alzheimer's disease. Journal of Neurology Neurosurgery and Psychiatry, 77(1), 8-11.

Starkstein, S. E., \& Leentjens, A. F. G. (2008). The nosological position of apathy in clinical practice. Journal of Neurology Neurosurgery and Psychiatry, 79(10), 1088-1092.

Starkstein, S. E., Migliorelli, R., Manes, F., Teson, A., Petracca, G., Chemerinski, E., et al. (1995). The Prevalence and Clinical Correlates of Apathy and Irritability in Alzheimer's Disease. European Journal of Neurology, 2(6), 540-546.

Starkstein, S. E., Petracca, G., Chemerinski, E., \& Kremer, J. (2001). Syndromic validity of apathy in Alzheimer's disease. American Journal of Psychiatry, 158(6), 872-877.

van Reekum, R., Stuss, D. T., \& Ostrander, L. (2005). Apathy: why care? Journal of Neuropsychiatry and Clinical Neurosciences, 17(1), 7-19.

Wongpakaran, N., van Reekum, R., Wongpakaran, T., \& Clarke, D. (2007). Selective serotonin reuptake inhibitors associates with apathy among depressed elderly: a case-control study. Annals of General Psychiatry, $6,7$.

World Health Organization. (1993). The ICD-10 Classification of Mental and Behavioural Disorders. Geneva: WHO.

Yeager, C., \& Hyer, L. (2008). Apathy in dementia: relations with depression, functional competence, and quality of life. Psychological Reports, 102(3), 718-722.

Zuidema, S., de Jonghe, J., Verhey, F., \& Koopmans, R. (2007). Neuropsychiatric Symptoms in Nursing Home Patients: Factor Structure Invariance of the Dutch Nursing Home Version of the Neuropsychiatric Inventory in Different Stages of Dementia. Dementia and Geriatric Cognitive Disorders, 24(3), 169-176. 



\section{CHAPTER 3 \\ Validation of diagnostic criteria for apathy in Parkinson's disease}

Drijgers, R.L., Dujardin, K., Reijnders, S.A.M., Defebvre, L., Leentjens, A.F.G., 2010. Parkinsonism \& Related Disorders, 16, 656-60. 


\section{Abstract}

Background: Apathy is a common neuropsychiatric syndrome in Parkinson's Disease (PD) that affects quality of life. Research into apathy has been hampered by a lack of broadly accepted diagnostic criteria. Recently, diagnostic criteria for apathy in neuropsychiatric disorders have been proposed, which to date have not been validated in PD. Aim: to validate the proposed diagnostic criteria for apathy in PD.

Design and methods: In a cross-sectional study, outpatients with PD visiting a movement disorders clinic underwent a protocolized assessment of motor function, activities of daily living ( $A D L)$, cognition and mood. In addition, the diagnostic criteria for apathy were administered as well as two apathy rating instruments: the Lille Apathy Rating Scale (LARS) and the apathy section of the Neuropsychiatric Inventory (NPI).

Results: Of the included patients $17.2 \%$ were diagnosed with apathy according to the criteria. Acceptability and internal consistency of the criteria was good, as was the concurrent validity with the LARS and apathy section of the NPI. Discriminant validity of the criteria with depression was moderate to good. All domains of criterion B (behaviour, cognition, emotion) contributed to the diagnosis of apathy, of which reduced goaldirected behaviour was the most frequently observed symptom.

Conclusion: The recently proposed diagnostic criteria for apathy are useful in clinical practice and in research with PD patients with and without cognitive impairment. 


\subsection{Introduction}

Parkinson's disease (PD) is a neurodegenerative disorder characterized by motor and non-motor symptoms, including psychiatric and behavioural problems. Apathy is one of the most common neuropsychiatric syndromes in PD. Frequencies of 17 to $70 \%$ have been reported, depending on the population characteristics and assessment procedures (Dujardin et al., 2007; Pluck \& Brown, 2002; Starkstein et al., 2009). In PD, apathy is associated with more severe cognitive deficits, more severe depressive symptoms, and a decreased quality of life (Oguru et al., 2010; Pedersen, Alves et al., 2009; Pedersen, Larsen et al., 2009). In research as well as in clinical practice, apathy is increasingly seen as a syndrome on its own rather than as a symptom of some other disorder, such as dementia or depression (Kirsch-Darrow et al., 2006; Starkstein \& Leentjens, 2008). To date, there is no effective treatment for apathy (Drijgers et al., 2009).

Research into apathy has been hampered by a lack of generally accepted diagnostic criteria (Drijgers et al., 2009). In 2008, a consensus meeting was held by the European Psychiatric Association (EPA), the European Alzheimer's Disease Consortium (EADC), the Association Française de Psychiatrie Biologique (AFPB), and invited experts from Europe, Australia and North America, to propose consensus diagnostic criteria for apathy as a syndrome (Robert et al., 2009) (table 1). These proposed diagnostic criteria have subsequently been validated in $\mathbf{3 0 6}$ patients suffering from a range of neuropsychiatric diseases including Alzheimer's Disease (AD), mixed dementia, Mild Cognitive Impairment ( $\mathrm{MCl}$ ), PD, Schizophrenia and Major Depressive Episode (Mulin et al., 2011). In this study, the criteria were shown to have good acceptability, inter-rater reliability and known groups validity. The aim of the present study was to further validate these diagnostic criteria in a sample of patients with PD.

\subsection{Methods}

\section{Design}

This cross-sectional cohort study was designed as an extension to a study into anxiety symptoms in PD (Leentjens et al., 2010).

\section{Sample}

One hundred and twenty-two patients from Lille University Medical Centre, Lille, France and Maastricht University Medical Centre, Maastricht, the Netherlands, underwent a single assessment. All patients suffered from idiopathic PD according to the Queens Square Brain Bank criteria (De Rijk et al., 1997). Patients were excluded if they suffered from neurodegenerative disorders other than PD, had a clinical diagnosis of 
Parkinson's Disease Dementia (PDD) as defined by criteria of the Diagnostic and Statistical Manual (DSM IV) of mental disorders, or severe cognitive decline, operationalised as a score on the Mini Mental State Examination (MMSE) < 23 (Folstein et al., 1975). The study was approved by the Medical Ethics Committee of both hospitals and patients gave informed consent before participation.

\section{Cognitive and behavioural assessment}

In a single visit, motor, cognitive, affective and other domains were assessed. Motor function was assessed with section 3 of the Unified Parkinson's Disease Rating Scale (UPDRS) (Fahn \& Elton, 1987). Cognitive status and activities of daily living (ADL) were evaluated using the Mini Mental State Examination (MMSE) and the Lawton Instrumental ADL (IADL) scale (Folstein et al., 1975; Lawton \& Brody, 1969). The presence of depressive disorders as defined by the criteria of the fourth edition of the Diagnostic and Statistical Manual (DSM IV) of the American Psychiatric Association (APA) was assessed with the Mini International Neuropsychiatric Inventory (MINI, a structured interview for DSM disorders) sections A (depressive disorder) and B (dysthymia) (American Psychiatric Association, 1994). Severity of depressive symptoms was assessed with the 17-item Hamilton Depression Rating Scale (HAMD) (Hamilton, 1960; Sheehan et al., 1998). Trained psychologists assessed the diagnostic criteria for apathy by means of an unstructured clinical interview. All criteria were individually questioned and additional information of the caregiver - if available - was used in the scoring procedure. Following criterion D of the diagnostic criteria, domain B1, reduced goaldirected behaviour, was only scored if it was thought not to be directly related to motor disability. For practical reasons, the raters were not blind to other assessment scales. In addition, two apathy instruments were administered: the Lille Apathy Rating Scale (LARS) and apathy section of the Neuropsychiatric Inventory (NPI) (Cummings, 1994; Sockeel et al., 2006). The LARS consists of 33 items divided over 9 domains and 4 subscales, with a score range from -36 to +36 points, with positive scores indicating more severe apathy (Sockeel et al., 2006). Since this study intends to validate a new gold standard for apathy, in the absence of another standard, the LARS and apathy section of the NPI were used to assess the concurrent validity of the diagnostic criteria. The NPI requires information from a caregiver. If this was not available, information was collected from the patient if this information - in the researcher's opinion - was reliable. 
Table 1. Diagnostic criteria for apathy (Robert et al., 2009)

For a diagnosis of apathy the patient should fulfil the criteria A, B, C and D

A. Loss of or diminished motivation in comparison to the patient's previous level of functioning and which is not consistent with his age or culture. These changes in motivation may be reported by the patient himself or by the observations of others.

B. Presence of at least one symptom in at least two of the three following domains for a period of at least four weeks and present most of the time.

\section{Domain B1- Behaviour:}

Loss of, or diminished, goal-directed behaviour as evidenced by at least one of the following:

- Initiation symptom: loss of self-initiated behaviour (for example: starting conversation, doing basic tasks of day-to-day living, seeking social activities, communicating choices).

- Responsiveness symptom: loss of environment-stimulated behaviour (for example: responding to conversation, participating in social activities).

\section{Domain B2 - Cognition:}

Loss of, or diminished, goal-directed cognitive activity as evidenced by at least one of the following:

- Initiation symptom: loss of spontaneous ideas and curiosity for routine and new events (i.e., challenging tasks, recent news, social opportunities, personal/family and social affairs).

- Responsiveness symptom: loss of environment-stimulated ideas and curiosity for routine and new events (i.e., in the person's residence, neighbourhood or community).

\section{Domain B3 - Emotion:}

Loss of, or diminished, emotion as evidenced by at least one of the following:

- Initiation symptom: loss of spontaneous emotion, observed or self-reported (for example, subjective feeling of weak or absent emotions, or observation by others of a blunted affect).

- Responsiveness symptom: loss of emotional responsiveness to positive or negative stimuli or events (for example, observer-reports of unchanging affect, or of little emotional reaction to exciting events, personal loss, serious illness, emotional-laden news).

C. These symptoms (A - B) cause clinically significant impairment in personal, social, occupational, or other important areas of functioning.

D. The symptoms (A - B) are not exclusively explained or due to physical disabilities (e.g. blindness and loss of hearing), to motor disabilities, to diminished level of consciousness or to the direct physiological effects of a substance (e.g. drug of abuse, a medication). 


\section{Statistical analysis}

All statistical analyses were conducted using the Statistical Package for the Social Sciences, version 16.0 (SPSS Inc. Chicago, 2008). To identify differences in scores, Kruskal-Wallis tests were used since none of the included variables were normally distributed. Chi-square-tests were used to compare proportions. The level of significance for all analyses was set at $p<0.05$.

The percentage of missing data was thought to reflect acceptability, with $<5 \%$ missing data considered acceptable. Cronbach's alpha was calculated as a measure of internal consistency, with $\leq 0.70$ considered acceptable.

Concurrent validity of the diagnostic criteria with the LARS and the apathy section of the NPI was estimated by calculating Phi correlation coefficients. Apathy was defined here as score on the LARS of $\geq-16$ (Sockeel et al., 2006) or as a score of $\geq 4$ on the apathy section of the NPI. A correlation $<0.3$ was considered weak, a correlation between 0.3 and 0.5 moderate, between 0.5 and 0.7 fair, and $>0.7$ good. Known-groups validity was assessed by comparing average scores obtained by apathetic and nonapathetic patients on the LARS and the apathy section of the NPI, using a Kruskal-Wallis test. Discriminant validity between the diagnostic criteria of apathy and those of major depressive disorder, as well as with the HAMD score and the score on the depression section of the NPI, was also estimated by calculating Phi correlation coefficients. In this case, lower correlation coefficients were thought to reflect better discriminant validity.

The frequency of each of the three domains of criterion B in apathetic and nonapathetic patients was reported and tested for differences by chi-square tests. The scores on subscales of the LARS in apathetic and non-apathetic patients were also compared and tested for differences with a Kruskal-Wallis test. The relationship between the four sub-factors of the LARS (intellectual curiosity, emotion, action initiation and self awareness) and the three domains of apathy (B1, 2 and 3) was examined using a point bi-serial correlation coefficient.

\subsection{Results}

\section{Demographic characteristics}

Demographic characteristics of the population and disease related variables of apathetic and non-apathetic patients are shown in table 2. The total sample consisted of 122 patients with an average age of 64.6 years, of which $41 \%$ was female. The two centers did not differ on any of the variables, except for the scores on the H\&Y stage (both a median of 2 and range from 1 to 3; $p<0.001$ ), IADL scale (a mean score of 16.9 for patients from Lille and 19.7 for patients from Maastricht; $p=0.001$ ) and the LARS (a score of -24.6 for patients from Lille versus -22.2 for patients from Maastricht; 
$p=0.048)$. However, these differences were small and not considered clinically relevant.

Patients meeting the diagnostic criteria for apathy scored significantly lower on the MMSE, and higher on the HAMD, the LARS and the apathy section of the NPI than nonapathetic patients. For the IADL score, a trend towards lower (worse) scores for apathetic patients was observed $(p=0.059)$.

\section{Acceptability and internal consistency}

There were no missing data for the diagnostic criteria for apathy. Cronbach's alpha was 0.88 .

\section{Frequency of apathy and overlap with depression}

Twenty-one of the 122 included patients (17.2\%) met the diagnostic criteria for apathy. According to the MINI, eight of the 122 patients (6.6\%) suffered from dysthymia and thirteen (10.7\%) from major depressive disorder. Four patients $(3.3 \%)$ out of the total population met the criteria for both dysthymia and apathy; seven patients $(5.7 \%)$ had both major depressive disorder and apathy. This implies that one third $(33.3 \%)$ of the 21 apathetic patients also had a depressive episode, while more than half $(53.8 \%)$ of the 13 patients with a depressive disorder met the diagnostic criteria for apathy (table 3).

\section{Validity}

The concurrent validity between the diagnostic criteria of apathy and the LARS and apathy section of the NPI yielded a Phi correlation coefficient of 0.72 and 0.76 , respectively $(p=0.01)$. The percentage of agreement between the diagnosis of apathy based on the diagnostic criteria and based on cut-off scores on the apathy rating scales was $81 \%$ for the LARS and $86 \%$ for the apathy section of the NPI, respectively. Ninety-four percent of the patients who were not diagnosed as apathetic on basis of the diagnostic criteria were also classified as non-apathetic by the LARS, which is the same percentage as for the apathy section of the NPI (table 4).

Discriminant validity between the diagnostic criteria for apathy and the diagnosis of depressive disorder, the HAMD and the depression section of the NPI was also assessed by Phi correlation. Both for the MINI as well as the depression section of the NPI, the correlations were 0.34 and 0.31 , respectively (both $p=0.01$ ), indicating a fair correlation, and thus good discriminant validity. For the HAMD, the correlation was 0.54 $(p=0.01)$, indicating a moderate correlation, and thus a moderate discriminant validity. 
Table 2. Demographic and disease-related characteristics of overall population and apathetic versus nonapathetic patients (standard deviation between brackets), as well as of the Lille and Maastricht population. Differences in values or proportions between the two participating centres were tested with Kruskal-Wallis, except sex, which was tested with a Chi square test

\begin{tabular}{|c|c|c|c|c|c|c|c|}
\hline & $\begin{array}{c}\text { Total } \\
\text { popula- } \\
\text { tion } \\
(\mathrm{N}=122)\end{array}$ & $\begin{array}{c}\text { Apathetic } \\
(\mathrm{N}=21)\end{array}$ & $\begin{array}{c}\text { Non- } \\
\text { apathetic } \\
(\mathrm{N}=101)\end{array}$ & $\begin{array}{c}\text { p- } \\
\text { value }^{a}\end{array}$ & $\begin{array}{c}\text { Lille } \\
(N=62)\end{array}$ & $\begin{array}{l}\text { Maas- } \\
\text { tricht } \\
(N=60)\end{array}$ & p-value \\
\hline Age & $64.6(8.5)$ & $64.2(8.7)$ & $64.6(8.5)$ & 0.844 & $63.4(8.1)$ & $65.7(8.7)$ & 0.138 \\
\hline Female (\%) & 41 & 42,9 & 40.6 & 0.939 & 57 & 38 & 0.558 \\
\hline $\begin{array}{l}\text { Disease } \\
\text { duration }\end{array}$ & $8.5(5.6)$ & 7.5 (5.7) & $8.7(5.6)$ & 0.220 & $9.6(6.3)$ & $7.5(4.6)$ & 0.099 \\
\hline $\begin{array}{l}\text { H\&Y stage } \\
\text { (median) }\end{array}$ & $2(3)$ & $2(3)$ & $2(3)$ & 0.298 & $2(3)$ & $2(3)$ & $<0.001$ \\
\hline UPDRS III & $19.4(8.0)$ & $21.8(7.0)$ & $18.9(8.2)$ & 0.05 & $20.7(9.3)$ & $18.1(6.2)$ & 0.063 \\
\hline MMSE & $28.2(1.8)$ & $27.2(2.1)$ & $28.5(1.6)$ & 0.010 & $28.0(1.9)$ & $28.5(1.6)$ & 0.15 \\
\hline IADL & $18.2(6.2)$ & $21.4(8.7)$ & $17.6(5.3)$ & 0.059 & $16.9(5.4)$ & $19.7(6.6)$ & 0.001 \\
\hline HAMD & $6.3(5.8)$ & $13.0(6.9)$ & $5.0(4.4)$ & $<0.001$ & $6.2(6.2)$ & $6.5(5.3)$ & 0.346 \\
\hline NPI apathy & $1.6(2.8)$ & $6.4(3.0)$ & $0.6(1.2)$ & $<0.001$ & $2.0(3.3)$ & $1.2(2.0)$ & 0.392 \\
\hline LARS & $-23.4(7.8)$ & $-11.7(5.9)$ & $-25.8(5.7)$ & $<0.001$ & $-24.6(8.1)$ & $-22.2(7.3)$ & 0.048 \\
\hline
\end{tabular}

${ }^{\mathrm{a}}$ comparison non-apathetic versus apathetic, ${ }^{\mathrm{b}}$ comparison Lille versus Maastricht

Table 3. Number and proportion (\%) of PD patients with depression and dysthymia that is classified as apathetic or non-apathetic following the diagnostic criteria

\begin{tabular}{lccc}
\hline & Apathetic & Non-apathetic & Total \\
\hline No depression & $10(8.2 \%)$ & $91(74.6 \%)^{* *}$ & $101(82.8 \%)$ \\
Major depressive disorder & $7(5.7 \%)$ & $6(5.0 \%)^{* *}$ & $13(10.7 \%)$ \\
Dysthymia & $4(3.3 \%)$ & $4(3.3 \%)^{*}$ & $8(6.6 \%)$ \\
Total & $21(17.2 \%)$ & $101(82.8 \%)$ & $122(100 \%)$ \\
\hline
\end{tabular}

$* p \leq 0.01, * * p<0.001$

Table 4. Numbers and percentage agreement of apathy when diagnosed on the basis of diagnostic criteria of apathy or on the basis of cut-off scores on the apathy section of the NPI and the LARS

\begin{tabular}{lccccc}
\hline & $\begin{array}{c}\text { NPI } \geq 4 \\
\text { Yes }\end{array}$ & $\begin{array}{c}\text { NPI } \leq \mathbf{3} \\
\text { No }\end{array}$ & $\begin{array}{c}\text { LARS } \geq-16 \\
\text { Yes }\end{array}$ & $\begin{array}{c}\text { LARS } \leq-17 \\
\text { No }\end{array}$ & Total \\
\hline Apathetic & $18(86 \%)$ & $3(14 \%)$ & $17(81 \%)$ & $4(19 \%)$ & 21 \\
Non-apathetic & $6(6 \%)$ & $95(94 \%)$ & $6(6 \%)$ & $95(94 \%)$ & 101 \\
Total & $24(20 \%)$ & $98(80 \%)$ & $23(19 \%)$ & $99(81 \%)$ & 122 \\
\hline
\end{tabular}


Known-groups validity was assessed by comparing the scores of the apathetic and non-apathetic patients on the LARS and the apathy section of the NPI. Apathetic patients scored significantly higher than non-apathetic patients on both scales $(p<0.001) \quad$ (table 2).

\section{Subdimensions of apathy}

Table 5 illustrates that all three domains of apathy described in criterion B contribute to the diagnosis of apathy. In apathetic patients, reduced goal-directed behaviour (B1) was the most frequently observed domain (95\%), followed by reduced goal-directed cognition (B2, 86\%) and reduced spontaneous emotion (B3, 52\%). Of the 21 apathetic patients, $38.1 \%$ scores positive on all three domains of criterion $B, 47.6 \%$ scored on domains B1 and B2 only, $9.5 \%$ on domains B1 and B3 only, and $4.8 \%$ on domains B2 and B3 only.

When comparing scores on the LARS domains and subscales between apathetic and non-apathetic patients, the apathetic group scored higher on all domains, except for the domains 'concern' and 'self awareness', and the 'self awareness' subscale (table 6). When correlating the three subdomains of criterion B with the four dimensions of the LARS (intellectual curiosity, emotion, action initiation and self awareness), criterion B1 (behaviour) correlated fair with the subscale 'intellectual curiosity', but only weak to moderate with the other subscales. Criterion B2 (cognition) correlated fair with the subscales 'intellectual curiosity' and 'action initiation', and only weakly with the other subscales. Criterion B3 (emotion) had only weak correlations with the subscales (table 7).

Table 5. Frequency of the three domains of the B criterion of the diagnostic criteria for apathetic and nonapathetic patients

\begin{tabular}{lcccc}
\hline & B1 & B2 & B3 & Total \\
\hline Apathetic & $95.2 \%$ & $85.7 \%$ & $52.4 \%$ & 21 \\
Non-apathetic & $23.8 \%$ & $12.9 \%$ & $9.9 \%$ & 101 \\
\hline
\end{tabular}


Table 6. Comparison of means between apathetic and non-apathetic patients on the domains and subscales of the LARS

\begin{tabular}{llll}
\hline & $\begin{array}{c}\text { Apathetic } \\
(\mathbf{n = 2 1})\end{array}$ & $\begin{array}{c}\text { Non-apathetic } \\
(\mathbf{n = 1 0 1})\end{array}$ & p-value $^{\mathbf{a}^{2}}$ \\
\hline Everyday productivity & $-2.10(1.87)$ & $-3.21(1.12)$ & 0.003 \\
Interest & $0.19(2.23)$ & $-1.73(1.40)$ & $<0.001$ \\
Taking initiative & $-1.05(2.04)$ & $-3.25(1.16)$ & $<0.001$ \\
Novelty seeking & $-0.19(2.04)$ & $-2.78(1.71)$ & $<0.001$ \\
Motivation & $-0.90(2.45)$ & $-3.21(1.42)$ & $<0.001$ \\
Emotional responses & $-1.86(1.82)$ & $-3.23(1.17)$ & $<0.001$ \\
Concern & $-2.52(1.72)$ & $-2.78(1.38)$ & 0.632 \\
Social life & $-0.62(2.18)$ & $-2.65(1.43)$ & $<0.001$ \\
Self awareness & $-2.52(2.11)$ & $-2.99(1.45)$ & 0.574 \\
& & & $<0.001$ \\
Intellectual curiosity & $-0.40(1.03)$ & $-2.61(0.85)$ & 0.001 \\
Emotion & $-2.12(1.08)$ & $-3.01(0.99)$ & $<0.001$ \\
Action initiation & $-1.55(1.43)$ & $-3.25(0.86)$ & 0.529 \\
Self awareness & $-2.52(2.11)$ & $-3.01(1.44)$ & \\
\hline Kruskal-Wallis & & & \\
\hline
\end{tabular}

${ }^{a}$ Kruskal-Wallis tests

Table 7. Correlation between subscales of the LARS and the three domains of criterion $B$ of the diagnostic criteria for apathy $(B 1,2,3)$

\begin{tabular}{lccc}
\hline & $\begin{array}{c}\text { Domain B1 } \\
\text { Behaviour }\end{array}$ & $\begin{array}{c}\text { Domain B2 } \\
\text { Cognition }\end{array}$ & $\begin{array}{c}\text { Domain B3 } \\
\text { Emotion }\end{array}$ \\
\hline Intellectual curiosity & $0.557^{* *}$ & $0.622^{* *}$ & $0.346^{* *}$ \\
Emotion & $0.236^{* *}$ & $0.204^{*}$ & $0.327^{* *}$ \\
Action initiation & $0.323^{* *}$ & $0.466^{* *}$ & $0.199^{*}$ \\
Self awareness & 0.157 & $0.281^{* *}$ & -0.013 \\
\hline
\end{tabular}

* correlation is significant at the 0.05 level (2-tailed), ** correlation is significant at the 0.01 level (2-tailed)

\subsection{Discussion}

This is the first study that validates the recently proposed diagnostic criteria for apathy in a population of patients with PD, with the aim of assessing their usefulness for clinical practice and research. Only one earlier study tested the criteria in patients with a range of neuropsychiatric diseases (Mulin et al., 2011). New instruments or criteria are generally validated against an existing gold standard. For apathy, no gold standard is available yet, which sets limitations to the assessment of clinimetric properties of the 
proposed criteria. While reliability can be assessed, assessing validity poses a problem, since this requires a gold standard. For assessment of concurrent validity and knowngroups validity, the LARS and apathy section of the NPI were used as 'proxy gold standard'. The NPI is a frequently used instrument in neurodegenerative disorders (including PD), while the LARS was designed specifically for PD patients (Leentjens et al., 2008). For both scales, we used proposed cut-off scores for apathy in accordance with those used in previous studies (Cummings, 1994; Leentjens et al., 2008; Sockeel et al., 2006).

Our study shows that the diagnostic criteria for apathy have good internal consistency and acceptability. Strong correlations were found between the diagnostic criteria for apathy, and both the LARS and apathy section of the NPI, which implies good concurrent validity. Known-groups validity was also good. Discriminant validity of the apathy criteria to distinguish apathy and depressive disorder as diagnosed on the basis of the MINI was good. When discriminant validity of the criteria was assessed using the HAMD or depression section of the NPI as indicator of depression, this discriminant validity was good against the NPI depression section and moderate when the HAMD is used. A possible explanation for this difference is the fact that the HAMD considers some apathetic symptoms as part of the depressive symptomatology, with one item specifically asking about apathy. The depression section of the NPI does not have such items referring to apathy, since the NPI includes a separate apathy item.

In our study, $17.2 \%$ of the included patients were diagnosed with apathy on the basis of the diagnostic criteria. In the literature, the reported frequency of apathy varies from 17 to $70 \%$, mostly on the basis of cut-off scores on a rating scale or assessment instrument (Dujardin et al., 2007; Pluck \& Brown, 2002; Starkstein et al., 2009). Thus, the frequency found in this study is in the lower part of that range. One potential explanation for this may be the fact that we did not included patients with a clinical diagnosis of PDD, whereas the frequency of apathy is higher in patients with cognitive decline and dementia. This was supported in a recent study of Dujardin and colleagues in which $24.2 \%$ of the non-demented PD patients had apathy against $56.4 \%$ among the demented patients (Dujardin et al., 2007). In an earlier validation study of the same criteria, a frequency of apathy of $27 \%$ in 44 PD patients was reported (Mulin et al., 2011). However, this study included PD patients with and without dementia. In line with our study, this latter study also suggests that the diagnostic criteria for apathy have a relatively higher threshold, when compared to cut-off scores on apathy rating scales.

All domains of the $\mathrm{B}$ criterion contributed to a diagnosis of apathy, with goaldirected behaviour being the most frequent reported domain. Domain 3, emotion, appears to occur mostly in combination with one or both of the other two domains, which may be interpreted as an indication of more severe levels of apathy. In a posthoc explorative analysis we could not confirm this hypothesis and results were inconclusive. The mean score on the apathy section of the NPI was significantly higher in 
patients meeting criterion B3 (8.2 versus $4.5 ; p=0.005)$, whereas the mean score on the LARS was not different for those that did or did not meet criterion B3 (10.9 versus $-12.9 ; p=0.75)$.

Our study had several limitations. First of all, the included patients were recruited in two different centers. In both settings, different raters performed the assessment. For practical reasons, inter-rater reliability was not assessed as well were the raters not blind to other assessment scales. Another limitation is that patients with a diagnosis of PDD were excluded from the study while it is known that dementia predisposes to apathy (Starkstein et al., 2009). Exclusion of these patients could give an underestimation of the frequency of apathy in PD and may explain the relatively low frequency of apathy found in this study. However, it underlines that in a clinical population of PD patients with and without cognitive decline, apathy is a quite frequent neuropsychiatric syndrome.

\subsection{Conclusion}

This study shows good acceptability, internal consistency, concurrent and knowngroups validity of the proposed diagnostic criteria for apathy. In addition, discriminant validity with depression is moderate to good. All domains of criterion B contribute to the syndromal diagnosis, of which diminished goal-directed behaviour was most frequent. Lack of emotion is possibly related to a more severe level of apathy. These properties make the proposed criteria valid, and useful for clinical practice and research. The criteria provide a gold standard for studies into the epidemiology, symptomatology, pathophysiology and treatment of apathy in patients with PD. Future studies have yet to examine the influence of cognitive functioning on the clinimetric properties of the diagnostic criteria. 


\section{References}

American Psychiatric Association. (1994). Diagnostic and statistical manual of mental disorders, 4th Edn. Washington, DC: American Psychiatric Press.

Cummings, J. L., Mega, M., Gray, K., Rosenberg-Thompson, S., Carusi, D.A., Gornbein, J. (1994). The Neuropsychiatric Inventory: Comprehensive assessment of psychopathology in dementia. Neurology, 44(12), 2308-2314.

De Rijk, M. C., Rocca, W. A., Anderson, D. W., Melcon, M. O., Breteler, M. M. B., \& Maraganore, D. M. (1997). A population perspective on diagnostic criteria for Parkinson's disease. Neurology, 48(5), 1277-1281.

Drijgers, R. L., Aalten, P., Winogrodzka, A., Verhey, F. R. J., \& Leentjens, A. F. G. (2009). Pharmacological treatment of apathy in neurodegenerative diseases: a systematic review. Dementia and Geriatric Cognitive Disorders, 28(1), 13-22.

Dujardin, K., Sockeel, P., Devos, D., Delliaux, M., Krystkowiak, P., Destee, A., et al. (2007). Characteristics of apathy in Parkinson's disease. Movement Disorders, 22(6), 778-784.

Fahn, S., \& Elton, R. L. (1987). Unified Parkinson's disease rating scale. New Jersey: McMillan Health Care.

Folstein, M. F., Folstein, S. E., \& McHugh, P. R. (1975). "Mini-mental state". A practical method for grading the cognitive state of patients for the clinician. Journal of Psychiatric Research, 12(3), 189-198.

Hamilton, M. (1960). A rating scale for depression. Journal of Neurology, Neurosurgery and Psychiatry, 23, 5662.

Kirsch-Darrow, L., Fernandez, H. H., Marsiske, M., Okun, M. S., \& Bowers, D. (2006). Dissociating apathy and depression in Parkinson disease. Neurology, 67(1), 33-38.

Lawton, M. P., \& Brody, E. M. (1969). Assessment of older people: Self-maintaining and instrumental activities. Gerontologist, 9(3), 179-186.

Leentjens, A. F. G., Dujardin, K., Marsh, L., Martinez-Martin, P., Richard, I. H., Starkstein, S. E., et al. (2008). Apathy and anhedonia rating scales in Parkinson's disease: critique and recommendations. Movement Disorders, 23(14), 2004-2014.

Leentjens, A. F. G., Dujardin, K., Marsh, L., Richard, I. H., Starkstein, S. E., \& Martinez-Martin, P. (2010). Anxiety rating scales in Parkinson's disease: a validation study of the Hamilton Anxiety Rating Scale, The Beck Anxiety Inventory and the Hospital Anxiety and Depression Scale. Movement Disorders, 26(3), 407-415.

Mulin, E., Leone, E., Dujardin, K., Delliaux, M., Leentjens, A. F. G., Nobili, F., et al. (2011). Diagnostic criteria for apathy in clinical practice. International Journal of Geriatric Psychiatry, 26(2), 158-165.

Oguru, M., Tachibana, H., Toda, K., Okuda, B., \& Oka, N. (2010). Apathy and Depression in Parkinson Disease. Journal of Geriatric Psychiatry and Neurology, 23(1), 35-41.

Pedersen, K. F., Alves, G., Aarsland, D., \& Larsen, J. P. (2009). Occurrence and risk factors for apathy in Parkinson disease: a 4 year prospective longitudinal study. Journal of Neurology, Neurosurgery and Psychiatry, 80(11), 1279-1282.

Pedersen, K. F., Larsen, J. P., Alves, G., \& Aarsland, D. (2009). Prevalence and clinical correlates of apathy in Parkinson's disease: A community-based study. Parkinsonism and Related Disorders, 15(4), 295-299.

Pluck, G. C., \& Brown, R. G. (2002). Apathy in Parkinson's disease. Journal of Neurology, Neurosurgery and Psychiatry, 73(6), 636-642.

Robert, P. H., Onyike, C. U., Leentjens, A. F. G., Dujardin, K., Aalten, P., Starkstein, S. E., et al. (2009). Proposed diagnostic criteria for apathy in Alzheimer's disease and other neuropsychiatric disorders. European Psychiatry, 24(2), 98-104.

Sheehan, D. V., Lecrubier, Y., Sheehan, K. H., Amorim, P., Janavs, J., Weiler, E., et al. (1998). The MiniInternational Neuropsychiatric Interview (M.I.N.I.): the development and validation of a structured diagnostic psychiatric interview for DSM-IV and ICD-10. Journal of Clinical Psychiatry, 59(Suppl 20), 22-33.

Sockeel, P., Dujardin, K., Devos, D., Deneve, C., Destee, A., \& Defebvre, L. (2006). The Lille apathy rating scale (LARS), a new instrument for detecting and quantifying apathy: validation in Parkinson's disease. Journal of Neurology, Neurosurgery and Psychiatry, 77(5), 579-584.

Starkstein, S. E., \& Leentjens, A. F. G. (2008). The nosological position of apathy in clinical practice. Journal of Neurology, Neurosurgery and Psychiatry, 79(10), 1088-1092. 
Starkstein, S. E., Merello, M., Jorge, R., Brockman, S., Bruce, D., \& Power, B. (2009). The Syndromal Validity and Nosological Position of Apathy in Parkinson's Disease. Movement Disorders, 24(8), 1211-1216. 


\section{CHAPTER 4}

Neuropsychological correlates of apathy in mild cognitive impairment and Alzheimer's disease: the role of executive functioning 


\section{Abstract}

Objective: To examine the association between apathy and neuropsychological functioning in patients with mild cognitive impairment $(\mathrm{MCl})$ and Alzheimer's disease (AD).

Methods: Two-hundred-and-sixty $A D$ patients and $178 \mathrm{MCl}$ patients visiting the Memory Clinic of the Maastricht University Medical Centre were included. Linear regression analysis, corrected for age, gender, level of education and depression was performed to reveal cross-sectional associations between apathy and scores on neuropsychological tests of memory, attention, psychomotor speed and executive functioning.

Results: In patients with $\mathrm{MCl}$, apathy was characterised by decreased verbal fluency and psychomotor tracking. In $A D$, patients with apathy differed from non-apathetic patients only on a verbal fluency task.

Conclusion: Apathy is related to executive dysfunction in the early phases of cognitive decline. In particular in the prodromal phase of $A D$, apathy seems to be characterized by poor initiating. In the more advanced stages of cognitive deterioration, associations between apathy and specific neuropsychological correlates may be obscured by the more severe neuropathology. Awareness of apathy in the early phase of cognitive impairment may help in early diagnostics of AD. 


\subsection{Introduction}

Apathy is as a syndrome characterized by a reduced motivation, reduced goal-directed behaviour and cognition and a flattening affect (Robert et al., 2009). It is a common and important behavioural syndrome in various neuropsychiatric diseases, such as several subtypes of dementia, Parkinson's disease (PD) and schizophrenia. Apathy is the most common neuropsychiatric symptom in Alzheimer's disease (AD), with reported prevalences ranging from 42 to $92 \%$ (Drijgers et al., 2009). It has a major impact on the quality of life of both patients and caregivers as evidenced by its widespread associations with caregiver distress, functional decline, and increased likelihood of institutionalization (Tun et al., 2007). Likewise, apathy is one of the most frequently observed neuropsychiatric symptoms in patients with mild cognitive impairment ( $\mathrm{MCl}$ ) (Robert et al., 2010). A recent systematic review reported that the prevalence of apathy in $\mathrm{MCl}$ varies from 12 to $15 \%$ in population-based studies to 11 to $53 \%$ in hospital-based studies (Monastero et al., 2009). Moreover, it has been suggested that apathy is an important feature of pre-dementia stages because it may be predictive for developing dementia (Robert et al., 2006a, Palmer et al., 2010, Onyike et al., 2007).

Apathy in dementia is increasingly considered as a syndrome on its own, independent of depression, with similar symptom constellations and pathophysiological correlates across diagnostic boundaries (Chase, 2011). Abnormalities within frontosubcortical circuits have been related to apathy, with particular emphasis on changes in the anterior cingulate, thought to be responsible for motivated behaviour (Chase, 2011, McPherson et al., 2002). These findings imply that apathy is associated with specific cognitive impairment caused by disruption of these brain areas. Indeed, apathy has been associated with executive dysfunction in previous studies, especially in $A D$ patients (McPherson et al., 2002, Kuzis et al., 1999).

However, whether apathy is associated with a specific neuropsychological profile across various stages of disease remains largely unknown. Studying the possible impact of apathy on cognitive status in $\mathrm{MCl}$ and comparing this with $\mathrm{AD}$ may provide insight into the underlying pathology and may lead to new options for early diagnosis and treatment options. So far, only few studies have compared the neuropsychological correlates of apathy in patients with $\mathrm{MCl}$ and dementia (Robert et al., 2006b, Ready et al., 2003, Kuzis et al., 1999, McPherson et al., 2002). Therefore the aim of the present study was to investigate the association between apathy and neuropsychological functioning in patients with $\mathrm{MCl}$ and $\mathrm{AD}$. We hypothesized that apathy is associated with decreased performance on tests involving initiation processes and executive functioning than with tests representing other cognitive domains and that this profile is consistent in both $\mathrm{MCl}$ and $\mathrm{AD}$. Furthermore, we hypothesized that this relationship is independent of depression. 


\subsection{Methods}

\section{Subjects}

Subjects were 438 ambulatory patients from the Memory Clinic of the Maastricht University Medical Centre. Of these, 260 (59\%) people had dementia according to DSM-IV (American Psychiatric Association, 1994). All patients were diagnosed with mild to severe AD in accordance with the NINCDS/ADRDA criteria (McKann et al., 1984). The remaining 178 patients (41\%) had objective cognitive impairment but did not meet the criteria for dementia and were therefore classified as having $\mathrm{MCl}$.

\section{Neuropsychological examination}

Cognitive staging and assessment of global cognitive functioning was done with the Global Deterioration Scale (GDS) and the Mini Mental State Examination (MMSE) respectively (Folstein et al., 1975, Reisberg et al., 1982). Verbal learning and memory was measured using the immediate recall, delayed recall and recognition trials of the Verbal Learning Test (VLT) (Van der Elst et al., 2005). Selective attention as well as information processing speed were assessed using the Stroop Color Word Test (STROOP) card 1 and 2, and the Letter-digit-symbol test or Symbol Digit Modalities Test (LDST, SDMT) (Van der Elst et al., 2006). Psychomotor tracking as well as attention was measured with the Concept Shifting task or Trail Making Test (CST, TMT) part A and B (number and letter tracing, respectively) (Van der Elst et al., 2006). The Verbal Fluency test, STROOP card 3 and CST/TMT part C (alternating between numbers and letters) were used to measure executive functioning (Van der Elst et al., 2006).

\section{Assessment of apathy}

Apathy and depression were assessed with the Neuropsychiatric Inventory (NPI) (Cummings, 1994). The NPI is a semi-structured instrument that evaluates the presence and severity of 12 neuropsychiatric symptoms. The validity and reliability of the NPI and of its Dutch version are well established (Kat et al., 2002). The frequency and severity of each symptom are scored on the basis of structured questions administered to the patient's primary caregiver. The continuous score for each symptom is obtained by multiplying severity (1-3) by frequency (1-4) and thus ranges from 1 to 12 . In line with previous studies, a score greater than 3 was taken to indicate the presence of 'clinically relevant' symptoms (Aalten et al., 2005).

The apathy subscale of the NPI consists of a screening question and 8 subquestions consistent with behaviours typically observed in apathetic patients. The questions evaluate several sub domains of apathy, such as lack of motivation, loss of interest in the world and reduction in affection. 


\section{Statistical analysis}

Differences in demographic characteristics and disease variables were analysed using the Kruskal-Wallis test for non-normally distributed continuous variables and the Chisquare test for categorical variables. The influence of apathy on the various neuropsychological tests was examined with linear regression analyses corrected for age, gender, level of education and depression. The level of significance for all analyses was set at $p<0.05$. Statistical analyses were conducted using STATA 11.0 (StataCorp, 2009).

To minimize potential bias by restricting analyses to complete observations multiple imputation (MI) of missing data was performed. Given the fact that data in observational studies are generally missing at random (MAR), meaning that missingness is probabilistic rather than deterministic, missing data can be imputed using available information (Rubin, 1976). MI constructs several alternative versions of the complete data set by predicting missing data points using data that is not missing. Each dataset contains slightly different imputed values by adding a random error term to the estimate. The analysis is then done on each of the imputed data sets separately and effect sizes and standard errors, which may vary, are then combined using simple arithmetics to obtain an overall estimate (Schafer and Graham, 2002). Only neuropsychological tests with less than $40 \%$ missing data may be included in MI. We imputed 20 datasets in STATA 11.0 using the ICE routine. After imputation, the linear regression analyses were conducted using the MIM prefix.

\subsection{Results}

\section{Demographic and clinical characteristics}

Demographic and clinical characteristics of the total $\mathrm{MCl}$ and $\mathrm{AD}$ group as well as the characteristics of patients stratified by apathy status are presented in table 1 . In total, 138 of the 438 patients (31.5\%) were apathetic. Apathy was significantly more prevalent in the $A D$ group than in the $\mathrm{MCl}$ group (35.3\% versus $25.8 \%$ respectively; $\chi 2$ value $(d f)=4.5(1), p=0.04)$. Of the $A D$ patients $53.7 \%$ had mild $A D(M M S E \geq 21)$, of whom $34.3 \%$ were apathetic, $43.1 \%$ had moderate AD (MMSE 11-20), of whom 36.7\% were apathetic and $3.1 \%$ suffered from severe AD (MMSE $\leq 10$ ), of whom $25 \%$ was apathetic. In both the $\mathrm{MCl}$ and $\mathrm{AD}$ group the apathetic patients did not significantly differ from the non-apathetic patients with respect to age, gender, level of education, MMSE score and GDS score. In both diagnostic groups the apathetic patients were significantly more depressed according to the NPI and showed a higher total score on the NPI than non-apathetic patients. Although NPI scores for depression and apathy were moderately correlated, (Pearson's $r=0.40, p<0.001$ ), 58\% of the apathetic patients were not depressed and $49 \%$ of the patients with depression were not apathetic. 
Table 1. Demographic characteristics of the $\mathrm{MCl}$ and $\mathrm{AD}$ group, divided by apathy status

\begin{tabular}{|c|c|c|c|c|c|}
\hline & $\mathrm{MCl}$ & & & & \\
\hline & $\begin{array}{c}\text { Total } \\
(n=178)\end{array}$ & $\begin{array}{l}\text { With apathy } \\
\qquad(n=46)\end{array}$ & $\begin{array}{l}\text { Without Apathy } \\
\qquad(n=132)\end{array}$ & $\begin{array}{l}\chi^{2} \text { value } \\
\text { (df) }\end{array}$ & p-value \\
\hline $\begin{array}{l}\text { Female gender, } \\
N(\%)\end{array}$ & 71 (39.9) & $14(30.4)$ & $57(43.2)$ & $2.3(1)$ & $0.13^{b}$ \\
\hline Age, years & $67.1 \pm 9.5$ & $69.0 \pm 10.3$ & $66.4 \pm 9.2$ & $3.2(1)$ & $0.07^{\mathrm{a}}$ \\
\hline Education, $\mathrm{N}(\%)$ & $33 / 77 / 34$ & 9/19/11 & $24 / 48 / 23$ & $0.7(2)$ & $0.70^{b}$ \\
\hline low/mid/high & $22.9 / 53.5 / 23.6$ & $23.1 / 48.7 / 28.2$ & $22.9 / 55.2 / 21.9$ & & \\
\hline MMSE score & $26.5 \pm 3.0$ & $26.2 \pm 3.1$ & $26.6 \pm 2.9$ & $0.7(1)$ & $0.41^{a}$ \\
\hline GDS & $2.7 \pm 0.6$ & $2.9 \pm 0.5$ & $2.7 \pm 0.6$ & $2.8(1)$ & $0.10^{a}$ \\
\hline NPI apathy & $2.1 \pm 3.2$ & $6.8 \pm 2.9$ & $0.5 \pm 0.8$ & $116.9(1)$ & $<0.001^{a}$ \\
\hline NPI depression & $1.8 \pm 3.1$ & $4.0 \pm 4.3$ & $1.0 \pm 2.0$ & $22.2(1)$ & $<0.001^{\mathrm{a}}$ \\
\hline Total NPI score & $13.6 \pm 16.8$ & $30.7 \pm 20.1$ & $7.7 \pm 10.3$ & $64.5(1)$ & $<0.001^{\mathrm{a}}$ \\
\hline
\end{tabular}

\begin{tabular}{|c|c|c|c|c|c|c|}
\hline & AD & & & & & $\begin{array}{c}\mathrm{MCl} \text { vs. } \\
\mathrm{AD}\end{array}$ \\
\hline & $\begin{array}{c}\text { Total } \\
(n=260)\end{array}$ & $\begin{array}{l}\text { With apathy } \\
\qquad(n=92)\end{array}$ & $\begin{array}{l}\text { Without } \\
\text { apathy } \\
(n=168)\end{array}$ & $\begin{array}{c}\chi^{2} \text { value } \\
\text { (df) }\end{array}$ & p-value & p-value \\
\hline $\begin{array}{l}\text { Female gender, } \\
N(\%)\end{array}$ & $146(56.2)$ & $51(55.4)$ & 95 (56.5) & $0.03(1)$ & $0.86^{b}$ & $0.001^{b}$ \\
\hline Age, years & $74.4 \pm 8.3$ & $74.6 \pm 9.2$ & $74.3 \pm 8.0$ & $0.6(1)$ & $0.45^{\mathrm{a}}$ & $<0.001^{\mathrm{a}}$ \\
\hline Education, $\mathrm{N}(\%)$ & $114 / 82 / 31$ & $39 / 32 / 10$ & $75 / 50 / 21$ & $0.7(2)$ & $0.72^{b}$ & $<0.001^{b}$ \\
\hline low/mid/high & $50.2 / 36.1 / 13.7$ & $48.1 / 39.5 / 12.3$ & $51.4 / 34.2 / 14.4$ & & & \\
\hline MMSE score & $20.3 \pm 4.8$ & $20.0 \pm 4.5$ & $20.4 \pm 5.0$ & $0.8(1)$ & $0.38^{\mathrm{a}}$ & $<0.001^{a}$ \\
\hline GDS & $3.7 \pm 0.8$ & $3.8 \pm 0.8$ & $3.7 \pm 0.8$ & $2.5(1)$ & $0.11^{\mathrm{a}}$ & $<0.001^{\mathrm{a}}$ \\
\hline NPI apathy & $2.8 \pm 3.4$ & $6.6 \pm 2.7$ & $0.6 \pm 1.0$ & $195.1(1)$ & $<0.001^{\mathrm{a}}$ & $0.049^{\mathrm{a}}$ \\
\hline NPI depression & $2.6 \pm 3.6$ & $3.9 \pm 4.3$ & $1.9 \pm 3.0$ & $15.2(1)$ & $<0.001^{\mathrm{a}}$ & $0.049^{a}$ \\
\hline Total NPI score & $18.0 \pm 18.0$ & $30.9 \pm 20.2$ & $11.6 \pm 12.8$ & $67.5(1)$ & $<0.001^{a}$ & $0.001^{a}$ \\
\hline
\end{tabular}

${ }^{a}$ Kruskal-Wallis, ${ }^{b}$ Chi-square, values represent mean \pm SD unless otherwise stated. 


\section{Results of neuropsychological tests}

In the $\mathrm{MCl}$ group, linear regression analysis showed a significant main effect of apathy on Verbal Fluency (animal naming, profession and aggregate measure), in which patients with apathy scored significantly lower than patients without apathy (table 2). Apathetic patients were also significantly slower on the TMT parts A and B than nonapathetic patients (table 2). No significant differences in neuropsychological performance were found on other tests. In $A D$, apathetic patients performed worse on Verbal Fluency animal naming, compared with non-apathetic patients, but no differences were observed in naming professions or the aggregated verbal fluency measure (table 3). Depression had no effect on any neuropsychological measure in either patient groups (data not shown).

Table 2. Neuropsychological data of the $\mathrm{MCl}$ group

\begin{tabular}{|c|c|c|c|c|c|}
\hline & Apathy & & & & \\
\hline & $\begin{array}{c}\text { Yes } \\
(n=46)\end{array}$ & $\begin{array}{c}\text { No } \\
(n=132)\end{array}$ & $\mathrm{B}^{*}$ & $\begin{array}{c}95 \% \\
\text { confidence interval }\end{array}$ & $\mathbf{p}$ \\
\hline VLT immediate recall & $31.7(10.0)$ & $33.9(10.5)$ & -2.53 & $-6.3 ; 1.3$ & 0.19 \\
\hline VLT delayed recall & $4.8(3.2)$ & $4.9(3.7)$ & 0.23 & $-1.1 ; 1.5$ & 0.73 \\
\hline VLT recognition & $12.1(3.2)$ & $12.2(3.0)$ & 0.04 & $-1.1 ; 1.2$ & 0.95 \\
\hline Stroop 1 & $62.1(23.2)$ & $59.2(15.2)$ & 2.52 & $-4.4 ; 9.4$ & 0.47 \\
\hline Stroop 2 & 75.4 (19.9) & 77.4 (17.9) & -1.02 & $-8.3 ; 6.3$ & 0.78 \\
\hline Stroop 3 & $155.0(52.3)$ & 156.7 (69.9) & -1.97 & $-28.2 ; 24.2$ & 0.88 \\
\hline TMTA & $80.8(51.6)$ & $59.0(28.5)$ & 18.36 & $3.6 ; 33.1$ & 0.02 \\
\hline TMTB & 95.3 (87.9) & $65.9(34.0)$ & 26.53 & $2.5 ; 50.5$ & 0.03 \\
\hline TMTC & $128.2(68.3)$ & $119.0(63.0)$ & 20.41 & $-13.6 ; 54.4$ & 0.24 \\
\hline SDMT 90s & $27.8(13.4)$ & $29.9(11.3)$ & -0.44 & $-5.0 ; 4.1$ & 0.85 \\
\hline Fluency animals & $14.4(3.7)$ & $16.7(5.8)$ & -2.43 & $-4.5 ;-0.4$ & 0.02 \\
\hline Fluency professions & $10.7(3.4)$ & $12.1(5.2)$ & -1.74 & $-3.5 ; 0.03$ & 0.05 \\
\hline Fluency average & 12.5 (3.9) & $14.4(4.9)$ & -2.09 & $-3.8 ;-0.4$ & 0.02 \\
\hline
\end{tabular}

*Adjusted for age, gender, level of education and depression 
Table 3. Neuropsychological data of the AD group

\begin{tabular}{lccccc}
\hline \multicolumn{7}{c}{ Apathy } & \multicolumn{3}{c}{} \\
\hline & $\begin{array}{c}\text { Yes } \\
\text { (n= 92) }\end{array}$ & $\begin{array}{c}\text { No } \\
(\mathbf{n = 1 6 8 )}\end{array}$ & $\mathbf{B}$ & $\begin{array}{c}\text { 95\% } \\
\text { confidence interval }\end{array}$ \\
\hline VLT immediate recall & $21.9(8.2)$ & $22.2(8.5)$ & -0.35 & $-2.5 ; 1.8$ & 0.75 \\
VLT delayed recall & $1.3(2.1)$ & $1.7(2.3)$ & -0.92 & $-0.8 ; 0.3$ & 0.36 \\
VLT recognition & $8.6(3.4)$ & $8.8(3.3)$ & -0.17 & $-1.1 ; 0.7$ & 0.70 \\
Stroop 1 & $74.2(28.1)$ & $72.3(27.6)$ & 1.08 & $-6.3 ; 8.5$ & 0.77 \\
Stroop 2 & $99.8(36.6)$ & $100.2(38.4)$ & 1.33 & $-9.0 ; 11.7$ & 0.80 \\
Stroop 3 & $223.2(115.1)$ & $204.7(97.7)$ & 19.7 & $-18.8 ; 58.3$ & 0.31 \\
CSTA & $64.6(45.8)$ & $60.4(40.1)$ & 2.23 & $-10.5 ; 14.9$ & 0.73 \\
Fluency animal & $10.2(4.7)$ & $11.2(4.6)$ & -1.21 & $-2.4 ;-0.03$ & 0.05 \\
Fluency professions & $7.1(4.2)$ & $7.5(4.2)$ & -0.57 & $-1.7 ; 0.5$ & 0.30 \\
Fluency average & $8.6(4.2)$ & $9.3(4.1)$ & -0.89 & $-1.9 ; 0.2$ & 0.10 \\
\hline
\end{tabular}

* Adjusted for age, gender, level of education and depression

\subsection{Discussion}

The present study investigated the association between apathy and neuropsychological functioning in patients with $\mathrm{MCl}$ and $\mathrm{AD}$. With a prevalence of $35.3 \%$, more $A D$ patients were apathetic than patients with $\mathrm{MCl}(25.8 \%)$. Apathetic $\mathrm{MCl}$ patients scored worse than non-apathetic $\mathrm{MCl}$ patients on tests for executive functioning and psychomotor tracking. This association was independent of the presence of depressive symptoms, as indicated by the NPI. In the AD group the difference between apathetic and nonapathetic patients was less pronounced and significant only for a single test of the Verbal Fluency (animal naming) representing executive functioning. No significant differences were found on measures of memory, attention and information processing speed.

Worse scores on Verbal Fluency by apathetic patients characterize poor initiating. Since impaired initiating capacities may be partly explained by psychomotor retardation, we corrected the scores on the Verbal Fluency task for psychomotor speed in a post-hoc analysis. In this analysis, part 1 of the TMT was used as covariate to correct for psychomotor speed. After this correction, no significant differences in verbal fluency remained between apathetic and non-apathetic $\mathrm{MCl}$ patients (animal naming: $\mathrm{B}=-1.70$, $\mathrm{Cl}=-3.7 ; 0.3, \mathrm{p}=0.10$; naming professions: $\mathrm{B}=-0.98, \mathrm{Cl}=-2.7 ; 0.8, \mathrm{p}=0.27$; aggregate measure: $B=-1.13, C l=-2.8 ; 0.6, p=0.20)$. These results confirm that apathy in $\mathrm{MCl}$ patients is particularly related to poor initiating related to reduced motor speed.

The prevalence rate of $\mathrm{MCl}$ patients observed in the current study fell within the range reported in previous studies (Clarke et al., 2010). Although the prevalence rate of apathy in AD patients was on the low side compared to other studies (Ishii et al., 2009), 
it is known that prevalence rates of apathy vary widely due to differences in population characteristics and assessment tools. Since apathy increases with disease severity, a possible explanation for the relatively low prevalence in our study could be that our $A D$ group consisted of an outpatient population with a relatively high percentage of mild AD patients.

In a cohort of community-based older adults, Onyike and colleagues (Onyike et al., 2007) reported findings in line with those of the present study. They also used a NPI cut-off score $>3$ and found deficits in executive functioning (Verbal Fluency) and psychomotor tracking (TMT) in cognitively normal people with apathy but not in participants with 'cognitive impairment not dementia' (CIND), and dementia. Since the mean MMSE score of this group was 21, it might be argued whether, on average, these people should be regarded as cognitively normal, or that they may be better be considered as having $\mathrm{MCl}$. Of major interest is that both our study and the study of Onyike and colleagues suggest that the effect of apathy on cognition becomes diluted with progression of overall cognitive impairment. A possible explanation is given by the latter authors who stated that when cognitive impairment is sufficiently severe, the impact of apathy on test performance is obscured or confounded by other cognitive disabilities (Onyike et al., 2007). Hence, neuropsychological outcome measures fail to distinguish between patients with and without apathy when neuropathology and associated cognitive deficits are severe enough. In particular, apathy seems to be related to executive functioning only in the early stages of cognitive deterioration, e.g. $\mathrm{MCl}$. In the revised view on the concept of $\mathrm{MCl}$ and $A D$, in which $\mathrm{MCl}$ is characterised by the onset of the earliest cognitive symptoms and seen as a prodromal phase of AD supported by one or more biomarkers (Jack et al., 2010, Dubois et al., 2010), apathy may be one of the first symptoms of early neurocognitive deterioration. This view is also in line with previous studies showing apathy to be an early predictor of $A D$ in patients with $\mathrm{MCl}$ (Robert et al., 2006a, Palmer et al., 2010).

Our results are partly in contrast with some results of previous studies. For instance, Robert and colleagues studied neuropsychological performance in $\mathrm{MCl}$ patients with and without apathy. They reported that apathy in $\mathrm{MCl}$ patients was not associated with executive dysfunction (Robert et al., 2006b). Kuzis et al. and McPherson et al. compared AD patients with and without apathy and depression. Kuzis and colleagues reported that apathy, independent of depression, is associated with worse performance on tests of verbal memory, naming, set shifting and verbal fluency than patients without apathy (Kuzis et al., 1999). McPherson et al. concluded that apathy was mainly related to executive functioning (McPherson et al., 2002). However, because these studies used either other apathy scales (Robert et al., 2006b, Kuzis et al., 1999), had smaller sample sizes (Kuzis et al., 1999, McPherson et al., 2002) or used less strict cut-off scores (Robert et al., 2006b, McPherson et al., 2002), their results are not strictly comparable to our outcomes. 
A major strength of our study is the relatively large sample size and the inclusion of patients with both $\mathrm{MCl}$ and $\mathrm{AD}$ who all underwent an extensive neuropsychological assessment. Moreover, we used strict cut-off scores of the NPI to insure the apathy symptoms were clinically relevant, whereas to some previous studies that applied very broad and mild cut-off scores (Kuzis et al., 1999, Robert et al., 2006b, McPherson et al., 2002). In addition, to deal with the missing data correctly multiple imputation methods were used and linear regression analyses were performed afterwards. We also conducted thorough statistical analyses in which we corrected for depressive symptoms.

This study also had some limitations. First of all, apathy was measured with the NPI. Although this is a commonly used, broad and validated instrument to assess neuropsychiatric symptoms, including apathy, it is not a specific apathy scale. Therefore we were not able to make a distinction between affective apathy, behavioural apathy and cognitive apathy (Chow et al., 2010). Besides that, some of the neuropsychological tests in our AD group had too many missing observations to be included in the multiple imputation method. Consequently, these were not included in the analyses. Another limitation is the broad inclusion of patients with objective cognitive complaints, without specific $\mathrm{MCl}$ criteria (Petersen, 2004). Nevertheless, subject with cognitive complaints due to severe neurological, somatic or psychiatric disorders were excluded.

In conclusion, our study showed in particular that apathy is associated with impaired executive function, characterized by poor initiating, in the early phase of cognitive impairment, but not in more advanced cognitive dysfunction. The association of apathy with executive dysfunction in the $\mathrm{MCl}$ group is interesting since it may be an early predictor of AD. More awareness of apathy and executive dysfunction in the early phase of cognitive impairment may help in the diagnostic process. More studies, preferable using a longitudinal design, should investigate the relationship of apathy and cognition. Since apathy is a highly prevalent syndrome in various neuropsychiatric diseases future studies should focus on a broad range of clinical diagnoses. In addition, the influence of different subtypes of apathy on cognitive performance should be studied. 


\section{References}

Aalten, P., de Vugt, M. E., Jaspers, N., Jolles, J., \& Verhey, F. R. J. (2005). The course of neuropsychiatric symptoms in dementia. Part I: findings from the two-year longitudinal Maasbed study. International Journal of Geriatric Psychiatry, 20(6), 523-530.

American Psychiatric Association. (1994). Diagnostic and statistical manual of mental disorders, 4th Edn. Washington, DC: American Psychiatric Press.

Chase, T. N. (2011). Apathy in Neuropsychiatric Disease: Diagnosis, Pathophysiology and Treatment. Neurotoxicity Research, 19(2), 266-278.

Chilovi, B. V., Conti, M., Zanetti, M., Mazzu, I., Rozzini, L., \& Padovani, A. (2009). Differential Impact of Apathy and Depression in the Development of Dementia in Mild Cognitive Impairment Patients. Dementia and Geriatric Cognitive Disorders, 27(4), 390-398.

Chow, T. W., Binns, M. A., Cummings, J. L., Lam, I., Black, S. E., Miller, B. L., et al. (2010). Apathy Symptom Profile and Behavioral Associations in Frontotemporal Dementia vs Dementia of Alzheimer Type. Archives of Neurology, 66(7), 888-893.

Clarke, D. E., Ko, J. Y., Lyketsos, C., Rebok, G. W., \& Eaton, W. W. (2010). Apathy and cognitive and functional decline in community-dwelling older adults: results from the Baltimore ECA longitudinal study. International Psychogeriatrics, 22(5), 819-29.

Cummings, J. L., Mega, M., Gray, K., Rosenberg-Thompson, S., Carusi, D.A., Gornbein, J. (1994). The Neuropsychiatric Inventory: Comprehensive assessment of psychopathology in dementia. Neurology, 44(12), 2308-2314.

Drijgers, R. L., Aalten, P., Winogrodzka, A., Verhey, F. R. J., \& Leentjens, A. F. G. (2009). Pharmacological treatment of apathy in neurodegenerative diseases: a systematic review. Dementia and Geriatric Cognitive Disorders, 28(1), 13-22.

Dubois, B., Feldman, H., Jacova, C., Cummings, J. L., DeKosky, S. T., Barberger-Gateau, P., et al. (2010). Revising the definition of Alzheimer's disease: a new lexicon. Lancet Neurology, 9(11), 1118-1127.

Folstein, M. F., Folstein, S. E., \& McHugh, P. R. (1975). "Mini-mental state". A practical method for grading the cognitive state of patients for the clinician. Journal of Psychiatric Research, 12(3), 189-198.

Ishii, S., Weintraub, N., \& Mervis, J. R. (2009). Apathy: a common psychiatric syndrome in the elderly. Journal of the American Medical Directors Association, 10(6), 381-393.

Jack, C. R., Knopman, D. S., Jagust, W. J., Shaw, L. M., Aisen, P. S., Weiner, M. W., et al. (2010). Hypothetical model of dynamic biomarkers of the Alzheimer's pathological cascade. Lancet Neurology, 9(1), 119-128.

Kat, M., de Jonghe, J., Aalten, P., Kalisvaart, C., Droes, R., \& Verhey, F. (2002). Neuropsychiatric symptoms of dementia: psychometric aspects of the Dutch Neuropsychiatric Inventory (NPI). Tijdschrift voor Gerontologie en Geriatrie, 33(4), 150-155.

Kuzis, G., Sabe, L., Tiberti, C., Dorrego, F., \& Starkstein, S. E. (1999). Neuropsychological correlates of apathy and depression in patients with dementia. Neurology, 52(7), 1403-1407.

McKann, G., Drachman, D., Folstein, M., Katzman, R., Price, D., \& Dtadlan, E., M. (1984). Clinical diagnosis of Alzheimer's disease: report of the NINCDS-ADRDA Work Group under the auspices of Department of Health and Human Services Task Force on Alzheimer's Disease. Neurology, 34(7), 939-944.

McPherson, S., Fairbanks, L., Tiken, S., Cummings, J. L., \& Back-Madruga. (2002). Apathy and executive function in Alzheimer's disease. Journal of the International Neuropsychological Society, 8(3), 373-381.

Monastero, R., Mangialasche, F., Camarda, C., Ercolani, S., \& Camarda, R. (2009). A systematic review of neuropsychiatric symptoms in mild cognitive impairment. Journal of Alzheimer's Disease, 18(1), 11-30.

Onyike, C. U., Sheppard, J. M., Tschanz, J. T., Norton, M. C., Green, R. C., Steinberg, M., et al. (2007). Epidemiology of apathy in older adults: the Cache County Study. American Journal of Geriatric Psychiatry, 15(5), 365-375.

Palmer, K., Di lulio, F., Varsi, A. E., Gianni, W., Sancesario, G., Caltagirone, C., et al. (2010). Neuropsychiatric Predictors of Progression from Amnestic-Mild Cognitive Impairment to Alzheimer's Disease: The Role of Depression and Apathy. Journal of Alzheimer's Disease, 20(1), 175-183. 
Petersen, R. C. (2004). Mild cognitive impairment as a diagnostic entity. Journal of Internal Medicine, 256(3), 183-194.

Ready, R. E., Ott, B. R., Grace, J., \& Cahn-Weiner, D. A. (2003). Apathy and Executive Dysfunction in Mild Cognitive Impairment and Alzheimer Disease. American Journal of Geriatric Psychiatry, 11(2), 222-228.

Reisberg, B., Ferris, S., de Leon, M., \& Crook, T. (1982). The Global Deterioration Scale for assessment of primary degenerative dementia. American Journal of Psychiatry, 139(9), 1136-1139.

Robert, P., Berr, C., Volteau, M., Bertogliati, C., Benoit, M., Sarazin, M., et al. (2006). Apathy in patients with mild cognitive impairment and the risk of developing dementia of Alzheimer's disease. A one-year followup study. Clinical Neurology and Neurosurgery, 108(8), 733-736.

Robert, P. H., Berr, C., Volteau, M., Bertogliati, C., Benoit, M., Mahieux, F., et al. (2006). Neuropsychological Performance in Mild Cognitive Impairment with and without Apathy. Dementia and Geriatric Cognitive Disorders, 21(3), 192-197.

Robert, P. H., Mulin, E., Mallea, P., \& David, R. (2010). Apathy Diagnosis, Assessment, and Treatment in Alzheimer's Disease. CNS Neuroscience \& Therapeutic, 16(5), 263-271.

Robert, P. H., Onyike, C. U., Leentjens, A. F. G., Dujardin, K., Aalten, P., Starkstein, S. E., et al. (2009). Proposed diagnostic criteria for apathy in Alzheimer's disease and other neuropsychiatric disorders. European Psychiatry, 24(2), 98-104.

Rubin, D. (1976). Inference and missing data. Biometrika, 63(3), 581-592.

Schafer, J., \& Graham, J. (2002). Missing data: our view of the state of the art. Psychological Methods, 7(2), 147-177.

StataCorp. (2009). STATA Statistical Software: Release 11.0. College Station, Texas.

Tun, S. M., Murman, D. L., Long, H. L., Colenda, C. C., \& von Eye, A. (2007). Predictive validity of neuropsychiatric subgroups on nursing home placement and survival in patients with Alzheimer disease. American Journal of Geriatric Psychiatry, 15(4), 314-27.

Van der Elst, W., van Boxtel, M. P., van Breukelen, G. J., \& Jolles, J. (2005). Rey's verbal learning test: normative data for 1855 healthy participants aged 24-81 years and the influence of age, sex, education, and mode of presentation. Journal of the International Neuropsychological Society, 11(3), 290-302.

Van der Elst, W., van Boxtel, M. P., van Breukelen, G. J., \& Jolles, J. (2006). The Concept Shifting Test: adult normative data. Psychological Assessment, 18(4), 424-432. 


\section{CHAPTER 5}

\section{Methylphenidate and the pathogenesis of apathy in Alzheimer's disease: a randomized controlled trial}




\begin{abstract}
Background: Apathy and mood disorders are common neuropsychiatric problems in patients with Alzheimer's disease (AD) that have a major impact on the quality of life of both patients and caregivers. Because of their role in self-reward and initiating processes, dopaminergic pathways have been implied in the pathophysiology of apathy. The aim of the current study was to examine the role of dopaminergic mechanisms in motivation, mood and cognition in AD.

Methods: In a randomized, double-blind placebo controlled crossover design, the effect of a pharmacological challenge with the dopamine reuptake inhibitor methylphenidate on measures of motivation, mood and cognition was examined in 12 patients with mild to moderate AD.
\end{abstract}

Results: There was a trend for improvement of mental speed after methylphenidate challenge compared to placebo challenge. Moreover, the observed differences on the Apathy Inventory, the anger and vigour subscales of the Profile of Mood States questionnaire, verbal fluency and a reaction time task, were in line with our expectations in that improvement appeared to be stronger in the methylphenidate condition than in the placebo condition.

Conclusion: Our study suggests that dopamine may be involved in the genesis of motivational deficits in AD. Further investigations into the dopaminergic mechanisms of motivation, mood and cognitive symptoms in $A D$, as well as into the clinical value of methylphenidate is needed, to provide more evidence base for potential treatment options, with the aim of improving quality of life of both patients as caregivers. 


\subsection{Introduction}

Apathy is defined as a syndrome characterized by loss of motivation and initiation, decreased social engagement, and emotional indifference (Robert et al., 2009). Apathy is the most frequent neuropsychiatric syndrome in dementia, with prevalences ranging from 42 up to 92\% (Drijgers et al., 2009, Aalten et al., 2005). Moreover, it is one of the most stressful comorbid syndrome for caregivers, with the greatest negative impact on the quality of relationship between patient and caregiver (de Vugt et al., 2003). Therefore, gaining more insight into the pathogenesis and underlying neurochemical mechanisms of apathy in dementia is necessary, in order to be able to develop appropriate treatment options.

Dysfunction of the dopaminergic system and executive dysfunction have been related to apathy in AD, especially in its earlier stages (Drijgers et al., 2011, McPherson et al., 2002, Mitchell et al., 2010). We hypothesize that patients with mild dementia are apathetic and may have problems of initiating as a result of deficient levels of dopamine in the brain. We expect that these patients can be triggered by a methylphenidate challenge task. Methylphenidate is a dopamine reuptake inhibitor that increases synaptic availability of dopamine. This may improve initiation processes, as is supported by two studies reporting improvement of apathy after using methylphenidate (Padala et al., 2010, Herrmann et al., 2008). Moreover, AD patients with apathy perform less well on frontal-related tasks, which we expect to improve after a methylphenidate challenge.

The aim of the present study was to examine the relationship between dopaminergic mechanisms and apathy, and related mood and cognitive functions, in patients with $A D$ using an acute challenge with methylphenidate.

\subsection{Methods}

\section{Subjects}

Twelve patients with mild to moderate $A D$ and apathy were included in the present study. Patients were recruited from the memory clinic of the Maastricht University Medical Centre and the elderly division of the Regional Institute for Community Mental Health (RIAGG), Maastricht. Patients were included 1) if they fulfilled the NINCDS/ADRDA criteria for AD (McKann et al., 1984), 2) if they were apathetic, which is defined here as a score $\geq 4$ on the apathy domain of the Neuropsychiatric Inventory (NPI) (Cummings, 1994), 3) if a reliable informant was available (who was required to have contact with the patient at least once a week), and 4) if the patient was capable of providing informed consent. Exclusion criteria were 1) a concurrent psychiatric disorder, such as major depressive disorder defined by DSM-IV criteria), 2) the presence of 
agitation or psychotic symptoms, 3) the use of psychopharmacological medication and/or 4) substance abuse. All subjects and their caregivers gave written informed consent prior to the study. The local Medical Ethics Committee of the Maastricht University Medical Centre approved the study. The study was registered in the National Academic Research and Collaborations (NARCIS), number OND1332651 (http://www.narcis.nl/research/RecordID/OND1332651).

\section{Design and intervention}

The study followed a randomized double-blind placebo-controlled design with a within subject cross-over design. Single dose intervention consisted of a $10 \mathrm{mg}$ dose of methylphenidate or a cellulose placebo. Outcome measures were rated before the pharmacological intervention and at the point of maximal challenge, which was 1.5 hours after intake. To control for biological and environmental influences subjects were tested at the same time of the day. In order to rule out any carry-over effects, the two challenge days were spaced 7 days apart. Randomization was performed by computer by the independent pharmacy department of the Maastricht Medical Centre, and followed a completely randomized design.

After screening for inclusion- and exclusion criteria and obtaining informed consent, patients underwent a baseline assessment measuring clinical characteristics of the patient and several cognitive tests. After this assessment subjects received a capsule containing either $10 \mathrm{mg}$ methylphenidate or a placebo. Measurements were repeated 1.5 hours after the challenge. The second test day followed the same protocol as day one, in which the only difference was the challenge condition. All subjects received the same tests in the same order and at the same time of day.

\section{Outcome measures}

\section{Primary outcome measures}

Primary and secondary outcome measures were assessed at baseline, and 1.5 hours after the challenge. The Profile of Mood States questionnaire (POMS) was used to measure the momentaneous mood state of the patient during the challenge task. The POMS assesses five different mood states: depression, tension, anger, vigour and fatigue (McNair et al., 1971), in which lower scores indicate higher symptom levels. The patient version of Apathy Inventory (AI) was used to assess apathy; the Al is specifically designed to assess apathy in patients with dementia providing self-ratings of emotion, interest and initiative (Robert et al., 2002). Higher scores on the Al indicate more apathy. 


\section{Secondary outcome measures}

The following secondary outcome measures were assessed: the Verbal Fluency Test to examine the ability to produce as many words as possible in the category animals, within one minute. It can be regarded as a measure for the adequate, strategy-driven retrieval of information of semantic memory. Moreover, it is often used and proven as a sensitive indicator of executive functioning in dementia (Lezak, 1995, Aalten et al., 2007). The Letter Digit Substitution Test (LDST) and the Stroop Colour Word Test (STROOP) card 1 and 2, to measure information processing speed (Van der Elst et al., 2006, Houx et al., 1993). The STROOP card 3 to assess executive functioning (Houx et al., 1993). And a simple reaction task (SRT) and choice reaction task (CRT) to measure reaction time.

\section{Other measures}

To assess the clinical status of the patient, the following baseline assessments were performed: the Mini Mental State Examination (MMSE) to examine global cognitive status (Folstein et al., 1975); the Cornell Scale for Depression in Dementia (CSDD), to assess symptoms of depression. A score of $>8$ on the CSDD indicates mild depressive symptoms (Alexopoulos, 1988); the 23-item version of the Alzheimer's Diseases Cooperative Study Activities of Daily Living ADCS-ADL to score activities of daily life (Galasko et al., 1997); the Frontal Assessment Battery (FAB) to explore executive functioning and in particular conceptualization, mental flexibility, motor programming, sensitivity to interference, inhibitory control, and environmental autonomy. A score of $<13$ on the FAB indicates frontal lobe dysfunction (Dubois et al., 2000); and the NPI, the Lille Apathy Rating Scale (LARS), and the Apathy Evaluation Scale (AES) to assess apathy (Cummings, 1994, Marin et al., 1991, Sockeel et al., 2006). The presence of apathy is determined by a score $>3$ on the NPI, a score of $>-16$ on the LARS or a score $>42$ on the AES.

\section{Statistics}

Statistical analyses were performed using the Statistical Package for Social Sciences, version 16.0 (SPSS Inc. Chicago, 2008). Correlations between clinical characteristics were calculated using Spearman correlations, since none of the included variables were normally distributed. Dependent variables of the POMS, Al, Verbal Fluency, LDST, STROOP, SRT and CRT were analyzed using a General Linear Model (GLM) repeated measures design with within factors 'intervention' (methylphenidate versus placebo) and 'time' (morning versus afternoon). P-values $<0.05$ were considered significant. 


\subsection{Results}

\section{Demographic and clinical characteristics}

Twelve AD patients were included in the study, with a mean age of $77.5( \pm 4.8)$ years and a mean MMSE score of $20( \pm 4.5)$, of which $50 \%$ was female. With mean scores of $5.8( \pm 2.8)$ on the NPI apathy item and $1.0( \pm 1.9)$ on the NPI depression item, patients showed clinically relevant symptoms of apathy, but not of depression. Mean scores on the AES and LARS were $47.9( \pm 10.5)$ and $5.7( \pm 13.1)$ respectively, both indicating the presence of apathetic symptoms as well. The CSDD score of $6.9( \pm 3.7)$ confirmed the absence of depression. The mean score on the FAB was $10.8( \pm 3.5)$, which implies frontal lobe dysfunction. At the time of testing 6 patients were treated with anticholinergic medication.

At baseline, higher scores on the apathy section of the NPI, the LARS, and the AES correlated with lower ADCS-ADL score, indicating more apathetic symptoms if the patient has less functional capacity ( $r$ o $=-0.52, p=0.01$; rho $=-0.78, p<0.001$; rho $=-0.76, p<0.001$, respectively). Lower MMSE score and FAB total score correlated with a lower score on the ADCS-ADL ( $r$ o $=0.67, p<0.001$; rho $=0.72, p<0.001$ ), and a higher score on the LARS and AES (rho $=-0.53, p=0.007$; rho $=-0.63, p=0.001$, rho $=-0.60, p=0.002$, respectively). Thus worse cognitive functioning, and especially executive functioning, was related to worse functional capacity and more severe apathy.

\section{Challenge effects}

There was no significant 'intervention by time' interaction effects for both the mood and apathy scale (POMS and AI) and the neuropsychological tests (Verbal Fluency, LDST, STROOP, SRT and CRT) (table 1).

\section{Profile of Mood State Questionnaire}

There were no differences on any of the POMS subscales between the methylphenidate and the placebo challenges. Using delta scores to correct for baseline performance did not alter this finding (table 2). However, AD patients scored less on the subscales for anger and tension, and more on the subscale for vigour after the methylphenidate challenge than after challenge with placebo (table 2).

\section{Apathy Inventory}

The score on the Al did not change after methylphenidate challenge. After the placebo challenge the score on the Al increased, indicating more apathy. However, this difference was not significant (table 2). 


\section{Neuropsychological assessment}

There were no differences between the two challenges on any of the neuropsychological tests. On the Verbal Fluency a trend for a main effect of time was observed $[F(1,11)=4.6, p=0.06]$, indicating better performance after each of the challenges than before. With a non-significant increase of 1.7 words compared to 0.3 words, this improvement appeared to be stronger in the methylphenidate condition than in the placebo condition (table 2), however this difference was not significant.

On the LDST, the performance of AD patients seemed to improve after each of the challenges (table 2). Again these improvements were not significantly different within each challenge, nor between the methylphenidate and placebo challenge.

On the STROOP card 1, a trend indicating better (faster) performance after methylphenidate challenge than after placebo challenge was observed $[F(1,11)=4.5, p=0.06]$ (table 1). On the STROOP card 2 and 3 no differences between the challenges were observed.

On both the SRT and CRT no significant differences between the two conditions were shown. Nevertheless, on the SRT observation of the delta scores showed a nonsignificant decrease in reaction time (thus improvement) after the methylphenidate challenge whereas after the placebo challenge reaction time increased non-significantly (table 2).

Table 1. Overview of two-way interaction effects

\begin{tabular}{|c|c|c|c|}
\hline & $\mathbf{F}$ & df. & p-value \\
\hline \multicolumn{4}{|c|}{ Profile of Mood State Questionnaire } \\
\hline Depression & 0.12 & 1 & 0.73 \\
\hline Anger & 0.71 & 1 & 0.42 \\
\hline Fatigue & 0.16 & 1 & 0.70 \\
\hline Vigour & 1.56 & 1 & 0.24 \\
\hline Tension & 0.64 & 1 & 0.44 \\
\hline \multicolumn{4}{|c|}{ Apathy Inventory } \\
\hline Total score & 1.61 & 1 & 0.23 \\
\hline \multicolumn{4}{|l|}{ Verbal Fluency } \\
\hline Total words & 0.85 & 1 & 0.38 \\
\hline \multicolumn{4}{|c|}{ Letter Digit Substitution Test } \\
\hline Total correct & 0.28 & 1 & 0.60 \\
\hline \multicolumn{4}{|c|}{ Stroop Colour Word Test } \\
\hline Card 1 & 4.48 & 1 & 0.06 \\
\hline Card 2 & 0.16 & 1 & 0.70 \\
\hline Card 3 & 2.76 & 1 & 0.14 \\
\hline \multicolumn{4}{|c|}{ Simple Reaction Time Task } \\
\hline Reaction time & 0.26 & 1 & 0.62 \\
\hline \multicolumn{4}{|c|}{ Choice Reaction Time Task } \\
\hline Reaction time & 0.95 & 1 & 0.36 \\
\hline
\end{tabular}


Table 2. Overview of mean scores and delta scores (afternoon - morning assessment) of all outcome measures after the methylphenidate and the placebo challenge

\begin{tabular}{|c|c|c|c|c|c|c|c|c|}
\hline & \multicolumn{3}{|c|}{ Methylphenidate } & \multicolumn{3}{|c|}{ Placebo } & \multirow[b]{2}{*}{$\begin{array}{c}\Delta \text { Methylphenidate - } \\
\Delta \text { placebo }\end{array}$} & \multirow[b]{2}{*}{ P-value } \\
\hline & Before & After & $\Delta$ score & Before & After & $\Delta$ score & & \\
\hline \multicolumn{9}{|c|}{ Profile of Mood State Questionnaire } \\
\hline Depression & 65.8 & 68.7 & 2.9 & 68.0 & 70.2 & 2.2 & 0.7 & 0.95 \\
\hline Anger & 79.5 & 80.6 & 1.1 & 79.9 & 79.2 & -0.7 & 1.8 & 0.66 \\
\hline Fatigue & 73.8 & 72.0 & -1.8 & 75.2 & 74.1 & -1.1 & -0.7 & 0.88 \\
\hline Vigour & 68.1 & 71.1 & 3.0 & 76.1 & 73.2 & -2.9 & 5.9 & 0.31 \\
\hline Tension & 73.3 & 76.7 & 3.4 & 77.3 & 78.3 & 1.0 & 2.4 & 0.64 \\
\hline \multicolumn{9}{|l|}{ Apathy Inventory } \\
\hline Total score & 5.3 & 5.3 & 0.0 & 4.6 & 5.3 & 0.7 & -0.7 & 0.36 \\
\hline \multicolumn{9}{|l|}{ Verbal Fluency } \\
\hline $\begin{array}{l}\text { Number of } \\
\text { animals }\end{array}$ & 10.1 & 11.8 & 1.7 & 10.9 & 11.2 & 0.3 & 1.4 & 0.27 \\
\hline \multicolumn{9}{|c|}{ Letter Digit Substitution Test } \\
\hline Total correct & 21.1 & 22.8 & 1.7 & 21.6 & 23.7 & 2.1 & -0.4 & 0.81 \\
\hline \multicolumn{9}{|c|}{ Stroop Colour Word Test } \\
\hline Card1 Time(sec) & 85.8 & 78.8 & -7.0 & 80.6 & 82.9 & 2.3 & -9.3 & 0.11 \\
\hline Card2 Time(sec) & 105.2 & 105.8 & 0.6 & 103.0 & 105.2 & 2.2 & -1.6 & 0.92 \\
\hline Card3 Time(sec) & 169.4 & 202.8 & 33.4 & 203.6 & 207.8 & 4.2 & 29.2 & 0.11 \\
\hline \multicolumn{9}{|c|}{ Simple Reaction Time Task } \\
\hline Time (msec) & 1272.9 & 1035.1 & -237.8 & 1025.5 & 1093.3 & 67.9 & -305.7 & 0.30 \\
\hline \multicolumn{9}{|c|}{ Choice Reaction Time Task } \\
\hline Time (msec) & 874.7 & 962.7 & 88.0 & 983.6 & 1988.9 & 955.1 & -867.1 & 0.39 \\
\hline
\end{tabular}

\subsection{Discussion}

This randomized placebo-controlled trial examined the effects of an acute challenge with the dopamine reuptake inhibitor methylphenidate and measures of apathy, mood and cognition. While differences between the two conditions on any of the outcome measures did not reach significance, the observed differences were in the expected direction. A trend was observed towards better performance on the Stroop card 1 after the methylphenidate challenge compared to the placebo challenge, indicating improved mental speed. This could imply that methylphenidate improves initiating 
processes, as a previous study into neuropsychological correlates of apathy in patients with mild cognitive impairment $(\mathrm{MCl})$ and $A D$ showed a relation between apathy and poor initiating related to reduced motor speed in the early phases of cognitive decline (Drijgers et al., 2011). Furthermore, patients with AD seemed less angry and more vigorous after methylphenidate challenge than after placebo challenge. This outcome is in line with a recently conducted challenge study with methylphenidate in patients with Parkinson's disease (PD), in which notably vigour scores improved significantly (Drijgers et al. submitted). Apathy scores stayed stable after the methylphenidate condition but seemed to worsen after the placebo challenge. A possible explanation may be that methylphenidate reduces the degree of fatigue that can come up during the day, and thus prevents worsening apathetic symptoms. In addition, performance on the Verbal Fluency and a reaction time task appeared to improve after a challenge with methylphenidate but not after a placebo challenge.

The few previous studies investigating the effect of methylphenidate on apathy in dementia patients were all treatment-based studies. Several case studies demonstrated the efficacy of longer term treatment with methylphenidate on apathy, as measured with the AES, in some dementia patients (Padala et al., 2007, Jansen et al., 2001). Furthermore, Padala and colleagues recently reported an improvement in apathy, depression, MMSE score and functional status during a 12 weeks open-label study with methylphenidate (Padala et al., 2010). In addition, Galynker et al. examined the effect of 10 to $20 \mathrm{mg} /$ day methylphenidate on negative symptoms, including apathy, depressive symptoms and cognitive impairment, in AD and vascular dementia. They concluded that negative symptoms were responsive to methylphenidate treatment, whereas in contrast to the study of Padala, depressive symptoms did not. Cognitive impairment, measured with the MMSE, decreased modestly (Galynker et al., 1997). However, none of these studies were randomized controlled trials (RCTs), which means that placebo effects cannot be excluded. There is only one RCT known investigating the treatment effect of methylphenidate on apathy (Herrmann et al., 2008). In this placebo-controlled, cross-over design, 13 mild-to moderate $A D$ patients were treated with $20 \mathrm{mg} /$ day methylphenidate $(10 \mathrm{mg}$ bid). A significant improvement of the AES score was reported after 5 weeks.

In contrast with previous studies into the treatment of apathy with methylphenidate, the primary purpose of the current study was to get more insight into the pathophysiological mechanism of apathy in AD. The advantage of an acute challenge was the possibility to measure the direct effects of an increased synaptic dopamine availability on apathy, mood and cognition, while results of a longer lasting treatment study may be more difficult to interpret because processes of down-regulation of post-synaptic dopamine receptors and other adaptation mechanisms. Another strength of the present study was its randomized, double blind, placebo-controlled, within subject design, which makes it more sensible than a RCT design as patients are their own control. Moreover, various cognitive tasks and measures of apathy and mood were 
assessed. A limitation was the small number of included AD patients. The initial aim was to include 35 apathetic AD patients. However, this number proved more challenging than we thought and turned out not feasible in the planned time frame and within the limits of available resources. As a post-hoc power calculation based on our primary outcome measure the Al showed a power of 0.22 our study may have not been able to detect true challenge effects.

Another limitation could be the relatively low dose of $10 \mathrm{mg}$ methylphenidate. In this study we deliberately chose to use a relatively low dose to limit possible side effects in this frail population, especially because Hermann and colleagues reported several adverse events in their study, using $20 \mathrm{mg} /$ day. Moreover, previous studies have shown positive results using dosages of 10 to $20 \mathrm{mg} /$ day (Jansen et al., 2001, Padala et al., 2010, Herrmann et al., 2008).

In conclusion, the present study remains inconclusive, but suggests that dopamine may be involved in the genesis of motivational deficits in AD. Further investigation into the dopaminergic mechanisms of apathy in $A D$ and the clinical value of methylphenidate as a treatment is needed, as it will improve the quality of life of both patients as caregivers. Therefore, more randomized controlled trials with larger study groups are required. 


\section{References}

Aalten, P., de Vugt, M. E., Jaspers, N., Jolles, J., \& Verhey, F. R. J. (2005). The course of neuropsychiatric symptoms in dementia. Part I: findings from the two-year longitudinal Maasbed study. International Journal of Geriatric Psychiatry, 20(6), 523-530.

Aalten, P., Jolles, J., de Vugt, M. E., \& Verhey, F. R. (2007). The influence of neuropsychological functioning on neuropsychiatric problems in dementia. Journal of Neuropsychiatry and Clinical Neuroscience, 19(1), 5056.

Alexopoulos, G. S., Abrams, R.C., Young, R.C., Shamoian, C.A. (1988). Cornell Scale for Depression in Dementia. Biological Psychiatry, 23(3), 271-284.

American Psychiatric Association. (1994). Diagnostic and statistical manual of mental disorders, 4th Edn. Washington, DC: American Psychiatric Press.

Cummings, J. L., Mega, M., Gray, K., Rosenberg-Thompson, S., Carusi, D.A., Gornbein, J. (1994). The Neuropsychiatric Inventory: Comprehensive assessment of psychopathology in dementia. Neurology, 44(12), 2308-2314.

de Vugt, M. E., Stevens, F., Aalten, P., Lousberg, R., Jaspers, N., Winkers, I., et al. (2003). Behavioural disturbances in dementia patients and quality of the marital relationship. International Journal of Geriatric Psychiatry, 18(2), 149-154.

Drijgers, R. L., Aalten, P., Winogrodzka, A., Verhey, F. R. J., \& Leentjens, A. F. G. (2009). Pharmacological treatment of apathy in neurodegenerative diseases: a systematic review. Dementia and Geriatric Cognitive Disorders, 28(1), 13-22.

Drijgers, R. L., Verhey, F. R. J., Leentjens, A. F. G., Kohler, S., \& Aalten, P. (2011). Neuropsychological correlates of apathy in mild cognitive impairment and Alzheimer's disease: the role of executive functioning. International Psychogeriatrics, 28(3), 1-7.

Dubois, B., Slachevsky, A., Litvan, I., \& Pillon, B. (2000). The FAB: a Frontal Assessment Battery at bedside. Neurology, 55(11), 1621-1626.

Folstein, M. F., Folstein, S. E., \& McHugh, P. R. (1975). "Mini-mental state". A practical method for grading the cognitive state of patients for the clinician. Journal of Psychiatric Research, 12(3), 189-198.

Galasko, D., Bennett, D., Sano, M., Ernesto, C., Thomas, R., Grudman, M., et al. (1997). An inventory to assess activities of daily living for clinical trials in Alzheimer's disease. The Alzheimer's Disease Cooperative Study. Alzheimer Disease and Associated Disorders, 11 Suppl 2, S33-39.

Galynker, I., leronimo, C., Miner, C., Rosenblum, J., Vilkas, N., \& Rosenthal, R. (1997). Methylphenidate treatment of negative symptoms in patients with dementia. Journal of Neuropsychiatry Clinical Neuroscience, 9(2), 231-239.

Herrmann, N., Rothenburg, L. S., Black, S. E., Ryan, M., Liu, B. A., Busto, U. E., et al. (2008). Methylphenidate for the Treatment of Apathy in Alzheimer Disease. Journal of Clinical Psychopharmacology, 28(3), 296301.

Houx, P., Jolles, J., \& Vreeling, F. (1993). Stroop interference: aging effects assessed with the Stroop ColorWord Test. Experimental Aging Research, 19(3), 209-224.

Jansen, I. H., Olde Rikkert, M. G., Hulsbos, H. A., \& Hoefnagels, W. H. (2001). Toward individualized evidencebased medicine: five " $\mathrm{N}$ of 1 " trials of methylphenidate in geriatric patients. Journal of the American Geriatric Society, 49(4), 474-476.

Lezak, M. (1995). Neuropsychological Assessment. New York: Oxford University Press.

Marin, R. S., Biedrzycki, R. C., \& Firinciogullari, S. (1991). Reliability and validity of the Apathy Evaluation Scale. Psychiatry Research, 38(2), 143-162.

Mckann, G., Drachman, D., Folstein, M., Katzman, R., Price, D. \& Dtadlan, E., M. (1984). Clinical diagnosis of Alzheimer's disease: report of the NINCDS-ADRDA Work Group under the auspices of Department of Health and Human Services Task Force on Alzheimer's Disease. Neurology, 34(7), 939-944.

McNair, D., Lorr, M., \& Droppleman, L. (1971). Manual for the Profile of Mood States. San Diego.

McPherson, S., Fairbanks, L., Tiken, S., Cummings, J. L., \& Back-Madruga. (2002). Apathy and executive function in Alzheimer's disease. Journal of the International Neuropsychological Society, 8(3), 373-381. 
Mitchell, R. A., Herrmann, N., \& Lanctôt, K. L. (2010). The role of dopamine in symptoms and treatment of apathy in Alzheimer's Disease. CNS Neuroscience and Therapeutics, 17(5), 411-427.

Padala, P., Burke, W. J., Bhatia, S. C., \& Petty, F. (2007). Treatment of Apathy with Methylphenidate. Journal of Neuropsychiatry and Clinical Neuroscience, 19(1), 81-83.

Padala, P. R., Burke, W. J., Shostrom, V. K., Bhatia, S. C., Wengel, S. P., Potter, J. F., et al. (2010). Methylphenidate for apathy and functional status in dementia of the Alzheimer type. American Journal of Geriatric Psychiatry, 18(4), 371-374.

Robert, P. H., Clairet, S., Benoit, M., Koutaich, J., Bertogliati, C., Tible, O., et al. (2002). The apathy inventory: assessment of apathy and awareness in Alzheimer's disease, Parkinson's disease and mild cognitive impairment. International Journal of Geriatric Psychiatry, 17(12), 1099-1105.

Robert, P. H., Onyike, C. U., Leentjens, A. F. G., Dujardin, K., Aalten, P., Starkstein, S. E., et al. (2009). Proposed diagnostic criteria for apathy in Alzheimer's disease and other neuropsychiatric disorders. European Psychiatry, 24(2), 98-104.

Sockeel, P., Dujardin, K., Devos, D., Deneve, C., Destee, A., \& Defebvre, L. (2006). The Lille apathy rating scale (LARS), a new instrument for detecting and quantifying apathy: validation in Parkinson's disease. Journal of Neurology, Neurosurgery and Psychiatry, 77(5), 579-584.

Van der Elst, W., van Boxtel, M. P., van Breukelen, G. J., \& Jolles, J. (2006). The Letter Digit Substitution Test: normative data for 1,858 healthy participants aged 24-81 from the Maastricht Aging Study (MAAS): influence of age, education, and sex. Journal of Clinical and Experimental Neuropsychology, 28(6), 998-1009. 


\section{CHAPTER 6}

The role of the dopaminergic system in mood, motivation and cognition in Parkinson's disease: a placebo-controlled double blind randomized experimental challenge with pramipexole and methylphenidate 


\section{Abstract}

Background: In Parkinson's disease (PD) reduced dopaminergic activity in the mesocorticolimbic pathway is implied in the pathophysiology of several non-motor symptoms related to mood, motivation and cognition. Insight in the pathophysiology of these syndromes may pave the way for more rational treatments.

Methods: In a double-blind, randomized, placebo controlled, crossover design with three arms, we studied the effects of a direct dopaminergic challenge with the dopamine 2 receptor agonist pramipexole, an indirect challenge with the dopamine reuptake inhibitor methylphenidate, and placebo on measures of mood, motivation and cognition in 23 agonist-naïve PD patients and 23 healthy controls.

Results: Acute challenge with pramipexole had a negative effect on mood and fatigue in both patients and controls. In addition, challenge with pramipexole lead to increased anger, fatigue, vigour and tension in healthy control subjects, but not in PD patients. Challenge with methylphenidate had a positive effect on anhedonia and vigour in PD patients.

Conclusion: Due to its side effects after a single administration, pramipexole is probably less suitable for acute challenge studies. The acute effects of a methylphenidate challenge on anhedonia and vigour in PD patients makes this drug an interesting choice for further studies of the treatment of mood and motivational disorders in this population. 


\subsection{Introduction}

Parkinson's disease (PD) is a neuropsychiatric disease characterized by degeneration of dopaminergic and non-dopaminergic cells in various brain areas (Braak et al., 2003; Delaville et al., 2011). Decreased striatal dopamine concentrations, due to degeneration of nigral dopaminergic cells, are responsible for the classical motor symptoms of the disease such as rigidity, bradykinesia, hypokinesia and tremor. Degeneration of dopaminergic cells in the mesocortical and mesolimbic pathways is implied in the pathophysiology of several non-motor symptoms related to mood and motivation, such as depression and apathy (Rodriquez-Oroz et al., 2009). Clinically relevant depressive symptoms are reported in up to $35 \%$ of patients, and apathy is present in 17 to $60 \%$ of patients (Bogart, 2011; Reijnders et al., 2008). Non-motor symptoms such as depression and apathy have a negative impact on everyday functioning, cognitive and motor performance, prognosis and quality of life for both patient and caregiver (Barone et al., 2009). Little is known about the pathophysiology of mood and motivation in PD. Previous studies have shown an association between depression and smaller orbitofrontal-gray matter volumes (Lavretsky et al., 2007), and apathy has been correlated with reduced grey matter density in the cingulate gyrus and inferior frontal gyrus (Reijnders et al., 2010). In addition, mood and motivational symptoms have been associated with cognitive impairment, (Reijnders et al., 2010) especially in the domain of executive functioning (Butterfield et al., 2010; Pluck \& Brown, 2002). The dopaminergic neurotransmitter system has been related to reward and initiating processes and is therefore thought to be involved in mood and motivational syndromes (Pedersen et al., 2010).

There are only few intervention studies that assess the influence of a pharmacological challenge on mood, motivation and cognitive functioning in PD (Chaudhuri \& Schapira, 2009; Evans et al., 2009). Some studies suggest that dopaminergic medication may improve mood and motivational symptoms (Czernecki et al., 2002; Leentjens et al., 2009). However, the underlying pathophysiology of motivation is far from being understood and although effective treatments are available for depression (Devos et al., 2008; Menza et al., 2009), no treatment is yet available for apathy (Drijgers et al., 2009). Better insight in the pathophysiology of mood and motivational syndromes may help to develop more effective treatment opportunities, and thereby increase the quality of life of both patients and caregivers.

The aim of this study was to investigate the role of the dopaminergic neurotransmitter system in the pathophysiology of mood, motivation and cognition in patients with PD. 


\subsection{Methods}

\section{Subjects}

Twenty-five patients with mild PD and 23 age, gender and education-matched healthy control subjects participated in the study. Agonist-naïve PD patients were recruited from the movement disorder clinics of Maastricht University Medical Centre, the Atrium Medical Centre Heerlen and Orbis Medical Centre Sittard. The diagnosis of idiopathic PD was established by using the Queens Square Brain Bank criteria (De Rijk et al., 1997). Exclusion criteria were neurological or psychiatric diseases other than PD, the use of psychopharmacological medication (with the exception of a low and stable dose of benzodiazepines) or dopamine agonists, abuse of alcohol and/or drugs, and cognitive deterioration, which was operationalized as a score $\leq 23$ on the Mini Mental State Examination (MMSE) (Folstein et al., 1975). Control subjects were recruited via a pre-existing bank of volunteer subjects of the Maastricht Aging Study (MAAS) (Jolles et al., 1995) and through an advertisement in a local newspaper. Except for the diagnosis of PD, the same in- and exclusion criteria applied to the control subjects. All subjects gave written informed consent prior to participation. The local Medical Ethics Committee of Maastricht University Medical Centre approved the study. The study was registered in the Netherlands Trial Register, number NTR1115 (http://www.trialregister.nl/trialreg/ admin/rctview.asp?TC=1115).

\section{Design and intervention}

The study followed a randomized double-blind, placebo controlled, cross-over design with three arms. Randomization was done via a computer-generated list by the pharmacy of the Maastricht University Medical Centre. These arms included a direct and an indirect dopaminergic challenge and a placebo condition. The direct challenge consisted of a $500 \mu \mathrm{g}$ dose of pramipexole, a dopamine D2 agonist with a preference for D3 receptors; the indirect challenge of a $10 \mathrm{mg}$ dose of methylphenidate, a dopamine re-uptake inhibitor. Outcome measures were assessed prior to the challenge and after 1.5 hours. For both pramipexole and methylphenidate maximum plasma concentrations (Tmax) were reached between 1 and 3 hours (Anonymous, 2009, 2010). To control for biological and environmental influences subjects were tested at the same time of the day and participants were not allowed to drink coffee before and during the assessment. The challenges were spaced at least 7 days apart in order to avoid any carry-over effects.

Baseline assessments were done prior to administration of the drug and included clinical characteristics and several neuropsychiatric and neuropsychological tests. One and a half hour after administration, the tests were repeated. All subjects received the tests in the same order. 


\section{Hypotheses}

Since pramipexole and methylphenidate both stimulate dopaminergic activity, we might expect that mood and motivational symptoms, as well as cognitive performance will improve in PD patients. Due to the mechanism of action, we expect that pramipexole as a dopamine agonist will have a more pronounced effect than methylphenidate, since a dopamine re-uptake inhibitor will only be optimally active when pre-synaptic dopaminergic function is not compromised (and in PD it is compromised). Finally we expect PD patients to have a better response than healthy controls, who do not have dopaminergic deficiencies.

\section{Assessments and outcome measures}

At baseline, the MMSE was used as a global measure of cognitive status (Folstein et al., 1975). Motor function was assessed with the Unified Parkinson's Disease Rating Scale (UPDRS) (Fahn \& Elton, 1987) and disease stage was classified according to the Hoehn and Yahr staging system (H\&Y) (Hoehn \& Yahr, 1967). Depressive symptoms were measured with the Hamilton Rating Scale for Depression (HAMD) (Hamilton, 1960). Apathy was assessed with the Lille Apathy Rating Scale (LARS) (Sockeel et al., 2006) and the Apathy Evaluation Scale (AES) (Marin et al., 1991). The presence of neuropsychiatric symptoms (including depression and apathy) was evaluated with the Neuropsychiatric Inventory (NPI) (Cummings, 1994).

Outcome measures were the performance on neuropsychiatric and neuropsychological tests, including assessments of mood, motivation and cognition. To assess changes in the momentaneous mood state of the subjects, the Profile of Mood States Questionnaire (POMS) was administered (McNair et al., 1971). The POMS assesses five different mood states: depression, tension, anger, vigour and fatigue. The POMS consists of 32 opposite word pairs divided by a visual analogue scale of $100 \mathrm{~mm}$. The intersection of the vertical slash mark with the horizontal line between the two extremes of mood was measured with a ruler. Higher scores indicate more favourable outcomes, while lower scores indicate worse outcome and higher symptom levels. In contrast to the HAMD, the POMS is sensitive for detecting momentaneous and transient mood fluctuations. It has been used and proven sensitive in challenge studies in PD before (Scholtissen et al., 2006).

As a measure of anhedonia, the Snaith-Hamilton Pleasure Scale (SHAPS) was administered (Snaith et al., 1995). This scale has 14 items and each item has a set of 4 response categories (1=definitely agree; 2=agree; 3=disagree; 4=definitely disagree). Total scores were computed by summing scores across the four response categories. Higher total scores indicating higher levels of state anhedonia (Franken et al., 2007). The Frontal Assessment Battery (FAB) was used to measure frontal lobe dysfunction (Dubois et al., 2000). The FAB is a useful tool to screen for executive dysfunction and consists of six subtests exploring conceptualization, mental flexibility, motor program- 
ming, sensitivity to interference, inhibitory control, and environmental autonomy (Lima et al., 2008).

To assess information processing speed, the Letter Digit Substitution Test (LDST) was used (Van der Elst et al., 2006). The LDST consists of a key that gives numbers 1 to 9, each paired with a different letter. The test items are printed beneath the key. Subjects are asked to replace the randomized letters with the appropriate digit as indicated by the key as fast as possible in 90 seconds. Outcome measure is the number of correctly completed digits.

The simple reaction time task (SRT) and choice reaction time task (CRT) were administered on a computer screen to measure motor and mental speed. Both reaction time tasks were presented in four runs of 12 trails each. Regarding the SRT, in each trial a white square $(4 \times 4)$ was presented on a black background, followed by a red square $(4 \times 4)$. Subjects were instructed to push the response button as fast as possible when the white square turned red. In case of the CRT, in each trial two white squares $(4 \times 4)$ were presented on a black background, one at the right side and one at the left side of the screen. Subjects had to push the congruent response button (left or right) as fast as possible when one of two squares turned red. Outcome measures are the reaction time in milliseconds.

\section{Statistics}

Power calculation was based on the effect size and standard deviation (SD) of a previously published study using a serotonergic challenge in PD that followed the same three-arm design, and a on the basis of the study of Mendonça et al. that also used a randomized, double-blind, placebo controlled trial to examine the usefulness of methylphenidate in patients with PD (Mendonca et al., 2007; Scholtissen et al., 2006). In the study of Scholtissen et al. 21 patients and 21 control subjects were adequate for detecting three-way interactions (Scholtissen et al., 2006) with a 90\% probability. Based on only between group fatigue measurements in the study by Mendoca et al, 20 patients per group are necessary to detect a standardized difference of 0.9 in outcome parameter with a power of $80 \%$. However, the additional within group design increases the power to detect differences in outcome. The target for inclusion was set somewhat higher at 25 subjects per group.

Differences in demographic and baseline clinical characteristics between PD patients and control subjects were analyzed using the Kruskal-Wallis test for nonnormally distributed continuous variables and the Chi-square test for categorical variables. Dependent variables of the SHAPS, POMS, FAB, LDST, SRT, and CRT were analyzed using a General Linear Model (GLM) repeated measures design. Within subjects factors were 'intervention' (placebo versus methylphenidate versus pramipexole), and 'time' (morning versus afternoon). 'Disease' (PD patients versus control 
subjects) was entered as between subjects factor. The level of significance was set at $p<0.05$.

\subsection{Results}

\section{Demographic and clinical characteristics}

25 PD patients were included, but during the intervention two patients dropped out because of side effects: one because of dizziness and panic, and one because of nausea. After deblinding (at the end of the study) these side effects were shown to be due to pramipexole. These two patients were not matched. Eventually 23 PD patients ( 21 men and 2 women) and 23 age, gender and education-matched healthy control subjects were included. Demographic and clinical characteristics are shown in table 1 . There were no significant differences in sex, age and educational level. Patients had a median score of 2 on the Hoehn and Yahr scale, indicating mild PD (Goetz et al., 2004). At the time of testing, one patient was treated with a COMT inhibitor, two patients used a MAO-B inhibitor, three patients were treated with anticholinergic medication, three patients were treated with an NMDA-antagonist, and 15 patients were on L-dopa therapy. Five patients used a combination of the medication described above.

In comparison with control subjects, PD patients scored significantly higher on the HAMD, LARS, AES and NPI depression item. For the NPI apathy item, the higher score of patients was not significant (table 1). However, with a mean of $5.7( \pm 5.1)$ for PD patients and $2.0( \pm 1.8)$ for healthy control subjects on the HAMD, both patients and controls scored in the non-depressed range (Leentjens et al., 2000).

\section{Intervention effects}

On none of the outcome measures three-way interactions were observed, indicating that PD patients did not react different on the challenges over time than control subjects. In order to further examine the intervention effects in the PD and control group separately, delta scores were used to correct for baseline performance.

\section{Profile of Mood State questionnaire}

At baseline, PD patients scored significantly worse than healthy control subjects on all mood states of the POMS questionnaire. 
Table 1. Demographic and clinical characteristics of the PD patients and control subjects

\begin{tabular}{lccc}
\hline & PD (N = 23) & Controls (N= 23) & p-value \\
\hline Age (yrs) & $63.9(9.8)$ & $65.4(9.2)$ & $0.57^{\mathrm{a}}$ \\
Female (\%) & 8.7 & 8.7 & $1.0^{\mathrm{b}}$ \\
Education (\% low-mid-high) & $30.4-43.5-26.1$ & $40.9-36.4-22.7$ & $0.76^{\mathrm{b}}$ \\
Disease duration (yrs) & $5.0(3.9)$ & $0(0)$ & $<0.001^{\mathrm{a}}$ \\
H\&Y stage (median \& range) & $2(2)$ & $0(0)$ & $<0.001^{\mathrm{a}}$ \\
UPDRS total score & $27.2(13.2)$ & $2.8(2.2)$ & $<0.001^{\mathrm{a}}$ \\
MMSE score & $28.8(1.0)$ & $29.3(1.0)$ & $0.05^{\mathrm{a}}$ \\
Hamilton score & $5.7(5.1)$ & $2.0(1.8)$ & $0.004^{\mathrm{a}}$ \\
LARS score & $-18.7(9.0)$ & $-23.9(6.1)$ & $0.02^{\mathrm{a}}$ \\
AES score & $33.1(10.0)$ & $25.5(5.2)$ & $0.02^{\mathrm{a}}$ \\
NPI depression score & $0.7(1.4)$ & $0.1(0.5)$ & $0.04^{\mathrm{a}}$ \\
NPI apathy score & $0.8(1.4)$ & $0.4(1.8)$ & $0.06^{\mathrm{a}}$ \\
NPI total score & $5.0(5.3)$ & $2.7(5.5)$ & $0.009^{\mathrm{a}}$ \\
\hline
\end{tabular}

Values represent mean (SD) unless otherwise stated

${ }^{\mathrm{a}}$ Kruskal-Wallis, ${ }^{\mathrm{b}} \chi 2$

H\&Y: Hoehn and Yahr Rating scale; UPDRS: Unified Parkinson Rating Scale; MMSE: Mini-Mental State Examination; LARS: Lille Apathy Rating Scale; AES: Apathy Evaluation Scale; NPI: Neuropsychiatric Inventory

In the control group, a significant difference was observed between the three challenges on the anger, fatigue, vigour and tension subscale (table $2 \mathrm{~b}$ ). A post-hoc analysis (Dunnett $\mathrm{t}$ ) showed that treatment with pramipexole had a negative effect on anger, fatigue, vigour and tension compared to the placebo intervention $(p=0.01 ; p=0.001$; $p=0.003 ; p=0.003$ respectively).

In the PD group, patients differed significantly after the challenges on the depression, fatigue and vigour subscales (table 2a). Dunnett's t post hoc analysis indicated that patients felt more depressed after pramipexole than after the placebo challenge $(p=0.03)$. Fatigue increased after challenge in all three conditions. In post hoc t-tests, the increase in fatigue after pramipexole challenge was significantly greater than the increase after methylphenidate challenge $(p=0.03)$; other two-way comparisons were not significant. Vigour worsened after pramipexole and placebo challenge, however, post-hoc t-testing showed that only the difference between pramipexole and methylphenidate was significant $(p=0.004)$. Vigour marginally, but significantly improved after challenge with methylphenidate compared to the placebo challenge $(p=0.045)$.

\section{Snaith-Hamilton Pleasure Scale}

At baseline no significant differences between PD patients and control subjects existed on the SHAPS. Using delta scores to correct for baseline performance, a significant difference in effects of the three challenges was observed in the PD group $(p=0.027)$ 
(table 2a). A post-hoc Dunnett $t$ analysis showed a small, but significant improvement on the SHAPS after the challenge with methylphenidate, but not after challenge with pramipexole or placebo $(p=0.021)$. In healthy controls there were no effects.

\section{Frontal Assessment Battery}

Patients with PD had a significantly lower FAB total score than control subjects. On the six subtests significant worse baseline scores for PD patients were observed on subtest 2 (lexical fluency task), subtest 4 (conflicting instructions task) and subtest 5 (go-no-go task). Using delta scores to correct for baseline performance, no significant difference of effects of the challenges was found in both PD patients and healthy controls (table $2 \mathrm{a}$ and $2 \mathrm{~b}$ ). On the separate subtests PD patients, but not healthy controls, scored significantly better on subtest 3 (motor series 'Luria' task) after the methylphenidate challenge compared to the placebo challenge (Dunnett $t: p=0.019$ ).

\section{Letter Digit Substitution Test}

On the LDST, control subjects scored significantly better than PD patients. No effect of challenge was observed in both PD patients and control subjects.

\section{Simple and Choice Reaction Time Tasks}

Patients and control subjects did not differ significantly on both reaction time tasks at baseline and no effect of challenge was found in both groups. 
Table 2a. Overview of mean scores (SD) and delta scores (afternoon - morning assessment) of the SHAPS, POMS, FAB, LDST, SRT and CRT after the pramipexole, methylphenidate, and placebo challenge in PD patients

\begin{tabular}{|c|c|c|c|c|c|c|c|c|c|c|}
\hline \multicolumn{4}{|c|}{ PD patients } & \multicolumn{3}{|c|}{ Methylphenidate } & \multicolumn{3}{|c|}{ Placebo } & \multirow[b]{2}{*}{ P-value } \\
\hline & Before & After & $\Delta$ score & Before & After & $\Delta$ score & Before & After & $\Delta$ score & \\
\hline \multicolumn{11}{|c|}{ Profile of Mood State Questionnaire } \\
\hline \multirow{2}{*}{$\begin{array}{l}\text { Depres- } \\
\text { sion }\end{array}$} & 72.4 & 67.0 & -5.4 & 71.7 & 70.4 & -1.1 & 72.8 & 71.2 & -1.6 & 0.02 \\
\hline & $(7.8)$ & $(10.8)$ & $(6.1)$ & $(6.3)$ & (8.9) & (3.8) & $(6.5)$ & (7.9) & $(5.4)$ & \\
\hline \multirow[t]{2}{*}{ Anger } & 83.3 & 78.2 & -5.1 & 81.9 & 80.0 & -1.9 & 82.5 & 79.2 & -3.3 & 0.29 \\
\hline & $(8.1)$ & (9.0) & (6.3) & (7.1) & (9.2) & (5.3) & (7.8) & (8.0) & $(7.4)$ & \\
\hline \multirow[t]{2}{*}{ Fatigue } & 75.6 & 62.6 & -13.0 & 77.1 & 73.0 & -4.1 & 78.0 & 70.7 & -7.3 & 0.03 \\
\hline & (11.6) & (16.3) & (13.2) & (10.1) & (13.4) & (7.8) & $(10.0)$ & (13.9) & (10.3) & \\
\hline \multirow[t]{2}{*}{ Vigour } & 71.6 & 59.9 & -11.7 & 70.7 & 71.4 & 0.7 & 74.5 & 66.7 & -7.8 & 0.005 \\
\hline & (17.2) & (18.6) & (15.3) & (16.8) & (15.8) & (10.4) & (15.0) & (16.1) & (10.9) & \\
\hline \multirow[t]{2}{*}{ Tension } & 80.1 & 76.7 & -5.0 & 78.6 & 78.3 & -0.3 & 81.4 & 79.1 & -1.3 & 0.21 \\
\hline & (11.4) & (14.6) & (12.6) & (10.3) & (11.3) & (6.8) & (9.0) & (9.1) & (6.3) & \\
\hline \multicolumn{4}{|c|}{ Snaith Hamilton Pleasure Scale } & & & & & & & \\
\hline Total & 20.9 & 21.2 & 0.3 & 22.1 & 21.6 & -0.5 & 21.2 & 21.8 & 0.6 & 0.03 \\
\hline score & (3.8) & (3.6) & $(1.2)$ & (4.1) & (3.7) & $(1.8)$ & (4.1) & $(4.3)$ & $(1.2)$ & \\
\hline \multicolumn{4}{|c|}{ Frontal Assessment Battery } & & & & & & & \\
\hline Total & 16.7 & 17.0 & 0.3 & 16.1 & 16.7 & 0.6 & 16.3 & 16.7 & 0.4 & 0.60 \\
\hline score & $(1.2)$ & $(0.7)$ & $(1.1)$ & (1.7) & $(1.1)$ & $(1.5)$ & (1.6) & $(1.2)$ & $(1.3)$ & \\
\hline \multicolumn{4}{|c|}{ Letter Digit Substitution Test } & & & & & & & \\
\hline & 40.5 & 41.4 & 0.9 & 40.1 & 41.7 & 1.6 & 41.8 & 43.5 & 1.7 & 0.75 \\
\hline & (10.4) & $(11.2)$ & (3.1) & (11.5) & $(11.8)$ & $(4.7)$ & (12.4) & $(12.5)$ & (2.9) & \\
\hline \multicolumn{4}{|c|}{ Simple Reaction Time Task } & & & & & & & \\
\hline & 333.6 & 358.2 & 24.6 & 321.3 & 327.7 & 6.4 & 320.3 & 328.2 & 7.9 & 0.51 \\
\hline & (59.0) & (83.2) & $(64.1)$ & (57.4) & (56.9) & $(25.3)$ & $(60.3)$ & $(57.8)$ & $(56.5)$ & \\
\hline \multicolumn{4}{|c|}{ Choice Reaction Time Task } & & & & & & & \\
\hline & 396.1 & 409.1 & 13.0 & 387.1 & 387.6 & 0.5 & 381.0 & 379.3 & -1.7 & 0.46 \\
\hline & (51.5) & (83.3) & (33.1) & $(48.6)$ & $(62.7)$ & (35.3) & $(51.2)$ & (54.4) & (43.3) & \\
\hline
\end{tabular}


Table 2b. Overview of mean scores (SD) and delta scores (afternoon - morning assessment) of the SHAPS, POMS, FAB, LDST, SRT and CRT after the pramipexole, methylphenidate, and placebo challenge in control subjects

\begin{tabular}{|c|c|c|c|c|c|c|c|c|c|c|}
\hline \multicolumn{4}{|c|}{ Control subjects } & \multicolumn{3}{|c|}{ Methylphenidate } & \multicolumn{3}{|c|}{ Placebo } & \multirow[b]{2}{*}{ P-value } \\
\hline & Before & After & $\Delta$ score & Before & After & $\Delta$ score & Before & After & $\Delta$ score & \\
\hline \multicolumn{11}{|c|}{ Profile of Mood State Questionnaire } \\
\hline Depres- & 76.5 & 73.5 & -3.0 & 76.2 & 75.8 & -0.4 & 76.5 & 76.0 & -0.5 & 0.09 \\
\hline sion & $(6.6)$ & (8.8) & $(5.5)$ & $(6.4)$ & $(7.4)$ & (3.5) & $(6.5)$ & $(6.4)$ & $(4.0)$ & \\
\hline \multirow[t]{2}{*}{ Anger } & 87.6 & 85.0 & -2.6 & 88.1 & 87.1 & -1.0 & 86.2 & 87.1 & 0.9 & 0.02 \\
\hline & (7.7) & (9.1) & (5.1) & (7.3) & $(8.8)$ & (3.3) & (8.7) & $(7.4)$ & $(3.8)$ & \\
\hline \multirow[t]{2}{*}{ Fatigue } & 86.3 & 78.0 & -8.3 & 87.3 & 87.1 & 0.2 & 86.6 & 87.0 & 0.4 & $<0.001$ \\
\hline & (9.6) & $(16.2)$ & (12.8) & (9.3) & (9.0) & (4.5) & (6.8) & (6.8) & (3.6) & \\
\hline \multirow[t]{2}{*}{ Vigour } & 87.0 & 77.7 & -9.3 & 85.9 & 85.3 & -0.6 & 85.9 & 85.1 & -0.8 & 0.001 \\
\hline & (11.3) & (15.5) & (12.2) & (11.3) & (12.6) & $(7.6)$ & (10.9) & $(11.6)$ & (3.6) & \\
\hline \multirow[t]{2}{*}{ Tension } & 88.7 & 85.3 & -3.4 & 88.4 & 88.0 & -0.4 & 87.1 & 88.3 & 1.2 & 0.006 \\
\hline & $(6.6)$ & (9.5) & $(6.4)$ & $(6.8)$ & $(8.0)$ & (3.9) & (7.3) & $(6.8)$ & (3.4) & \\
\hline \multicolumn{11}{|c|}{ Snaith Hamilton Pleasure Scale } \\
\hline Total & 22.3 & 22.6 & 0.3 & 22.0 & 21.7 & -0.3 & 21.7 & 22.0 & 0.3 & 0.32 \\
\hline score & $(4.0)$ & $(4.4)$ & $(1.6)$ & $(4.0)$ & $(4.1)$ & $(1.1)$ & $(4.2)$ & $(4.6)$ & $(1.3)$ & \\
\hline \multicolumn{11}{|c|}{ Frontal Assessment Battery } \\
\hline Total & 17.3 & 17.1 & -0.2 & 17.2 & 17.2 & 0.0 & 16.8 & 16.9 & 0.04 & 0.76 \\
\hline score & $(0.7)$ & $(0.7)$ & $(1.1)$ & $(0.8)$ & $(1.0)$ & $(1.2)$ & $(1.5)$ & $(1.5)$ & $(0.9)$ & \\
\hline \multicolumn{11}{|c|}{ Letter Digit Substitution Test } \\
\hline & 47.0 & 46.8 & -0.2 & 48.1 & 50.4 & 2.3 & 47.4 & 48.4 & 1.0 & 0.12 \\
\hline & $(9.1)$ & $(10.5)$ & $(4.2)$ & $(8.8)$ & $(9.6)$ & (3.8) & $(9.3)$ & $(8.5)$ & $(4.0)$ & \\
\hline \multicolumn{11}{|c|}{ Simple Reaction Time Task } \\
\hline & 316.1 & 339.6 & 23.5 & 331.4 & 346.9 & 15.5 & 322.8 & 337.0 & 14.2 & 0.06 \\
\hline & $(44.6)$ & $(52.2)$ & $(51.6)$ & $(47.3)$ & $(53.1)$ & $(49.7)$ & $(53.7)$ & $(37.3)$ & $(43.3)$ & \\
\hline \multicolumn{11}{|c|}{ Choice Reaction Time Task } \\
\hline & 408.4 & 419.9 & 11.5 & 424.8 & 407.1 & -17.7 & 404.0 & 401.6 & -2.4 & 0.78 \\
\hline & $(43.8)$ & (62.3) & $(45.6)$ & (49.9) & $(54.2)$ & (37.9) & $(54.2)$ & (54.1) & (36.9) & \\
\hline
\end{tabular}

\subsection{Discussion}

The present study examined the role of the dopaminergic neurotransmitter system in the pathophysiology of mood, motivation and cognition in PD, using a direct challenge with pramipexole, a dopamine agonist, and indirect challenge with methylphenidate, a dopamine reuptake inhibitor. Pramipexole had a negative effect on mood and motivation in PD patients as well as control subjects, the latter feeling more angry, fatigued and tensed. Moreover, PD patients had a better mood and felt somewhat more vigorous after taking methylphenidate than control subjects. Cognitive measures did not change after acute challenge with either pramipexole or methylphenidate. Whereas we expected PD patients to be more pronouncedly stimulated by pramipexole in comparison with methylphenidate (because of the direct post-synaptic effects of pramipexole, which do not require intact presynaptic dopaminergic nerve endings), this 
drug had a negative effect on mood in both patients and controls. This is in contrast with our hypothesis and also in contrast with several studies using pramipexole as longer term treatment. In a meta-analysis of 7 randomized controlled trials, pramipexole was shown to have a beneficial effect on mood and motivation in nondepressed PD patients (Leentjens et al., 2009). In these studies pramipexole was used as longer-term treatment for motor symptoms and not as an acute challenge. In addition, 6 of the 7 included RCTs involved patients with advanced PD, whereas our study mainly consisted of patients with mild PD. The only trial that enrolled patients with early PD found a non-homogeneous effect. Another study that included patients with mild PD also failed to find an effect of pramipexole on mood (Navan et al., 2003). Our findings of a decreased mood might be explained by the use of an acute challenge with a single, moderate dose of prami-pexole, instead of a gradual increase in dose and prolonged treatment, as is common in treatment settings. The clinical effects of an acute challenge may differ from those of prolonged treatment due to the fact that secondary receptor adaptations (up- or down regulation) has not yet taken place. From these results we conclude that the pharmacological effects of an acute challenge with pramipexole in PD on mood and motivation may not predict the long-term effects of the medication on these domains.

In addition, gradual dose increase allows the participant to get used to the medication, whereas an acute challenge may increase the risk of possible side effects, such as drowsiness or jitteriness, which could overshadow potential positive effects. These sedative effects, as well as a decreased mood, have previously been described in a study assessing the effect of a single low to moderate dose of pramipexole on cognition and impulsivity in healthy volunteers (Hamidovic et al., 2008). These observations may imply that pramipexole is not a suitable drug to use in acute pharmacological challenge studies.

Methylphenidate on the other hand stimulated PD patients, and improved anhedonia and vigour. There are hardly any reports on the effects of methylphenidate on mood and motivational symptoms in PD (Auriel et al., 2009). Evans et al. showed that the effect of a pharmacological challenge may depend on the co-medication the patient is using. They report an increased positive affect and enhanced reward responsivity after methylphenidate, but not levodopa, challenge only in patients on regular dopaminergic therapy, but not in drug-naive patients (Evans et al., 2009). This is in line with our findings. Most of our patients were using levodopa (15 of 23), and only methylphenidate, but not pramipexole, lead to subjective improvements. The positive effects of methylphenidate is also supported by the treatment study of Mendonca et al., who reported a significant improvement of fatigue in patients with PD after treatment with methylphenidate (Mendonca et al., 2007). Moreover, one case study reported improvement of apathy after treatment with methylphenidate (Chatterjee \& Fahn, 2002). 
An acute dopaminergic challenge appeared not to have any effect on executive functioning, attention and psychomotor speed as measured with the FAB, LDST, SRT and CRT in both patients and control subjects. Few studies have previously reported on the effects of pramipexole and methylphenidate on cognition in PD (Auriel et al., 2009; Chaudhuri \& Schapira, 2009). Auriel et al reported an improvement of attention, but not of executive function after a single dose of $20 \mathrm{mg}$ (Auriel et al., 2009). Another study reported minimal effects on cognition in a pilot study using $0.2 \mathrm{mg} / \mathrm{kg}$ methylphenidate (Camicioli et al., 2001) Conflicting results exist for pramipexole. One study showed an improvement of working memory in de-novo patients after of $0.7 \mathrm{mg}$ pramipexole TID for at least a month, but this effect was only seen in 'low performer patients' and not in 'high performer patients' (Costa et al., 2009). Another study indicates a slight worsening of cognitive functioning in patients with mild PD after a mean dose of $3.9 \pm 1.2 \mathrm{mg}$ for one month (Brusa et al., 2003). Relja and Klepac conclude that 6 months of $3 \pm 0.5 \mathrm{mg}$ pramipexole does not affect cognitive functioning when used as add-on therapy to levodopa (Relja \& Klepac, 2006). Altogether, these results do not contradict our findings and support the conclusion that in early PD both pramipexole and methylphenidate do not affect cognitive functioning.

Our study has strengths and weaknesses. The strength of the present study is the randomized, double blind, placebo-controlled design with a within and between subject comparison, in which both a dopamine agonist as a dopamine re-uptake inhibitor were used. In addition, sensitive measures for mood, motivation and a number of cognitive tasks related to attention, mental speed and executive function were used. Limitations of our study are that the included PD patients were mostly in the early clinical stage of the disease (median Hoehn and Yahr stage II) and exhibited only less severe mood and motivational symptoms. Moreover, de-novo and unmedicated patients would have been the preferred population in this study, but it was considered unfeasible to include large enough numbers of drug-naïve patients, and stopping medication for the sake of this study was not considered ethical. Therefore, we decided not to exclude patients using dopaminergic medication, if they were on a stable dose for at least three months. Nevertheless, patients using a dopamine agonist were excluded, since this was the challenge medication. We used a relatively low, single dose of $10 \mathrm{mg}$ methylphenidate, which suggest that the effects on anhedonia and vigour may be larger if the dose is increased. At last, we did not adjust for multiplicity because of our relatively small number of included PD patients and control subjects. Therefore, the increased chance of a type I error is accepted, and results should be interpreted with caution. However, the results of this exploratory study give more insight into the role of the pre- and postsynaptic contributions of the dopaminergic system in mood, motivation and cognition.

In conclusion, after acute stimulation methylphenidate but not pramipexole improved anhedonia and vigour in PD patients whereas cognitive performance did not change. This may imply that dopamine plays a role in mood but not in cognition. Further investigation of the clinical value of pramipexole and methylphenidate in the 
treatment of mood and motivational syndromes such as depression and apathy is required, as treatment options will improve quality of life of patients and caregivers. Larger randomized controlled trials with a longer slow increase of medication dose and a longer treatment duration may provide more information on the clinical usefulness of dopaminergic treatment. In addition, positive effects may be better visible if patients in the more advanced stages of the disease with more severe psychopathology are included.

\section{Acknowledgements}

We would like to thank the Stichting Internationaal Parkinson Fonds for funding this research. 


\section{References}

Anonymous. (2009). The European Public Assessment Report (EPAR) for Sifrol.

Anonymous. (2010). IB-tekst Ritalin. Arnhem: Novartis.

Auriel, E., Hausdorff, J. M., \& Giladi, N. (2009). Methylphenidate for the treatment of Parkinson disease and other neurological disorders. Clinical Neuropharmacology, 32(2), 75-81.

Barone, P., Antonini, A., Colosimo, C., Marconi, R., Morgante, L., Avarello, T., et al. (2009). The PRIAMO study: a multicenter assessment of nonmotor symptoms and their impact on quality of life in Parkinson's disease. Movement Disorders, 24(11), 1641-1649.

Bogart, K. R. (2011). Is apathy a valid and meaningful symptom or syndrome in Parkinson's disease? A critical review. Health Psychology, 30(4), 386-400.

Braak, H., Del Tredici, K., Rub, U., de Vos, R. A., Jansen Steur, E. N., \& Braak, E. (2003). Staging of brain pathology related to sporadic Parkinson's disease. Neurobiology of Aging, 24(2), 197-211.

Brusa, L., Bassi, A., Stefani, A., Pierantozzi, M., Peppe, A., Caramia, M. D., et al. (2003). Pramipexole in comparison to I-dopa: a neuropsychological study. Journal of Neural Transmission, 110(4), 373-380.

Butterfield, L. C., Cimino, C. R., Oelke, L. E., Hauser, R. A., \& Sanchez-Ramos, J. (2010). The Independent Influence of Apathy and Depression on Cognitive Functioning in Parkinson's Disease. Neuropsychology, 24(6), 721-730.

Camicioli, R., Lea, E., Nutt, J. G., Sexton, G., \& Oken, B. S. (2001). Methylphenidate increases the motor effects of L-Dopa in Parkinson's disease: a pilot study. Clinical Neuropharmacology, 24(4), 208-213.

Chatterjee, A., \& Fahn, S. (2002). Methylphenidate treats apathy in Parkinson's disease. Journal of Neuropsychiatry and Clinical Neuroscience, 14(4), 461-462.

Chaudhuri, K., \& Schapira, A. (2009). Non-motor symptoms of Parkinson's disease: dopaminergic pathophysiology and treatment. Lancet Neurology, 8(5), 464-474.

Costa, A., Peppe, A., Dell'Agnello, G., Caltagirone, C., \& Carlesimo, G. A. (2009). Dopamine and cognitive functioning in de novo subjects with Parkinson's disease: Effects of pramipexole and pergolide on working memory. Neuropsychologia, 47(5), 1374-1381.

Cummings, J. L., Mega, M., Gray, K., Rosenberg-Thompson, S., Carusi, D.A., Gornbein, J. (1994). The Neuropsychiatric Inventory: Comprehensive assessment of psychopathology in dementia. Neurology, 44(12), 2308-2314.

Czernecki, V., Pillon, B., Houeto, J. L., Pochon, J. B., Levy, R., \& Dubois, B. (2002). Motivation, reward, and Parkinson's disease: influence of dopatherapy. Neuropsychologia, 40(13), 2257-2267.

De Rijk, M. C., Rocca, W. A., Anderson, D. W., Melcon, M. O., Breteler, M. M. B., \& Maraganore, D. M. (1997). A population perspective on diagnostic criteria for Parkinson's disease. Neurology, 48(5), 1277-1281.

Delaville, C., Deurwaerdere, P. D., \& Benazzouz, A. (2011). Noradrenaline and Parkinson's disease. Frontiers in systems neuroscience, 5(31), Epud ahead of print.

Devos, D., Dujardin, K., Poirot, I., Moreau, C., Cottencin, O., Thomas, P., et al. (2008). Comparison of desipramine and citalopram treatments of depression in Parkinson's disease: a double-blind, randomized, placebo-controlled study. Movement Disorders, 23(6), 850-857.

Drijgers, R. L., Aalten, P., Winogrodzka, A., Verhey, F. R. J., \& Leentjens, A. F. G. (2009). Pharmacological treatment of apathy in neurodegenerative diseases: a systematic review. Dementia and Geriatric Cognitive Disorders, 28(1), 13-22.

Dubois, B., Slachevsky, A., Litvan, I., \& Pillon, B. (2000). The FAB: a Frontal Assessment Battery at bedside. Neurology, 55(11), 1621-1626.

Evans, A., Lawrence, A., \& Lees, A. (2009). Changes in psychomotor effects of L-dopa and methylphenidate after sustained dopaminergic therapy in Parkinson's disease. Journal of Neurology Neurosurgery and Psychiatry, 80(3), 267-272.

Fahn, S., \& Elton, R. L. (1987). Unified Parkinson's disease rating scale. New Jersey: McMillan Health Care.

Folstein, M. F., Folstein, S. E., \& McHugh, P. R. (1975). "Mini-mental state". A practical method for grading the cognitive state of patients for the clinician. Journal of Psychiatric Research, 12(3), 189-198. 
Franken, I. H. A., Rassin, E., \& Muris, P. (2007). The assessment of anhedonia in clinical and non-clinical populations: further validation of the Snaith-Hamilton Pleasure Scale (SHAPS). Journal of Affective Disorders, 99(1-3), 83-89.

Goetz, C. G., Poewe, W., Rascol, O., Sampaio, C., Stebbins, G. T., Counsell, C., et al. (2004). Movement disorder society task force report on the Hoehn and Yahr staging scale: status and recommendations. Movement Disorders, 19(9), 1020-1028.

Hamidovic, A., kang, U. J., \& de Wit, H. (2008). Effect of low to moderate acute doses of pramipexole on impulsivity and cognition in healthy volunteers. Journal of Clinical Psychopharmacology, 28(1), 45-51.

Hamilton, M. (1960). A rating scale for depression. Journal of Neurology, Neurosurgery and Psychiatry, 23, 5662.

Hoehn, M. M., \& Yahr, M. D. (1967). Parkinsonism: onset, progression and mortality. Neurology, 17(5), 427442.

Jolles, J., Houx, P. J., Van Boxtel, M. P. J., \& Ponds, R. W. H. M. (1995). The Maastricht aging study; determinants of cognitive aging. Maastricht: Neuropsych Publishers.

Lavretsky, H., Ballmaier, M., Pham, D., Toga, A., \& Kumar, A. (2007). Neuroanatomical characteristics of geriatric apathy and depression: a magnetic resonance imaging study. American Journal of Geriatric Psychiatry, 15(5), 386-394.

Leentjens, A. F. G., Koester, J., Fruh, B., Shephard, D. T. S., Barone, P., \& Houben, J. J. G. (2009). The effect of pramipexole on mood and motivational symptoms in Parkinson's disease: a meta-analysis of placebo controlled studies. Clinical Therapeutics, 31(1), 89-98.

Leentjens, A. F. G., Verhey, F. R., Lousberg, R., Spitsbergen, H., \& Wilmink, F. W. (2000). The validity of the Hamilton and Montgomery-Asberg depression rating scales as screening and diagnostic tools for depression in Parkinson's disease. International Journal of Geriatric Psychiatry, 15(7), 644-649.

Lima, C. F., Meireles, L. P., Fonseca, R., Castro, S. L., \& Garett, C. (2008). The Frontal Assessment Battery (FAB) in Parkinson's disease and correlations with formal measures of executive functioning. J Neurol, 255(11), 1756-1761.

Marin, R. S., Biedrzycki, R. C., \& Firinciogullari, S. (1991). Reliability and validity of the Apathy Evaluation Scale. Psychiatry Research, 38(2), 143-162.

McNair, D., Lorr, M., \& Droppleman, L. (1971). Manual for the Profile of Mood States. San Diego.

Mendonca, D. A., Menezes, K., \& Jog, M. S. (2007). Methylphenidate Improves Fatigue Scores in Parkinson Disease: A Randomized Controlled Trial. Movement Disorders, 22(14), 2070-2076.

Menza, M., Dobkin, R. D., Marin, H., Mark, M. H., Gara, M., Buyske, S., et al. (2009). A controlled trial of antidepressants in patients with Parkinson's disease and depression. Neurology, 72(10), 886-892.

Navan, P., Findley, L. J., Jeffs, J. A. R., Pearce, R. K. B., \& Bain, P. G. (2003). Randomized, double-blind, 3month parallel study of the effects of pramipexole, pergolide, and placebo on Parkinsonian tremor. Movement Disorders, 18(11), 1324-1331.

Pedersen, K. F., Alves, G., Bronnick, K., Aarsland, D., Tysnes, O., \& Larsen, J. P. (2010). Apathy in drug-naive patients with incident Parkinson's disease: the Norwegian ParkWest study. Journal of Neurology, 257, 217-223.

Pluck, G. C., \& Brown, R. G. (2002). Apathy in Parkinson's disease. Journal of Neurology, Neurosurgery and Psychiatry, 73(6), 636-642.

Reijnders, J. S. A. M., Ehrt, U., Weber, W. E. J., Aarsland, D., \& Leentjens, A. F. G. (2008). A systematic review of prevalence studies of depression in Parkinson's disease. Movement Disorders, 23(2), 183-189.

Reijnders, J. S. A. M., Scholtissen, B., Weber, W. E. J., Aalten, P., Verhey, F. R. J., \& Leentjens, A. F. G. (2010). Neuroanatomical correlates of apathy in Parkinson's disease: a magnetic resonance imaging study using voxel-based morphometry. Movement Disorders, 25(14), 2318-2325.

Relja, M., \& Klepac, N. (2006). A dopamine agonist, pramipexole, and cognitive functions in Parkinson's disease. Journal of Neurological Sciences, 248(1-2), 251-254.

Rodriquez-Oroz, M. C., Jahanshahi, M., Krack, P., Litvan, I., Macias, R., Bezard, E., et al. (2009). Initial clinical manifestations of Parkinson's disease: features and pathophysiological mechanisms. Lancet Neurology, 8(12), 1128-1139. 
Scholtissen, B., Verhey, F. R., Adam, J. J., \& Leentjens, A. F. G. (2006). Challenging the serotonergic system in Parkinson's Disease patients: effects on cognition, memory, motor performance and mood. Clinical Neuropharmacology, 29(5), 276-285.

Snaith, R. P., Hamilton, M., Morley, S., Humayan, A., Hargreaves, D., \& Trigwell, P. (1995). A scale for the assessment of hedonic tone the Snaith-Hamilton Pleasure Scale. British Journal of Psychiatry, 167(1), 99103.

Sockeel, P., Dujardin, K., Devos, D., Deneve, C., Destee, A., \& Defebvre, L. (2006). The Lille apathy rating scale (LARS), a new instrument for detecting and quantifying apathy: validation in Parkinson's disease. Journal of Neurology, Neurosurgery and Psychiatry, 77(5), 579-584.

Van der Elst, W., van Boxtel, M. P., van Breukelen, G. J., \& Jolles, J. (2006). The Letter Digit Substitution Test: normative data for 1,858 healthy participants aged 24-81 from the Maastricht Aging Study (MAAS): influence of age, education, and sex. Journal of Clinical and Experimental Neuropsychology, 28(6), 998-1009. 



\section{CHAPTER 7 \\ Pharmacological treatment of apathy in neurodegenerative diseases: a systematic review}




\section{Abstract}

Objective: To evaluate the efficacy of pharmacological treatment of apathy in patients with neurodegenerative diseases.

Methods: Systematic review of studies assessing the effects of pharmacological treatment on apathy in neurodegenerative diseases.

Results: Thirty-five studies were included: 2 meta-analyses, 13 randomized controlled trials (RCTs), 14 open-label studies, 5 case series, and 1 single case study. Eight studies included apathy as a primary outcome. A cholinesterase inhibitor was investigated in 24 studies, methylphenidate in 5, and other medications in 6. Most RCTs of cholinesterase inhibitors reported a small but statistically significant improvement of apathetic symptoms.

Conclusions: Although some medications are promising candidates for further study, there is as yet insufficient evidence that pharmacological treatment improves apathetic symptoms in patients with neurodegenerative disease. Large-scale, placebo-controlled RCTs with apathy as a primary outcome measure are needed to establish the potential benefit of pharmacological treatment of apathy. 


\subsection{Introduction}

Apathy is defined as a lack of motivation characterized by diminished goal-oriented behaviour and cognition, and diminished emotional concomitant to goal-directed behaviour (Starkstein \& Leentjens, 2008). It is common in neurodegenerative diseases such as Alzheimer's disease (AD) and Parkinson's disease (PD). Apathy is the most frequently reported behavioural syndrome in dementia, with an estimated prevalence of $42 \%$ to $92 \%$ (Aalten et al., 2005; Boyle \& Malloy, 2004; Landes et al., 2001; M. S. Mega et al., 1996; Steinberg et al., 2007). In PD, apathy is reported in $17 \%$ to $70 \%$ of the patients (Dujardin et al., 2007; Leentjens et al., 2008; Pluck \& Brown, 2002; Sockeel et al., 2006).

Apathy is increasingly considered a distinct syndrome instead of a symptom of neuropsychiatric disorders. Its neuroanatomical and neurochemical substrates are still largely unknown, although limbic structures and striato-thalamo-cortical circuits are thought to be involved (Brown \& Pluck, 2000). Apathy decreases the quality of life of patients with $A D$ and their caregivers, is associated with caregiver distress, and increases the likelihood of institutionalization (Chan et al., 2003; de Vugt et al., 2003; Finkel, 1998; Onyike et al., 2007; Shin et al., 2005; Yeager \& Hyer, 2008). In patients with PD apathy is associated with more severe cognitive dysfunction and a decreased ability to perform activities of daily living (ADL) (Aarsland et al., 1999; Isella et al., 2002; Levy et al., 1998; Pluck \& Brown, 2002). For these reasons, apathy is increasingly considered a potential target for treatment. Although non-pharmacological interventions, such as multisensory stimulation, protocolized activity therapy, communication therapy, and massage therapy, have been tested as therapy for apathy, to date results have been either inconclusive or negative (Chapman et al., 2004; Chung et al., 2002; Hirakawa et al., 2005; Politis et al., 2004). However, the pharmacological treatment of apathy has not yet been critically evaluated. Therefore, the aim of this study is to systematically review the evidence for pharmacological treatment of apathy in patients with neurodegenerative diseases.

\subsection{Methods}

\section{Search strategy and selection criteria}

The Pubmed database was searched up to June 2008, using the keyword 'apathy', applying the following limits: 'humans', 'clinical trial', 'meta-analysis', 'practice guideline', and 'randomized controlled trial'. Abstracts of the retrieved articles were screened for relevance. Criteria for inclusion in the review were: (i) the study population involved patients with a neurodegenerative disease; (ii) the study objective was to evaluate the effects of a pharmacological treatment; (iii) apathy was reported as a 
primary or secondary outcome; (iv) the article was written in English, Dutch, German, or French. Further articles for inclusion were identified by searching the references of retrieved articles and by checking the Cochrane library. There were no limitations regarding study design, and thus the review included meta-analyses, randomized controlled trials (RCTs), open-label studies, and case studies. Studies that were included in a meta-analysis were not also included separately as RCTs.

All articles were read in full and their level of evidence and outcome were assessed by two of the authors (RD, AW). If there was a difference of opinion, a consensus meeting was held with the last author $(A L)$ to discuss the disagreement and to reach a final decision. Studies were classified by their level of evidence following the system of the Oxford Centre for Evidence-Based Medicine (Medicine, May, 2001; Phillips et al., 2008). Grades of recommendation were also scored with this classification (table 1).

\subsection{Results}

\section{Literature search}

The initial search yielded 136 articles. Of these, 23 articles were selected on basis of title and abstract and the remainder were excluded because the study population did not suffer from a neurodegenerative disease $(n=46)$, the study did not investigate pharmacotherapy $(n=59)$, or the article was written in a language other than English, German, French or Dutch $(n=8)$. Another 32 potentially relevant articles were identified from the references of the included articles, 19 of which were excluded because the study population did not suffer from a neurodegenerative disease $(n=1)$, the study did not investigate a pharmacological intervention $(n=2)$, or apathy was not a primary or secondary outcome $(n=16)$. Three studies known by the authors, but not retrieved by the search, were also included. Four studies were not considered individually because they were included in two meta-analyses. In total, 35 studies were included in the review.

\section{Appraisal of studies}

Of these 35 studies, only 9 had the treatment of apathy in a neurodegenerative disease as primary outcome, whereas the other 26 studies included apathy as a secondary outcome variable, often as part of a broader measure of neuropsychiatric symptoms, such as the Neuropsychiatric Inventory (NPI) (Cummings, Mega, M., Gray, K., Rosenberg-Thompson, S., Carusi, D.A., Gornbein, J., 1994). The review includes 2 metaanalyses, 13 RCTs, 14 open-label studies, and 6 case studies. 
Table 1. Levels of evidence and grades of recommendation*

\begin{tabular}{|c|c|}
\hline & Levels of Evidence \\
\hline Level & Explanation \\
\hline 1 & $\begin{array}{l}\text { One or more randomized controlled trials (RCT) (or systematic } \\
\text { review of trials) of sufficient size to ensure a low risk of false } \\
\text { positive or false negative results (narrow confidence interval) }\end{array}$ \\
\hline 2 & $\begin{array}{l}\text { Good quality cohort studies or low quality RCT (e.g. too small, } \\
<80 \% \text { follow-up) }\end{array}$ \\
\hline 3 & Case-control studies, including systematic reviews of case-control studies \\
\hline 4 & Case series, and poor quality cohort and case-control studies \\
\hline 5 & $\begin{array}{l}\text { Expert opinion without explicit critical appraisal, or based on } \\
\text { physiology, bench research, or "first principles" }\end{array}$ \\
\hline & Grades/Strengths of Recommendations \\
\hline Level & Explanation \\
\hline A & Consistent level 1 studies \\
\hline B & Consistent level 2 or 3 studies OR extrapolations from level 1 studies \\
\hline $\mathrm{C}$ & Level 4 studies OR extrapolations from level 2 or 3 studies \\
\hline D & Level 5 evidence OR troublingly inconsistent or inconclusive studies of any level \\
\hline
\end{tabular}

* Summarized from "Levels of Evidence and Grades of Recommendation", Oxford Centre for Evidence-Based Medicine, May 2001. http://www.cebm.net/levels_of_evidence

Cholinesterase inhibitors were investigated in 24 studies, methylphenidate in 5 studies, and other drugs (paroxetine, amantadine, memantine, levodopa, tianeptine, and ginkgo biloba) in 6 studies (one study each). Both meta-analyses, 9 of the 13 RCTs, and 9 of the 14 open-label studies involved patients with AD; the other studies included patients with dementia with Lewy bodies (DLB) $(n=3)$, frontotemporal dementia (FTD) 
$(n=4)$, vascular dementia $(n=2)$, and PD $(n=3)$. Two studies included both patients with $A D$ and vascular dementia, and one study did not define the type of dementia (table 2 ).

Study recommendations were graded according to the criteria of the Oxford Centre for Evidence-Based Medicine (table 1) (Medicine, May, 2001), and where possible, effect sizes were calculated with Cohen's d (Cohen, 1988). Both meta-analyses and 11 of the 13 RCTs were classified as grade A. None of these studies included apathy as a primary outcome variable. Two RCTs were classified as grade B, and the open studies and the case studies were classified as grade $\mathrm{C}$ (see table 2 ).

\section{Meta-analyses}

Cummings et al. performed a meta-analysis of the combined data from two previously published double-blind, multicenter, placebo-controlled RCTs involving 672 patients treated with the cholinesterase inhibitor metrifonate (Cummings et al., 2001; Morris et al., 1998; Raskind et al., 1999). After 26 weeks, treatment with metrifonate (30 or 60 $\mathrm{mg}$ daily) resulted in a significant reduction in the average score on the NPI apathy item ( $p=0019$ ), with $51 \%$ of the metrifonate-treated versus $36 \%$ of the placebo-treated patients achieving a reduction of at least $30 \%(p=0.020)$.

Herrmann and colleagues (Herrmann et al., 2005) performed a meta-analysis of 3 large placebo-controlled RCTs examining the effectiveness of the cholinesterase inhibitor galantamine. Two of these trials had been published before (Rockwood et al., 2001; Tariot et al., 2000). The meta-analysis included 2033 patients with mild to moderate $A D$ treated for 13,22 , or 26 weeks with doses varying from 16 to $32 \mathrm{mg}$ daily. Apathy was assessed, as a secondary outcome variable, using the NPI apathy item. There was no significant difference in outcome between treatment with galantamine or placebo.

\section{RCTs}

Thirteen RCTs assessed the effects of pharmacological treatment on apathy, of which 1 evaluated apathy as a primary outcome, measured with the Apathy Evaluation Scale (AES) (Herrmann et al., 2008; Marin et al., 1991). The other 12 studies included apathy as a secondary outcome, mostly measured with the NPI apathy item. Seltzer et al. used another validated scale, the Apathy Scale (AS), to measure apathy as a secondary outcome (Seltzer et al., 2004; Starkstein et al., 1992). Ten studies involved a cholinesterase inhibitor, one involved methylphenidate, one paroxetine, and one ginkgo biloba extract. Of the cholinesterase inhibitors, donepezil was used in 6 studies, metrifonate in 2, and galantamine and rivastigmine in 1 each. 


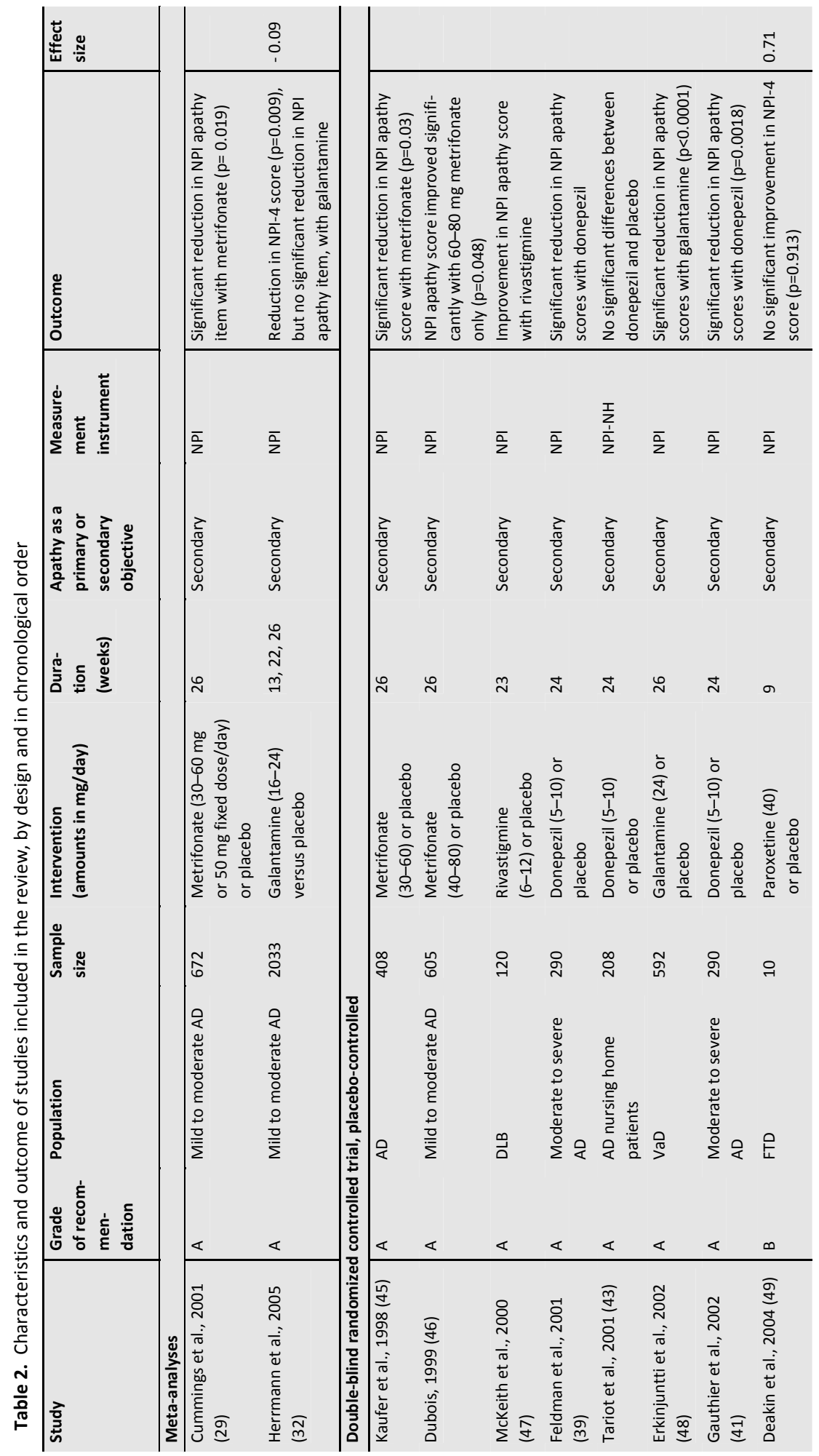




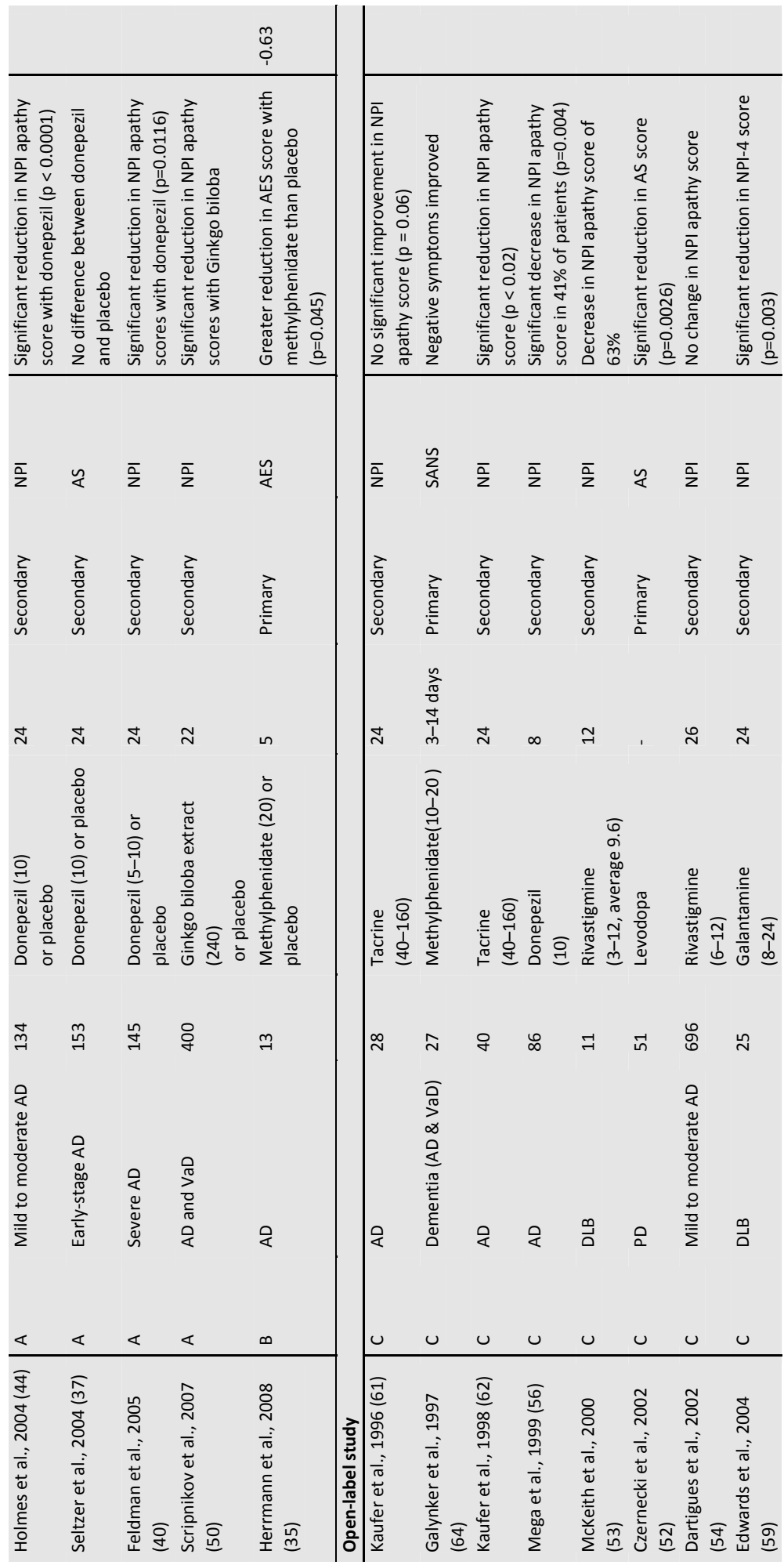




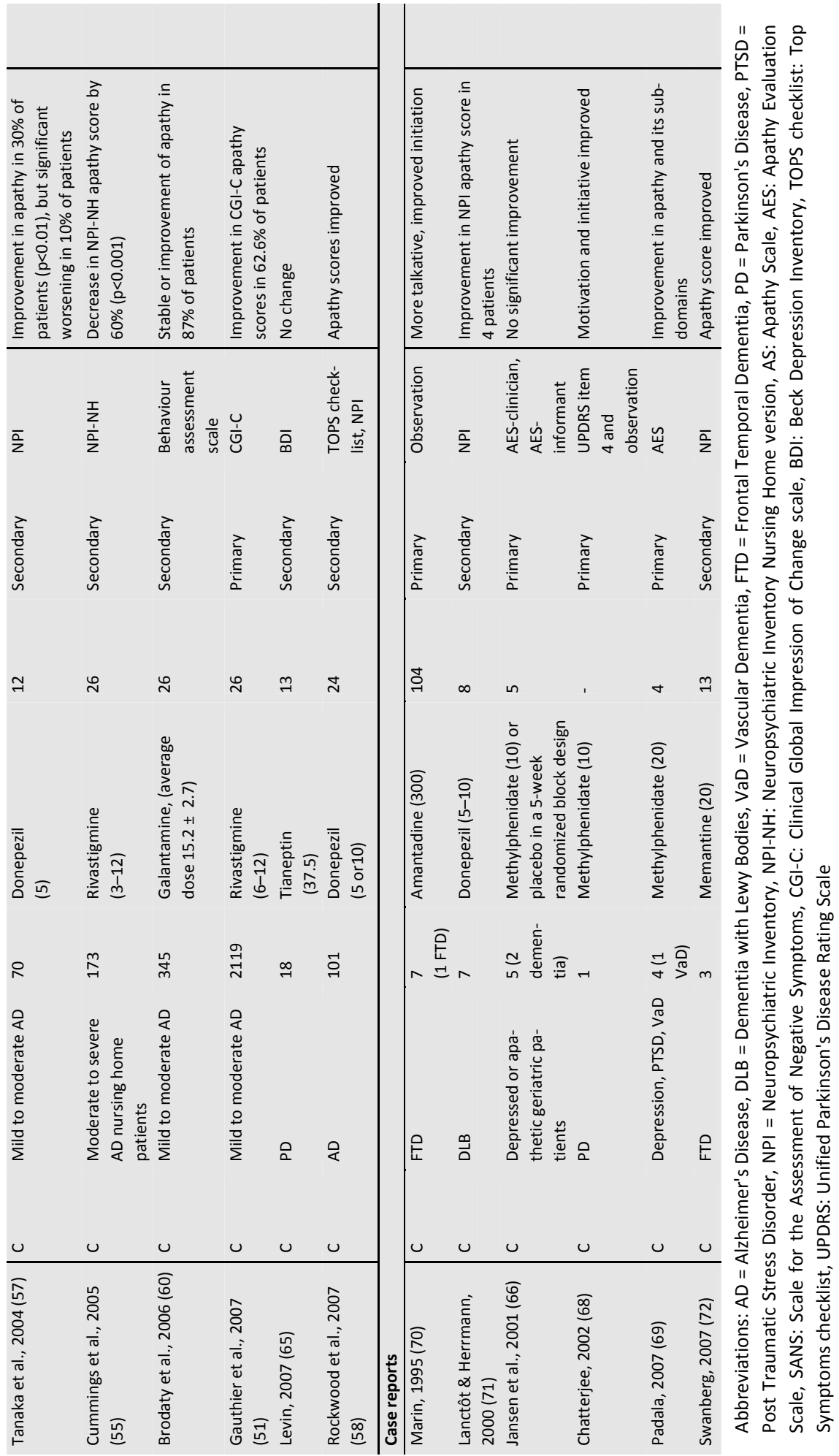


Donepezil was the most-studied cholinesterase inhibitor. Feldman et al. reported that donepezil produced a significantly greater reduction in NPI apathy score than placebo in 290 patients with AD but failed to report the $p$ value (Feldman et al., 2001). The same database was used for two sub-analyses (Feldman et al., 2005; Gauthier et al., 2002). Gauthier et al. included the same 290 patients and found significant treatment differences on the NPI apathy score $(p=0.0018)$ (Gauthier et al., 2002), whereas Feldman et al. found a significant improvement in NPI apathy score with donepezil in 145 patients with more severe $A D$, operationalized as a score between 5 and 12 on the Mini Mental State Examination (MMSE) ( $p=0.012$ ) (Feldman et al., 2005; Folstein et al., 1975). Tariot and coworkers (Tariot et al., 2001) did not find donepezil to improve apathy (assessed using the NPI apathy item) in 208 nursing home patients with AD, whereas Holmes et al. reported a significant reduction in NPI apathy score after 12 weeks of open-label treatment with donepezil in 134 patients with $A D(p<0.001)$. No results were reported for the subsequent randomization phase (Holmes et al., 2004). Seltzer et al. found no difference in scores on the AS between treatment with donepezil and placebo in 253 patients with AD (Seltzer et al., 2004).

Kaufer et al. and Dubois et al. both studied the effect of metrifonate in patients with AD (Dubois et al., 1999; Kaufer, 1998). Kaufer et al. reported a significant improvement in apathy (NPI apathy item) in 408 patients treated with metrifonate compared with placebo $(p=0.03)$, whereas Dubois et al. $(n=605)$ reported a significant improvement $(p=0.048)$ in the NPI apathy score of patients treated with a high $(60-80$ $\mathrm{mg}$ ) but not low (40-50 mg) dose of metrifonate, compared with placebo.

Of the other pharmacological treatments, McKeith et al. reported an improvement in NPI apathy score after 23 weeks of treatment with rivastigmine (6-12 mg) in 120 patients with DLB (McKeith et al., 2000), however no p-value was mentioned. Erkinjuntti et al. reported that galantamine significantly improved the NPI apathy score of 592 patients with vascular dementia ( $p<0.0001$ ) (Erkinjuntii et al., 2002). In a recent study, Herrmann et al. found methylphenidate (10 $\mathrm{mg}$, bid) to improve apathy (measured with the AES) compared with placebo in 13 apathetic patients with $A D$ (Herrmann et al., 2008). In their study of 10 patients with FTD, Deakin and coworkers defined a NPI-4 score to measure apathy based on factor analysis of the full NPI. This NPI-4 score represented a sub-score consisting of the items disinhibition, apathy, aberrant motor behaviour and euphoria. The authors did not find paroxetine to significantly improve apathy compared with placebo (Deakin et al., 2004). A study by Scripnikov et al. examined the effects of ginkgo biloba extract (EGb 761) in 400 patients with vascular dementia and AD. One of the largest drug-placebo differences in favour of EGb 761 was found for the NPI apathy score, but the significance level was not reported (Scripnikov et al., 2007). 


\section{Open-label studies}

Fourteen open-label studies were retrieved, of which 9 included patients with AD; the other 5 studies included patients with DLB, PD, and both AD and vascular dementia. The studies of Gauthier et al. (Gauthier et al., 2007) and Czernecki et al. (Czernecki et al., 2002) included apathy as a primary outcome variable, measured with the Clinical Global Impression of Change scale (CGI-C) and the AS, respectively. Eleven studies used a cholinesterase inhibitor: rivastigmine $(n=4)$, donepezil $(n=3)$, galantamine $(n=2)$, and tacrine $(n=2)$. One study investigated methylphenidate, one L-dopa therapy, and one tianeptine.

Of the studies investigating rivastigmine, McKeith and colleagues reported a $63 \%$ reduction in the NPI apathy score of 11 patients with DLB, (McKeith et al., 2000) and Dartigues et al. ( $n=696)$ reported a significant improvement in NPI apathy score after 12 weeks $(p=0.011)$ but not after 6 months of treatment. (Dartigues et al., 2002) Cummings et al. found a 60\% improvement in NPI apathy score in 173 patients with AD ( $p<0.001$ ) (Cummings et al., 2005), and Gauthier et al. found that $62.6 \%$ of 2119 patients with $A D$ showed improvement of apathy, measured as primary outcome with the CGI-C (Gauthier et al., 2007).

Donepezil was investigated in 3 studies. Mega et al. reported a significant improvement in apathy in $41 \%$ of 86 patients with $A D$ and apathy $(p=0.004)$ (Mega et al., 1999). While Tanaka et al. reported that $30 \%$ of 70 patients with $A D$ showed an improvement in total NPI score and the NPI apathy score after donepezil treatment $(p<0.01)$; apathy became significantly worse in $10 \%$ of the patients. (Tanaka et al., 2004) Rockwood et al. ( $n=101$ ) reported that donepezil consistently improved apathy but these authors failed to mention the significance of the finding (Rockwood et al., 2007).

Two open-label studies examined the effect of galantamine. Edwards et al. examined 25 patients with DLB and observed a significant improvement in the scores of a NPI-4 subscale, which included delusions, hallucinations, apathy, and depression $(p=0.003)$ (Edwards et al., 2004). Brodaty et al. reported that 6 months of galantamine treatment stabilized or improved the apathy scores of $87 \%$ of 345 patients with $A D$ (Brodaty et al., 2006).

Kaufer et al. investigated tacrine in two open-label studies involving patients with AD (Kaufer et al., 1996, 1998). In the first study ( $n=28)$, apathy, as measured with the $\mathrm{NPI}$, was one of the most responsive symptoms, although the improvement did not reach statistical significance $(p=0.06)$ (Kaufer et al., 1996). In the second study, in which 28 of the 40 patients came from the previous study, a significant reduction in NPI apathy score was detected $(p<0.02)$. Apathy improved equally in patients with mild, moderate, or severe dementia (Kaufer et al., 1998). In a pilot study, Galynker et al. investigated the effect of methylphenidate on negative symptoms, including apathy, in 27 patients with AD or vascular dementia. Negative symptoms were measured with the 
Scale for the Assessment of Negative Symptoms (SANS) (Andreasen, 1983). Results showed that the negative symptoms of patients with dementia appeared to be responsive to treatment with methylphenidate (Galynker et al., 1997). Czernecki and coworkers studied the effects of levodopa on motivation in non-demented, non-depressed patients with PD with response fluctuations, comparing patients in "on" and "off" states to controls and using the AS to measure apathy. While patients with PD were apathetic, their apathy responded to levodopa treatment $(p=0.0026)$ (Czernecki et al., 2002). Levin focused on the use of tianeptine in 18 patients with PD. While core symptoms of depression, measured with de Beck Depression Inventory (BDI), improved, those of apathy did not (Levin, 2007).

\section{Case studies}

Six case studies investigated the effect of pharmacological treatment of apathy, of which 3 studies focused on methylphenidate. Notable was that 4 studies assessed apathy as a primary outcome. The patients had various neurodegenerative diseases, including PD, (vascular) dementia, FTD, DLB, and AD. Jansen et al. used the AES as outcome measure for apathy and reported a treatment-associated improvement in AES-clinician score and AES-informant score, however $p$-values were not significant ( $p=0.077$ and $p=0.086$ respectively) (Jansen et al., 2001). Chatterjee and Fahn studied methylphenidate in one patient with PD, measuring apathy with item 4 (motivation/initiative) of part I of the UPDRS (Fahn \& Elton, 1987). They found methylphenidate to improve motivation/initiative, with scores decreasing from 3 to 0 ( $0=$ =none; 4=complete loss of motivation) (Chatterjee \& Fahn, 2002). Padala et al. reported an improvement in apathy (AES scores) of $18.3 \%$ in a patient with vascular dementia. (Jansen et al., 2001; Padala et al., 2007) One case, part of a series involving patients with apathy, reported that amantadine, in combination with bupropion or levodopa, improved observed initiative and communication (the patient became more talkative) in a man with frontal lobe dementia (Marin et al., 1995). Lanctôt and Herrmann studied the effects of treatment with donepezil on neuropsychiatric symptoms in 7 patients with DLB, 4 of whom showed an improvement in NPI apathy score (Lanctôt \& Herrmann, 2000). A case series of 3 patients with FTD using memantine reported an improvement in NPI apathy score (Swanberg, 2007).

\subsection{Discussion}

This is the first systematic review of the pharmacological treatment of apathy in patients with neurodegenerative diseases. Of the 35 articles included, 2 meta-analyses provided grade A evidence, 11 RCTs provided grade A evidence, and 2 RCTs provided grade $B$ evidence. The grading of quality was based on the general design and 
methodology of the studies. However, apathy was a primary outcome in only 1 RCT. From this it may be concluded that there is not much high quality research that focuses specifically on apathy.

Among pharmacological treatments, cholinesterase inhibitors have been studied the most. Of the two meta-analyses, one reported positive (metrifonate) and the other no (galantamine) effects of these agents on apathy. Of the 9 RCTs of cholinesterase inhibitors, 3 derived from the same trial (Feldman et al., 2001; Feldman et al., 2005; Gauthier et al., 2002) and another 2 derived from the same study (Kaufer et al., 1996, 1998). Six studies reported positive effects (metrifonate, galantamine, and donepezil), 2 no effect (donepezil), and 2 did not report on the significance of their findings (rivastigmine, donepezil). Of the 11 open-label studies with cholinesterase inhibitors, 5 reported a significant improvement in apathy, while 6 reported inconsistent effects or did not report the significance of the findings. Given the lack of a placebo condition an open design is not the most appropriate for studying the effects of drugs on apathy. Many of the included articles did not contain enough information to calculate the size of the effect on apathy, and for those that did, effect sizes were small, which makes the clinical relevance of the effects doubtful. This is in line with a review of the treatment of neuropsychiatric symptoms of dementia by Sink et al., who also concluded that effect sizes were mostly modest and that positive effects on neuropsychiatric symptoms were trivial (Sink et al., 2005).

Concerning the other drugs that were used besides cholinesterase inhibitors, one RCT provided evidence for a positive effect of gingko biloba extract, and 1 small RCT and 3 case reports suggested that methylphenidate was beneficial. No conclusions could be drawn about the other medications investigated. Taken together, the metaanalyses and RCTs with cholinesterase inhibitors yielded inconclusive results, so that it is not possible to draw firm conclusions about the efficacy of cholinesterase inhibitors for the treatment of symptoms of apathy in patients with neurodegenerative diseases. However, several studies provided some promising indications for the effectiveness of in particular cholinesterase inhibitors and methylphenidate, although this needs thorough investigation in the future. These results are in line with the conclusion of Boyle and Malloy, who stated that cholinesterase inhibitors reduce the neuropsychiatric symptoms of $A D$, with apathy showing the most consistent improvement, and that other activating neuropsychotropic agents may be useful in the treatment of apathy (Boyle \& Malloy, 2004).

This review had several limitations. The first is that the conclusions drawn necessarily depend on the quality of the studies included. Although apathy is a common symptom of many neurodegenerative diseases, few RCTs have investigated apathy as primary outcome. Most studies have focused on cognitive deterioration, with apathy as a secondary outcome, or on neuropsychiatric symptoms in a broad sense as measured by the NPI, with apathy being one of several outcome variables investigated. For identifying the effectivity of the interventions two different types of scales were used; a 
composite measure as a product of frequency and severity such as the NPI, and scales consisting only of severity rating, such as the Apathy Evaluation Scale (AES) (Marin et al., 1991). In the absence of generally accepted diagnostic criteria, most of the rating instruments in use have not been validated in this specific population. Studies focusing on apathy as a primary outcome were generally case studies; only one small RCT focused on apathy as primary outcome (Herrmann et al., 2008). Moreover, most of these studies involved patients with $A D$, varying widely in disease stage and severity. From earlier research is known that apathy is correlated with the severity of cognitive problems in community-based older adults (Onyike et al., 2007). In dementia the occurrence and severity of apathy increased with disease severity and persisted during the more advances stages of dementia (Aalten et al., 2005). The response to treatment may depend on the disease stage, which may in part explain the inconclusive results of this review (Kaufer et al., 1998). Studies of pharmacological treatment of apathy in other neurodegenerative diseases were under-represented. Many of the studies included were small, lacked a control group, and did not control for concomitant psychotropic medication. In some studies, apathy was part of a cluster of several NPI items, yet the validity of such an 'apathy' cluster is unclear. All these issues make a generalization of the results questionable.

Another limitation is that our results may have been influenced by publication bias. We retrieved only studies that explicitly reported apathy. While many studies have used the NPI, scores on NPI sub-items are usually only reported if there is a general effect on the NPI. This may have led to non-retrieval of negative studies, with a consequent overestimation of the effect of pharmacological treatment.

In this systematic review, we evaluated the evidence base for pharmacological treatment of apathy in patients with neurodegenerative diseases. We found limited and inconsistent evidence for the efficacy of any specific drug in treating apathy in these patients and hence could not draw firm conclusions about their efficacy. Although research is hampered by the lack of generally accepted criteria for apathy as a syndrome (Robert et al., 2009), cholinesterase inhibitors and methylphenidate may be the best candidates for further study. Future research should include high quality RCTs with apathy as primary outcome. To facilitate this research, reliable and validated diagnostic criteria for apathy and validated scales that differentiate between apathy, depression, and executive dysfunction are of high importance. In addition, studies need to address different individual neurodegenerative diseases to be able to generalize results to other forms of dementia. Moreover, studies should take potential differences in treatment response between patients with different severity stages of disease into consideration. Study of the potential of pharmacological treatment of apathy in neurodegenerative disease is warranted because effective treatment would improve the quality of life of both patients and their caregivers. 


\section{References}

Aalten, P., de Vugt, M. E., Jaspers, N., Jolles, J., \& Verhey, F. R. J. (2005). The course of neuropsychiatric symptoms in dementia. Part I: findings from the two-year longitudinal Maasbed study. International Journal of Geriatric Psychiatry, 20(6), 523-530.

Aarsland, D., Larsen, J., Lim, N., Janvin, C., Karlsen, K., Tandberg, E., et al. (1999). Range of neuropsychiatric disturbances in patients with Parkinson's disease. Journal of Neurology, Neurosurgery and Psychiatry, 67(4), 492-496.

Andreasen, N. (1983). Scale for the Assessment of Negative Symptoms (SANS). lowa City: University of lowa.

Boyle, P. A., \& Malloy, P. F. (2004). Treating apathy in Alzheimer's disease. Dementia and Geriatric Cognitive Disorders, 17(1-2), 91-99.

Brodaty, H., Woodward, M., Barnes, N., \& Allen, G. (2006). A naturalistic study of galantamine for Alzheimer's disease. CNS Drugs, 20(11), 935-943.

Brown, R. G., \& Pluck, G. (2000). Negative symptoms: the 'pathology' of motivation and goal-directed behaviour. Trends in Neurosciences, 23(9), 412-417.

Chan, D. C., Kasper, J. D., Black, B. S., \& Rabins, P. V. (2003). Presence of behavioral and psychological symptoms predicts nursing home placement in community-dwelling elders with cognitive impairment in univariate but not multivariate analysis. Journal of Gerontology series A: Biological Sciences and Medical Sciences, 58(6), 548-554.

Chapman, S., Weiner, M., Rackley, A., Hynan, L., \& Zientz, J. (2004). Effects of cognitive-communication stimulation for Alzheimer's disease patients treated with donepezil. Journal of Speech, Language and Hearing Research, 47(5), 1149-1163.

Chatterjee, A., \& Fahn, S. (2002). Methylphenidate treats apathy in Parkinson's disease. Journal of Neuropsychiatry and Clinical Neuroscience, 14(4), 461-462.

Chung, J., Lai, C., Chung, P., \& French, H. (2002). Snoezelen for dementia. Cochrane Database Systematic Review, 4(CD003152).

Cohen, J. (1988). Statistical power analysis for the behavioral sciences. Hillsdale: Lawrence Earlbaum Associates.

Cummings, J. L., Koumaras, B., Chen, M., \& Mirski, D. (2005). Effects of rivastigmine treatment on the neuropsychiatric and behavioral disturbances of nursing home residents with moderate to severe probable Alzheimer's disease: a 26-week, multicenter, open-label study. American Journal of Geriatric Psychiatry, 3(3), 137-148.

Cummings, J. L., Mega, M., Gray, K., Rosenberg-Thompson, S., Carusi, D.A., Gornbein, J. (1994). The Neuropsychiatric Inventory: Comprehensive assessment of psychopathology in dementia. Neurology, 44(12), 2308-2314.

Cummings, J. L., Nadal, A., Masterman, D., \& Cyrus, P. (2001). Efficacy of metrifonate in improving the psychiatric and behavioral disturbances of patients with Alzheimer's disease. Journal of Geriatric Psychiatry Neurology, 14(3), 101-108.

Czernecki, V., Pillon, B., Houeto, J. L., Pochon, J. B., Levy, R., \& Dubois, B. (2002). Motivation, reward, and Parkinson's disease: influence of dopatherapy. Neuropsychologia, 40(13), 2257-2267.

Dartigues, J., Goulley, F., Bourdeix, I., Pere, J., \& Barberger-Gateau, P. (2002). Rivastigmine in current clinical practice in patients with mild to moderate Alzheimer's disease. Revue Neurologique (Paris), 158(8-9), 807-812.

de Vugt, M. E., Stevens, F., Aalten, P., Lousberg, R., Jaspers, N., Winkers, I., et al. (2003). Behavioural disturbances in dementia patients and quality of the marital relationship. International Journal of Geriatric Psychiatry, 18(2), 149-154.

Deakin, J., Rahman, S., Nestor, P., Hodges, J., \& Sahakian, B. (2004). Paroxetine does not improve symptoms and impairs cognition in frontotemporal dementia: a double-blind randomized controlled trial. Pharmacology, 172(4), 400-408. 
Dubois, B., McKeith, I., Orgogozo, J., Collins, O., \& Meulien, D. (1999). A multicentre, randomized, doubleblind, placebo-controlled study to evaluate the efficacy, tolerability and safety of two doses of metrifonate in patients with mild-to-moderate Alzheimer's disease: the MALT study. International Journal of Geriatric Psychiatry, 14(11), 973-982.

Dujardin, K., Sockeel, P., Devos, D., Delliaux, M., Krystkowiak, P., Destee, A., et al. (2007). Characteristics of apathy in Parkinson's disease. Movement Disorders, 22(6), 778-784.

Edwards, K., Hershey, L., Wray, L., Bednarczyk, E., Lichter, D., Farlow, M., et al. (2004). Efficacy and Safety of Galantamine in Patients with dementia with Lewy Bodies: a 12-week interim analysis. Dementia and Geriatric Cognitive Disorders, 17(Suppl 1), 40-48.

Erkinjuntii, T., Kurz, A., \& Gauthier, S. (2002). Efficacy of galantamine in probable vascular dementia and Alzheimer's disease combined with cerebrovascular disease: a randomized trial. Lancet, 359(9314), 12831290.

Fahn, S., \& Elton, R. L. (1987). Unified Parkinson's disease rating scale. New Jersey: McMillan Health Care.

Feldman, H., Gauthier, S., Hecker, J., Vellas, B., Subbiah, P., \& Whalen, E. (2001). A 24-week, randomized, double-blind study of donepezil in moderate to severe Alzheimer's disease. Neurology, 57(4), 613-620.

Feldman, H., Gauthier, S., Hecker, J., Vellas, B., Xu, Y., Ieni, J., et al. (2005). Efficacy and safety of donepezil in patients with more severe Alzheimer's disease: a subgroup analysis from a randomized placebocontrolled trial. International Journal of Geriatric Psychiatry, 20(6), 559-569.

Finkel, S. (1998). The significance of the behavioural and psychological symptoms of dementia. Clinician, 16(1), 33-42.

Folstein, M. F., Folstein, S. E., \& McHugh, P. R. (1975). "Mini-mental state". A practical method for grading the cognitive state of patients for the clinician. Journal of Psychiatric Research, 12(3), 189-198.

Galynker, I., leronimo, C., Miner, C., Rosenblum, J., Vilkas, N., \& Rosenthal, R. (1997). Methylphenidate treatment of negative symptoms in patients with dementia. Journal of Neuropsychiatry Clinical Neuroscience, 9(2), 231-239.

Gauthier, S., Feldman, H., Hecker, J., Vellas, B., Ames, D., Subbiah, P., et al. (2002). Efficacy of donepezil on behavioral symptoms in patients with moderate to severe Alzheimer's disease. International Psychogeriatric, 14(4), 389-404.

Gauthier, S., Juby, A., Rehel, B., \& Schecter, R. (2007). EXACT: rivastigmine improves high prevalence of attention deficits and mood and behaviour symptoms in Alzheimer's disease. International Journal of Clinical Practice, 61(6), 886-895.

Herrmann, N., Rabheru, K., Wang, J., \& Binder, C. (2005). Galantamine treatment of problematic behavior in Alzheimer's disease: post-hoc analysis of pooled data from three large trials. American Journal of Geriatric Psychiatry, 13(6), 527-534.

Herrmann, N., Rothenburg, L. S., Black, S. E., Ryan, M., Liu, B. A., Busto, U. E., et al. (2008). Methylphenidate for the Treatment of Apathy in Alzheimer Disease. Journal of Clinical Psychopharmacoly., 28(3), 296-301.

Hirakawa, Y., Masuda, Y., \& Kimata, T. (2005). Effects of home massage rehabilitation therapy for the bedridden elderly: a pilot trial with a three-month follow-up. Clinical Rehabilitation, 19(1), 20-27.

Holmes, C., Wilkinson, D., Dean, C., Vethanayagam, S., Olivieri, S., \& Langley, A. (2004). The efficacy of donepezil in the treatment of neuropsychiatric symptoms in Alzheimer disease. Neurology, 63(2), 214-219.

Isella, V., Melzi, P., Grimaldi, M., Iurlaro, S., Piolti, R., Ferrarese, C., et al. (2002). Clinical, neuropsychological, and morphometric correlates of apathy in Parkinson's disease. Movement Disorders, 17(2), 366-371.

Jansen, I. H., Olde Rikkert, M. G., Hulsbos, H. A., \& Hoefnagels, W. H. (2001). Toward individualized evidencebased medicine: five " $\mathrm{N}$ of 1 " trials of methylphenidate in geriatric patients. Journal of the American Geriatric Society, 49(4), 474-476.

Kaufer, D. (1998). Beyond the Cholinergic Hypothesis: the effect of metrifonate and other cholinesterase inhibitors on neuropsychiatric symptoms in Alzheimer's disease. Dementia and Geriatric Cognitive Disorders, 9(Suppl 2), 8-14.

Kaufer, D., Cummings, J. L., \& Christine, D. (1996). Effect of tacrine on behavioral symptoms in Alzheimer's disease: an open-label study. Journal of Geriatric Psychiatry and Neurology, 9(1), 1-6. 
Kaufer, D., Cummings, J. L., \& Christine, D. (1998). Differential Neuropsychiatric Symptom Response to Tacrine in Alzheimer's Disease: Relationship to Dementia Severity. Journal Neuropsychiatry and Clinical Neuroscience, 10(1), 55-63.

Lanctôt, K. L., \& Herrmann, N. (2000). Donepezil for behavioural disorders associated with lewy bodies: a case series. International Journal of Geriatric Psychiatry, 15(4), 338-345.

Landes, A. M., Sperry, S. D., Strauss, M. E., \& Geldmacher, D. S. (2001). Apathy in Alzheimer's disease. Journal of the American Geriatric Society, 49(12), 1700-1707.

Leentjens, A., Dujardin, K., Marsh, L., Martinez-Martin, P., Richard, I., Starkstein, S., et al. (2008). Apathy and anhedonia rating scales in Parkinson's disease: Critique and recommendations. Movement Disorders, 23(14), 2004-2014.

Levin, O. (2007). Coaxil (Tianeptine) in the Treatment of Depression in Parkinson's Disease. Neuroscience and Behavioral Physiology, 37(4), 419-424.

Levy, M., Cummings, J., Fairbanks, L., Masterman, D., Miller, B., Craig, A., et al. (1998). Apathy is not depression. Journal of Neuropsychiatry and Clinical Neurosciences, 10(3), 314-319.

Marin, R. S., Biedrzycki, R. C., \& Firinciogullari, S. (1991). Reliability and validity of the Apathy Evaluation Scale. Psychiatry Research, 38(2), 143-162.

Marin, R. S., Fogel, B. S., Hawkins, J., Duffy, J., \& Krupp, B. (1995). Apathy: a treatable syndrome. Journal of Neuropsychiatry and Clinical Neuroscience, 7(1), 23-30.

McKeith, I., Crace, J., Walker, Z., Byrne, E., Wilkinson, D., Stevens, T., et al. (2000). Rivastigmine in the treatment of dementia with Lewy bodies: preliminary findings from an open trial. International Journal of Geriatric Psychiatry, 15(5), 387-392.

McKeith, I., Del Ser, T., Spano, P., Emre, M., Wesnes, K., Anand, R., et al. (2000). Efficacy of rivastigmine in dementia with Lewy bodies: a randomized, double-blind, placebo-controlled international study. Lancet, 356(9247), 2031-2036.

Medicine,O.C.f.E.-b. (May, 2001). Levels of Evidence and Grades of Recommendation.

Mega, M., Masterman, D., O'Connor, S., Barclay, T., \& Cummings, J. L. (1999). The spectrum of behavioral responses to cholinesterase inhibitor therapy in Alzheimer disease. Archives of Neurology, 56(11), 13881393.

Mega, M. S., Cummings, J. L., Fiorello, T., \& Gornbein, J. (1996). The spectrum of behavioral changes in Alzheimer's disease. Neurology, 46(1), 130-135.

Morris, J., Cyrus, P., Orazem, J., Mas, J., Bieber, F., Ruzicka, B., et al. (1998). Metrifonate benefits cognitive, behavioral, and global function in patients with Alzheimer's disease. Neurology, 50(5), 1222-1230.

Onyike, C. U., Sheppard, J. M., Tschanz, J. T., Norton, M. C., Green, R. C., Steinberg, M., et al. (2007). Epidemiology of apathy in older adults: the Cache County Study. American Journal of Geriatric Psychiatry, 15(5), 365-375.

Padala, P., Burke, W. J., Bhatia, S. C., \& Petty, F. (2007). Treatment of Apathy with Methylphenidate. Journal of Neuropsychiatry and Clinical Neurosciences, 19(1), 81-83.

Phillips, B., Ball, C., Badenoch, D., Straus, S., Haynes, B., \& Dawes, M. (2008). Levels of Evidence. BJU International, 101(7), 932.

Pluck, G. C., \& Brown, R. G. (2002). Apathy in Parkinson's disease. Journal of Neurology, Neurosurgery and Psychiatry, 73(6), 636-642.

Politis, A. M., Vozzella, S., Mayer, L. S., Onyike, C. U., Baker, A. S., \& Lyketsos, C. G. (2004). A randomized, controlled, clinical trial of activity therapy for apathy in patients with dementia residing in long-term care. International Journal of Geriatric Psychiatry, 19(11), 1087-1094.

Raskind, M., Cyrus, P., Ruzicka, B., \& Gulanski, B. (1999). The Effects of Metrifonate on the Cognitive, Behavioural, and Functional Performance of Alzheimer's Disease Patients. Journal of Clinical Psychiatry, 60(5), 318-325.

Robert, P. H., Onyike, C. U., Leentjens, A. F. G., Dujardin, K., Aalten, P., Starkstein, S. E., et al. (2009). Proposed diagnostic criteria for apathy in Alzheimer's disease and other neuropsychiatric disorders. European Psychiatry, 24(2), 98-104. 
Rockwood, K., Black, S., Bedard, M., Tran, T., \& Lussier, i. (2007). Specific symptomatic changes following donepezil treatment of Alzheimer's disease: a multi-centre, primary care, open-label study. International Journal of Geriatric Psychiatry, 22(4), 312-319.

Rockwood, K., Mintzer, J., Truyen, L., \& al., e. (2001). Effects of a flexible galantamine dose in Alzheimer's disease: a randomized, controlled trial. Journal of Neurology, Neurosurgery and Psychiatry, 71(5), 589595.

Scripnikov, A., Khomenko, A., \& Napryenyenko, O. (2007). Effects of Ginkgo biloba Extract EGb 761 on neuropsychiatric symptoms of dementia: findings from a randomized controlled trial. Wiener Medizinische Wochenschrift, 157(13-14), 295-300.

Seltzer, B., Zolnouni, P., Nunez, M., Goldman, R., Kumar, D., leni, J., et al. (2004). Efficacy of Donepezil in Early-Stage Alzheimer Disease. Archives of Neurology, 61(12), 1852-1856.

Shin, I., Carter, M., Masterman, D., Fairbanks, L., \& Cummings, J. L. (2005). Neuropsychiatric symptoms and quality of life in Alzheimer disease. American Journal of Geriatric Psychiatry, 13(6), 469-474.

Sink, K. M., Holden, K. F., \& Yaffe, K. (2005). Pharmacological Treatment of Neuropsychiatric Symptoms of Dementia, a review of the evidence. Journal of the American Medical Association, 293(5), 596-608.

Sockeel, P., Dujardin, K., Devos, D., Deneve, C., Destee, A., \& Defebvre, L. (2006). The Lille apathy rating scale (LARS), a new instrument for detecting and quantifying apathy: validation in Parkinson's disease. Journal of Neurology, Neurosurgery and Psychiatry, 77(5), 579-584.

Starkstein, S. E., \& Leentjens, A. F. G. (2008). The nosological position of apathy in clinical practice. Journal of Neurology Neurosurgery and Psychiatry, 79(10), 1088-1092.

Starkstein, S. E., Mayberg, H. S., Preziosi, T. J., Andrezejewski, P., Leiguarda, R., \& Robinson, R. G. (1992). Reliability, validity, and clinical correlates of apathy in Parkinson's disease. Journal of Neuropsychiatry and Clinical Neuroscience, 4(2), 134-139.

Steinberg, M., Shao, H., Zandi, P., Lyketsos, C. G., Welsh-Bohmer, K. A., Norton, M. C., et al. (2007). Point and 5-year period prevalence of neuropsychiatric symptoms in dementia: the Cache County Study. International Journal of Geriatric Psychiatry, 23(2), 170-177.

Swanberg, M. (2007). Memantine for behavioral disturbances in frontotemporal dementia, a case series. Alzheimer Dis Assoc Disord, 21(2), 164-166.

Tanaka, M., Namiki, C., Thuy, D., Yoshida, H., Kawasaki, K., \& Hashikawa, K. (2004). Prediction of psychiatric response to donepezil in patients with mild to moderate Alzheimer's disease. Journal of Neurological Sciences, 225(1-2), 135-141.

Tariot, P., Cummings, J. L., Katz, I. R., Mintzer, J., Perdomo, C., \& Schwam, E. (2001). A randomized, doubleblind, placebo-controlled study of the efficacy and safety of donepezil in patients with Alzheimer's disease in the nursing home setting. Journal of the American Geriatric Society, 49(12), 1590-1599.

Tariot, P., Solomon, R., Morris, J., \& al., e. (2000). A 5-month, randomized, placebo-controlled trial of galantamine in AD. Neurology, 54(2269-2276).

Yeager, C., \& Hyer, L. (2008). Apathy in dementia: relations with depression, functional competence, and quality of life. Psychological Reports, 102(3), 718-722. 


\section{CHAPTER 8 \\ General discussion}




\subsection{Summary of main findings}

The main aim of this thesis was to gain more insight in the assessment, pathophysiology and treatment of apathy in Alzheimer's disease (AD) and Parkinson's disease (PD). Apathy is one of the most common neuropsychiatric problems in patients with $A D$ and $\mathrm{PD}$ and has a major impact on the quality of life of both patients and their caregivers (Barone et al., 2009; de Vugt et al., 2006). For a long time, apathy was an unrecognized, underestimated and neglected problem. Nowadays, the impact of apathy in neurodegenerative diseases, and especially in $A D$ and $P D$, is increasingly recognized. Nevertheless, many questions remain unanswered; the etiology of apathy is still unclear and there is as yet no effective treatment for apathy.

In chapter 2 and 3 we focused on the recently proposed clinical diagnostic criteria for apathy in patients with PD. In our validation study these showed good acceptability and internal consistency, as well as good concurrent validity with the Lille Apathy Rating Scale (LARS) and the apathy item of the Neuropsychiatric Inventory (NPI) (Drijgers et al., 2010). Moreover, in PD patients, contrary to AD patients, the discriminant validity with depression was moderate to good (Drijgers et al., 2010; Mulin et al., 2011). In chapter 4 the neuropsychological correlates of apathy were examined in patients with Mild Cognitive Impairment $(\mathrm{MCl})$ and $A D$. We found an association between increased levels of apathy and reduced motor speed and worsened executive functioning, more particular reduced initiation, in the early phases of cognitive decline but not in AD. This implies that apathy may be an early predictor of AD. For PD, the fact that apathy may be a predictor of cognitive decline was shown by Dujardin et al. (Dujardin et al., 2009). To gain insight into the neuropathology of apathy we examined the role of the dopaminergic system in apathy by means of an acute challenge with the dopamine re-uptake inhibitor methylphenidate in patients with $A D$ (chapter 5) and an acute challenge with methylphenidate and the dopamine agonist pramipexole in patients with PD (chapter 6 ). In patients with AD we found a trend for increased mental speed after methylphenidate challenge compared to placebo challenge. In addition, challenge with methylphenidate led to a non-significant improvement in apathy, anger, vigour, and initiative. In patients with PD, challenge with methylphenidate resulted in reduced anhedonia and increased vigour whereas challenge with pramipexole resulted in worsened mood and increased fatigue in both patients and controls. These results suggest an involvement of dopamine in mood and motivational deficits in both AD and PD. In chapter 7, a systematic review showed that at the moment there is as yet no evidence base for any pharmacological treatment. Nevertheless, cholinesterase inhibitors and methylphenidate are promising candidates for further research (Drijgers et al., 2009).

In this final chapter our findings will be further discussed. Conceptual and methodological considerations will be described and recommendations for future research will be given. 


\subsection{Conceptual considerations}

\section{Clinical diagnostic criteria}

Apathy is a complex concept. In chapter 2 the development of the recently proposed diagnostic criteria for apathy as a syndrome is described. These criteria define apathy as a syndrome of diminished motivation, characterized by reduced goal-directed behaviour (lack of initiative), reduced goal-directed cognitive activity (lack of interest) and emotional blunting. The diagnostic criteria stress the differentiation of apathy into three sub-dimensions (behaviour, cognition and emotion) of which at least two out of three need to be present for a diagnosis of apathy (Robert et al., 2009). In chapter 3 we showed that all these three domains contributed to a diagnosis of apathy, with goaldirected behaviour being the most frequent reported domain and a lack of emotion the least often, indicating the latter being possibly related to a more severe level of apathy. A proper diagnosis of apathy is of great importance for both clinical practice and scientific research. Therefore, one of our goals was to validate the proposed diagnostic criteria in PD patients, and facilitate future research into the correlates and treatment of apathy. In this validation study (chapter 3 ) $17.2 \%$ of the included PD patients were apathetic according to the diagnostic criteria. This prevalence is low compared to previous studies from other groups, which reported prevalences varying from 17 to $70 \%$, measured with different rating scales. This may be explained by the fact that only non-demented patients with PD were included, whereas the prevalence of apathy is higher in patients with cognitive decline and dementia (Dujardin et al., 2007). Nevertheless, it also suggests that the diagnostic criteria for apathy are more specific and have a higher threshold compared to apathy rating scales. Similar results were found for depression in PD (Reijnders et al., 2008), where prevalences tend to diminish when diagnostic criteria are used instead of cut-off scores on rating scales. We showed that the diagnostic criteria of apathy have good concurrent validity with the Lille Apathy Rating Scale (LARS) (Sockeel et al., 2006) and apathy section of the Neuropsychiatric Inventory (NPI) (Cummings, et al., 1994). In addition, discriminant validity of the apathy criteria with depressive disorder as measured by the DSM IV and the NPI was fair. This is in contrast with the low discriminative validity in patients with Alzheimer disease (Mulin et al 2009).

\section{Apathy and depression}

Although there is a considerable overlap in core symptoms of depression and apathy, many studies have shown that apathy can exist as an independent syndrome (Aalten et al., 2007; Kirsch-Darrow et al., 2011; Tagariello et al., 2009). In this thesis this was once more confirmed in both $P D$ and $A D$ patients by the results of our validation study (chapter 3), in which $67 \%$ of the apathetic PD patients had no major depressive 
disorder, and in our study into neuropsychological correlates of apathy (chapter 4), where $58 \%$ of the apathetic $\mathrm{MCl}$ and $\mathrm{AD}$ patients were not depressed. Moreover, in chapter 4, depression had no effect on any of the examined neuropsychological measures, in contrast to apathy, which was associated with reduced executive functioning and motor speed. Similar results were reported in a study with PD patients, in which apathy, but not depression, was associated with executive impairment (Varanese et al., 2011). This indicates that apathy and depression have different neuropsychological correlates (Butterfield et al., 2010; Kuzis et al., 1999). Furthermore, a differential role of apathy and depression in the development of dementia has been argued by Vicini Chilovi, in which a diagnosis of apathy was a risk factor for conversion from $\mathrm{MCl}$ to dementia and depression was not (Vicini Chilovi et al., 2009). Several studies have also shown that apathy and depression have different etiologies, different neuroanatomical correlates and differential treatment options (Kirsch-Darrow et al., 2011; Lavretsky et al., 2007; Maas et al., 2009; Tagariello et al., 2009; van der Mast et al., 2008).

\section{Apathy and cognition}

Our study into neuropsychological correlates of apathy (chapter 4) showed that apathy was more prevalent in $A D$ group than in $\mathrm{MCl}$ group and thus seemed to be associated with increased cognitive impairment. This finding is in agreement with other studies that found apathy to be related to more severe cognitive dysfunction and faster cognitive decline (Starkstein et al., 2006; van Reekum et al., 2005). However, this does not mean that apathy is equal or inherent to cognitive impairment; $68.5 \%$ of the $\mathrm{MCl}$ and $A D$ patients were not apathetic. Since patients with Parkinson's disease dementia (PDD) were excluded in our validation study, we have no data in this population.

In chapter 4 we found that apathy was associated with worse executive dysfunction, especially initiating, and reduced motor speed, in the early stages of cognitive deterioration. In AD this association was not found, which could be explained by more severe neuropathology that obscures the impact of apathy on cognition. This finding suggests that apathy might be an early risk factor for cognitive deterioration and implies that assessment and diagnosis of apathy is essential in all phases of the disease. In PD as well, apathy was shown to be a predictor of later PDD (Dujardin et al., 2009). Awareness of apathy in an early phase of cognitive impairment could be important for the early diagnostics in AD and Parkinson's disease dementia (PDD).

In chapter 6 , an acute challenge of the dopaminergic system with the dopamine reuptake inhibitor methylphenidate and the D2/3 agonist pramipexol did not result in improvement of cognitive parameters in PD. On the other hand, in AD patients an acute challenge with methylphenidate resulted in non-significant improvement of several cognitive measures. Unfortunately this study was underpowered and no definite conclusions can be drawn. A possible explanation for this discrepancy between AD and PD 
patients could be the difference in severity of cognitive impairment, as the mean MMSE score of AD patients was $20( \pm 4.5)$ and of the PD patients $28.8( \pm 1.0)$, and the relatively low prevalence of apathy in our PD population.

\section{Apathy and pathophysiology}

The aim of the challenge studies described in chapter 5 and 6 was to examine the role of dopaminergic mechanisms in mood, motivation and cognition in AD and PD. The neurochemical substrate of motivational deficits such as apathy is poorly understood. Dysfunction of the frontal subcortical circuits has been related to apathy, and in particular changes in the cingulate gyrus and basal ganglia (Chase, 2011; Levy \& Dubois, 2006; Reijnders et al., 2010). Consequently, neurotransmitters mediating frontalsubcortical circuit function are thought to be involved in the pathophysiology of apathy. Previous data link dysfunction of dopaminergic transmission in the mesocorticolimbic reward pathway to apathy (Chase, 2011). A PET study in PD patients demonstrated that the degree of apathy was inversely correlated with [11C]RTI-32 binding (dopamine and noradrenaline) in the ventral striatum (Remy et al., 2005). In dementia patients the severity of apathy was associated with lower dopamine transporter (DAT) striatal levels (David et al., 2008). However, because of the association between apathy and cognitive impairment, Dujardin et al. suggested also a participation of non-dopaminergic circuits in PD (Dujardin et al., 2007). In addition, in AD, Cummings and Back proposed that limbic cholinergic deficits might underlie apathy and other neuropsychiatric symptoms (Cummings \& Back, 1998). Evidence for the participation of e.g. cholinergic, serotonergic and noradrenalinergic systems mainly relies on observations during clinical evaluation of pharmaceuticals that selectively act upon these transmitters. However, as shown in our systematic review in chapter 7 , studies of pharmacological interventions on apathy as a primary objective are sparse, often small, and its findings contradictory. The results of chapter 5 and 6 suggest at least partly an involvement of dopamine in the pathogenesis of mood and motivational deficits in both $A D$ and PD, which is in line with the initiating hypothesis. Apathy can thus not only be explained by the extinction hypothesis, which states that apathy simply reflects decreased information processing capacities of the brain. Accordingly, the finding that apathy is not just the result of atrophy of the brain suggests that treatment options need to be an important issue of research. In particular, the association of the dopaminergic system as well as to what extent non-dopaminergic neurotransmitter systems play a role in apathy requires further investigation, especially since there is still insufficient evidence for the efficacy of pharmacological treatment (chapter 7). Cholinergic and dopaminergic agents appear most promising from our systematic review. Mitchell and colleagues concluded that the dopaminergic system may be a useful and rational target for pharmacotherapy in the treatment of apathy as well (Mitchell et al., 2010). More specific, from our challenge studies follow that methylphenidate is a good candidate for further study. 
At last, besides biological factors apathy may possibly be influenced by psychosocial factors as well, such as stress, social deprivation, hearing or visual problems, and use of medication. However, as the impact of these factors on apathy has never been systematically examined, scientific evidence is lacking (van Reekum et al., 2005).

\section{The generic concept of apathy}

The clinical diagnostic criteria for apathy were developed with the intention that they should be applicable in different neurodegenerative and neuropsychiatric diseases. This is based on the proposition that apathy is thought to be, at least mainly, a syndrome with similar symptom constellations across various disorders (P.H. Robert et al., 2009; Winograd-Gurvich et al., 2006). Several previous studies have indicated that apathy has the same pathophysiological correlates across various diseases, such as the cingulate gyrus and the inferior frontal gyrus (Lavretsky et al., 2007; Marshall et al., 2006; van Reekum et al., 2005). This thesis addresses the two most common neurodegenerative diseases: $A D$ and PD. The challenge studies described in chapter 5 and 6 examined the role of the dopaminergic system in apathy in both AD and PD. Although results should be interpreted with caution, especially in $A D$ as our group was small, outcomes were partly comparable. After challenge with methylphenidate vigour scores seemed to improve in both $A D$ and PD patients. Furthermore, in chapter 4 we concluded that apathy was associated with worse executive dysfunction and worse motor speed in the early phases of cognitive deterioration and that apathy probably is an early sign of AD. In line with this result, Robert and colleagues found that $\mathrm{MCl}$ patients who developed $A D$ after one year had a trend to present more frequently symptoms of apathy at baseline (P. Robert et al., 2006). A correlation of apathy with reduced executive dysfunction, and more specific with verbal fluency deficits, was also reported in patients with PD (Isella et al., 2002). This is consistent with the finding that apathy was a predictive factor for cognitive decline and dementia in PD (Dujardin et al., 2009).

Although apathy may have specific characteristics across different neurodegenerative and neuropsychiatric disorders, our findings strengthen the hypothesis that apathy is a generic concept, with similar neuropsychological and pathophysiological correlates across different, at least neurodegenerative, disorders.

\subsection{Methodological considerations}

\section{Study populations}

This thesis focused on patients with a neurodegenerative disease (chapter 2, 7) and more specific on patients with $A D$ (chapter 4, 5) and PD (chapter 3,6). The subjects with $A D$ and $\mathrm{MCl}$ (chapter 4 ) were recruited from the Memory Clinic of the Maastricht 
University Medical Centre. In chapter 6, PD patients were recruited from the movement disorder clinics of the Maastricht University Medical Centre, Atrium Medical Centre Heerlen and Orbis Medical Centre Sittard. In chapter 3, an outpatient study population from the Maastricht University Medical Centre was combined with an outpatient study population of the Lille University Medical Centre. In case of combined study groups, population differences were checked and reported.

Most AD patients in chapter 4 and 5 were mild to moderate $A D$ patients (mean MMSE score $20 \pm 4.5$ ). PD patients in chapter 3 and 6 were mainly mild PD patients (median Hoehn \& Yahr stage II).

Preferably we would have included medication free patients only, particularly in our challenge studies. However, this was not feasible as the vast majority of the patients started on medication immediately after being diagnosed. The use of medication may be a confounding factor in our studies. Nevertheless, the use of psychopharmacological medication was an exclusion criteria for both $A D$ and PD patients. PD patients using dopamine agonists were also excluded. PD patients were allowed to use other dopaminergic medication, if they were on a stable dose for at least 3 months.

All patients participated on a voluntary basis, which might have caused a selection bias. As a consequence patients were generally highly motivated participants. This could explain the relatively low prevalence of psychopathology in our PD population (chapter 6 ) and the extreme difficulty of including apathetic AD patients (chapter 5), as apathetic patients are less inclined to participate.

\section{Diagnostics}

The diagnosis of AD and PD was made with the help of operational criteria, which have some limitations. The diagnosis of idiopathic PD (chapters 3 and 6) was made using the clinical Queen Square Brain Bank criteria (De Rijk et al., 1997). As we did not verify the diagnosis by additional assessment such as a dopamine transporter (DaT) scan or IBZM single photon emission tomography (SPECT), some patients could have been misdiagnosed with PD. Nevertheless, when compared with post-mortem pathological findings the operational criteria have shown good diagnostic accuracy of $76 \%$ (Hughes et al., 1992). For a diagnosis of dementia (chapters 4 and 5) the criteria of the DSM-IV of the American Psychiatric Association (APA) were used. The clinical diagnosis of AD was made in accordance with the NINCDS/ADRDA criteria (McKann et al., 1984). For AD patients a similar risk of misdiagnosis exists, as a definite diagnosis of AD can only made post mortem. However, diagnostic accuracy rates of the NINCDS/ADRDA criteria are over $80 \%$ (Lopez et al., 2000). In chapter 4 , patients were classified with $\mathrm{MCl}$ when they had objective cognitive impairment but did not fulfil the criteria for dementia or depression. 
The criteria of the DSM-IV of the American Psychiatric Association (APA) (American Psychiatric Association, 1994) were used to assess the presence of major depression in PD in chapter 3.

As described in chapter 2, clinical diagnostic criteria for apathy as a syndrome were proposed during a consensus meeting between different international associations and experts in 2008. The criteria have been subsequently validated in 306 patients suffering of different neuropsychiatric disorders. They showed good acceptability, inter-rater reliability, and know-groups validity (Mulin et al., 2011). In this thesis we have validated these criteria in a large group of PD patients. Unfortunately, during the data collection of the studies described in chapter 4,5 and 6 in this thesis the proposed diagnostic criteria were not yet available. Instead, different apathy rating scales were used to assess the presence of apathetic symptoms.

\section{Rating scales}

In this thesis the following apathy rating scales were used: the Lille Apathy Rating Scale (LARS) (Sockeel et al., 2006), the Apathy Evaluation Scale (AES) (Marin et al., 1991), the Neuropsychiatric Inventory (NPI) (J. L. Cummings, Mega, M., Gray, K., RosenbergThompson, S., Carusi, D.A., Gornbein, J., 1994) and the Apathy Inventory (AI) (P. H. Robert et al., 2002). All used rating scales are well-validated and reliable measures (Clarke et al., 2011). The rating scales used in PD (LARS, AES and NPI) all met the criteria for 'suggested scale' as classified by the Movement Disorder Society (MDS) task force (Leentjens et al., 2008). In chapter 3 strong correlations were found between the LARS and apathy item of the NPI with the clinical diagnostic criteria for apathy, which shows us that they measure a similar construct. Yet, overall reported prevalences of apathy when assessed by rating scales appear to be higher than when assessed with the clinical diagnostic criteria, at least for AD and PD (Mulin et al., 2011). This implies that prevalences of apathy rated with rating scales might be slightly overestimated. However, comparing frequencies of apathy remains rather difficult because of the use of different rating scales and cut-off scores, and the discrepancy between self-reports and caregiver-reports (McKinlay et al., 2008). Consensus about the use of rating scales is therefore highly recommended.

For the assessment of depressive symptoms in AD we used the Cornell Scale for Depression in Dementia (CSDD) and the NPI, both based on caregiver's reports and validated in dementia patients (Alexopoulos et al., 1988; Kat et al., 2002) . In PD we used the Hamilton Depression Rating Scale (HAMD) (Hamilton, 1960), which was recommended for screening and assessment of severity of depression in PD by the MDS (Schrag et al., 2007) and the NPI. The Snaith Hamilton Pleasure Scale (SHAPS) was used to assess anhedonia, as was suggested by the MDS (Leentjens et al., 2008). In the challenge studies of chapter 5 and 6 the Profile of Mood States Questionnaire (POMS) was used next to other measures of mood because of its capability to assess momen- 
tous mood states. This self-rated questionnaire has proved to be sensitive in challenge studies in PD before (Scholtissen et al., 2006). However, as assessment of mood disturbances in patients with neurodegenerative diseases is complicated, especially in demented patients, cautiousness is warranted. Nonetheless, a visual analog mood scale comparable to the POMS has been proved valid in patients with dementia (Temple et al., 2004).

\section{An ecological measure of apathy}

In the challenge studies described in chapter 5 and 6 of this thesis we implemented an experimental assessment method of a 15-minute systematic observation period in an ecological space. In appendix A this method is extensively described and discussed. As correlations of the current scoring system with existing rating scales such as the NPI, AES and LARS were low, further refining and the development of a valid and reliable scoring system is required. However, more objective assessment methods, such as systematic observation, perhaps in combination with ambulatory actigraphy (David et al., 2011), could add value above existing rating scales that might be biased by the subjective evaluation of the patient or caregiver.

\section{Challenge studies}

In chapter 5 and 6 the dopaminergic system was challenged to examine the role of dopamine on apathy, mood and cognition. A dopamine reuptake inhibitor (methylphenidate) and a D2/D3 agonist (pramipexole, only in PD) were used for this purpose. It is of importance to stress that the aim of our study was not to study treatment effects but to investigate the pathophysiology of apathy. From this perspective, an advantage of an acute challenge is the possibility to measure direct effects of instant neurotransmitter alterations on apathy, mood and cognition. However, this method also had some limitations. Because participants received a single dose we were not able to gradually increase in dose. Therefore we chose to use relatively low, but safe doses, to minimize possible side effects. Nevertheless, in chapter 6 , an acute challenge with pramipexole resulted in sedative effects and a decreased mood in both PD and control subjects. Methylphenidate was well tolerated in all participants. The relatively low dose of methylphenidate as well as the sedative effects of pramipexole might have suppressed positive results.

Furthermore, the participants were tested repeatedly as the challenge studies consisted of two (in AD) or three (in PD) testing days. This could have led to a learning effect. To minimize the risk of confounding learning effects we used a double blind, randomized, placebo-controlled design. 


\subsection{Clinical implications}

Our findings have several clinical implications. With our growing aging population, the number of people with AD or PD will increase in the next decades. This implicates more apathetic patients and an increase in caregiver burden. Since on the other hand capacity of professional care will decrease, it is important that quality of life of both patients and caregivers is maintained. Caregiver burden should be minimized, while at the same time patients should be able to stay in their own homes as long as possible. Therefore clinicians should be more aware of apathy, especially in an early phase of cognitive deterioration, as our results from chapter 5 show, it could be an early sign of $A D$, or may herald cognitive decline in PD (Dujardin et al., 2009). This can be achieved by embedding the use of clinical diagnostic criteria and apathy rating scales in clinical practice. Special attention should be given to the differentiation of apathy and depression, especially because of the important clinical consequences. Depression can be treated with antidepressants but in contrast, apathy can be worsened by the use of antidepressants (Wongpakaran et al., 2007). In addition, we advise to provide good caregiver information and support. Educating patients and caregivers plays an important role in understanding and acceptation of the problem as caregivers may misattribute the pathological loss of drive to laziness (Landes et al., 2001) or depression. Prior research demonstrated that deterioration of relationship quality is specifically associated with apathy (de Vugt et al., 2003). At this moment there is still insufficient evidence for any pharmacological treatment of apathy. Hence, the focus should be on non-pharmacological interventions, such as live music therapy or activity therapy (Holmes et al., 2006; Politis et al., 2004; Raglio et al., 2010). However, as evidence of these therapies is limited as well (Verkaik et al., 2005), additional research into both pharmacological interventions and psychosocial therapies is required.

\subsection{Further research}

Based on our findings, some recommendations for further research can be given.

First of all, since diagnostic criteria to diagnose apathy are clinically important, these should be further validated in a large group of AD patients, as well as in other neurodegenerative and psychiatric diseases, taking dementia severity into account (Mulin et al., 2011). The proposed diagnostic criteria have so far not been validated specifically in AD. Inclusion of such criteria as 'criteria for further research' in official classification systems such as the DSM or ICD would facilitate international acceptance and promote their use in both clinical practice and scientific research. Consensus about preferential rating scales and agreement on cut-off points in specified populations would be an advantage as well, especially for scientific research, as at the moment 
different rating scales and different cut-off points are used, making it hard to compare results across studies.

Another challenge for future research is the development of more objective measures of apathy. Alternative assessment methods such as ambulatory actigraphy (although probably not suitable for PD patients with a tremor) and systematic observation would be interesting to further investigate and refine, as it could be a valuable approach to monitor spontaneous behaviour.

Our most important task is to improve the quality of life for patients and their relatives. However, the impact of apathy for those affected is often hard to measure, especially in demented patients, and warrants further research. To pave the way for better treatment options it is important to study underlying biological mechanisms and get more insight into the pathophysiology of apathy. The challenge studies in this thesis suggest a role of the dopaminergic system, which needs further investigation. Methylphenidate showed promising results from both our systematic review as challenge studies. However, other neurotransmitter systems should be further examined as well, as e.g. the role of cholinesterase inhibitors in apathy is still inconclusive. To increase insight in the neuropathology of apathy, which hopefully will lead to effective treatment options, more high quality randomized controlled trials, with apathy as a primary outcome measure, are needed. Besides pharmacological treatment options also nonpharmacological interventions lack evidence and therefore should be addressed in future studies.

\subsection{Conclusion}

With this thesis we contributed to the increasing knowledge on the assessment, neuropathology and treatment of apathy in AD and PD. We found the recently proposed diagnostic criteria for apathy valid for PD patients. We showed that one should be aware of apathy in the early phases of cognitive impairment, as it could be an early sign of $A D$. Furthermore, our results suggested a role for the dopaminergic system in apathy in $A D$ and PD. However, as we noted before, apathy remains a complex issue with still many questions to be answered. As there is no effective treatment for apathy at the moment, the most important challenge for further research is unravelling the neuropathology of apathy. Hopefully this will lead to effective treatment options and a better quality of life of both patients and caregivers. 


\section{References}

Aalten, P., Verhey, F. R., Boziki, M., Bullock, R., Byrne, E. J., Camus, V., et al. (2007). Neuropsychiatric Syndromes in Dementia; Results from the European Alzheimer Disease Consortium: Part I. Dementia and Geriatric Cognitive Disorders, 24(6), 457-463.

Alexopoulos, G. S., Abrams, R. C., Young, R. C., \& Shamoian, C. A. (1988). Cornell Scale for Depression in Dementia. Biological Psychiatry, 23(3), 271-284.

American Psychiatric Association. (1994). Diagnostic and statistical manual of mental disorders, 4th Edn. Washington, DC: American Psychiatric Press.

Barone, P., Antonini, A., Colosimo, C., Marconi, R., Morgante, L., Avarello, T., et al. (2009). The PRIAMO study: a multicenter assessment of nonmotor symptoms and their impact on quality of life in Parkinson's disease. Movement Disorders, 24(11), 1641-1649.

Butterfield, L. C., Cimino, C. R., Oelke, L. E., Hauser, R. A., \& Sanchez-Ramos, J. (2010). The Independent Influence of Apathy and Depression on Cognitive Functioning in Parkinson's Disease. Neuropsychology, 24(6), 721-730.

Chase, T. N. (2011). Apathy in Neuropsychiatric Disease: Diagnosis, Pathophysiology and Treatment. Neurotoxicity Research, 19(2), 266-278.

Clarke, D. E., Ko, J. Y., Kuhl, E. A., van Reekum, R., Salvador, R., \& Marin, R. S. (2011). Are the available apathy measures reliable and valid? A review of the psychometric evidence. Journal of Psychosomatic Research, 70(1), 73-97.

Cummings, J. L., \& Back, C. (1998). The cholinergic hypothesis of neuropsychiatric symptoms in Alzheimer's disease. American Journal of Geriatric Psychiatry, 6(2 suppl 1), S64-78.

Cummings, J. L., Mega, M., Gray, K., Rosenberg-Thompson, S., Carusi, D.A., Gornbein, J. (1994). The Neuropsychiatric Inventory: Comprehensive assessment of psychopathology in dementia. Neurology, 44(12), 2308-2314.

David, R., Koulibaly, M., Benoit, M., Garcia, R., Caci, H., Carcourt, J., et al. (2008). Stratial dopamine transporter levels correlate with apathy in neurodegenerative diseases A SPECT study with partial volume effect correlation. Clinical Neurology and Neurosurgery, 110(1), 19-24.

David, R., Mulin, E., Friedman, L., Le Duff, F., Cygankiewicz, E., Deschaux, O., et al. (2011). Decreased Daytime Motor Activity Associated With Apathy in Alzheimer Disease: An Actigraphy Study. American Journal of Geriatric Psychiatry, Epub ahead of print.

De Rijk, M. C., Rocca, W. A., Anderson, D. W., Melcon, M. O., Breteler, M. M. B., \& Maraganore, D. M. (1997). A population perspective on diagnostic criteria for Parkinson's disease. Neurology, 48(5), 1277-1281.

de Vugt, M. E., Riedijk, S. R., Aalten, P., Tibben, A., van Swieten, J. C., \& Verhey, F. R. (2006). Impact of behavioural problems on spousal caregivers: a comparison between Alzheimer's disease and frontotemporal dementia. Dementia and Geriatric Cognitive Disorders, 22(1), 35-41.

de Vugt, M. E., Stevens, F., Aalten, P., Lousberg, R., Jaspers, N., Winkers, I., et al. (2003). Behavioural disturbances in dementia patients and quality of the marital relationship. International Journal of Geriatric Psychiatry, 18(2), 149-154.

Drijgers, R. L., Aalten, P., Winogrodzka, A., Verhey, F. R. J., \& Leentjens, A. F. G. (2009). Pharmacological treatment of apathy in neurodegenerative diseases: a systematic review. Dementia and Geriatric Cognitive Disorders, 28(1), 13-22.

Drijgers, R. L., Dujardin, K., Reijnders, J. S. A. M., Defebvre, L., \& Leentjens, A. F. G. (2010). Validation of diagnostic criteria for apathy in Parkinson's disease. Parkinsonism and Related Disorders., 16(10), 656-660.

Dujardin, K., Sockeel, P., Delliaux, M., Destee, A., \& Defebvre, L. (2009). Apathy may herald cognitive decline and dementia in Parkinson's disease. Movement Disorders, 15(16), 2391-2397.

Dujardin, K., Sockeel, P., Devos, D., Delliaux, M., Krystkowiak, P., Destee, A., et al. (2007). Characteristics of apathy in Parkinson's disease. Movement Disorders, 22(6), 778-784.

Hamilton, M. (1960). A rating scale for depression. Journal of Neurology, Neurosurgery and Psychiatry, 23, 5662. 
Holmes, C., Knights, A., Dean, C., Hodkinson, S., \& Hopkins, V. (2006). Keep music live: music and the alleviation of apathy in dementia subjects. International Psychogeriatrics, 18(4), 623-630.

Hughes, A. J., Daniel, S. E., Kilford, L., \& Lees, A. J. (1992). Accuracy of clinical diagnosis of ideopathic Parkinson's disease: a clinicopathological study of 100 cases. Journal of Neurology Neurosurgery and Psychiatry, 55(3), 181-184.

Isella, V., Melzi, P., Grimaldi, M., Iurlaro, S., Piolti, R., Ferrarese, C., et al. (2002). Clinical, neuropsychological, and morphometric correlates of apathy in Parkinson's disease. Movement Disorders, 17(2), 366-371.

Kat, M., de Jonghe, J., Aalten, P., Kalisvaart, C., Droes, R., \& Verhey, F. (2002). Neuropsychiatric symptoms of dementia: psychometric aspects of the Dutch Neuropsychiatric Inventory (NPI). Tijdschrift voor Gerontologie en Geriatrie, 33(4), 150-155.

Kirsch-Darrow, L., Marsiske, M., Okun, M. S., Bauer, R., \& Bowers, D. (2011). Apathy and Depression: Separate Factors in Parkinson's Disease. Journal of International Neuropsychological Society, 17(6), 1058-1066.

Kuzis, G., Sabe, L., Tiberti, C., Dorrego, F., \& Starkstein, S. E. (1999). Neuropsychological correlates of apathy and depression in patients with dementia. Neurology, 52(7), 1403-1407.

Landes, A. M., Sperry, S. D., Strauss, M. E., \& Geldmacher, D. S. (2001). Apathy in Alzheimer's disease. Journal of the American Geriatric Society, 49(12), 1700-1707.

Lavretsky, H., Ballmaier, M., Pham, D., Toga, A., \& Kumar, A. (2007). Neuroanatomical characteristics of geriatric apathy and depression: a magnetic resonance imaging study. American Journal of Geriatric Psychiatry, 15(5), 386-394.

Leentjens, A. F. G., Dujardin, K., Marsh, L., Martinez-Martin, P., Richard, I. H., Starkstein, S. E., et al. (2008). Apathy and anhedonia rating scales in Parkinson's disease: critique and recommendations. Movement Disorders, 23(14), 2004-2014.

Levy, R., \& Dubois, B. (2006). Apathy and the functional anatomy of the prefrontal cortex-basal ganglia circuits. Cerebral Cortex, 16(7), 916-928.

Lopez, O. L., Becker, J. T., Klunk, W., Saxton, J., Hamilton, R. L., Kaufer, D. I., et al. (2000). Research evaluation and diagnosis of probable Alzheimer's disease over the last two decades: I. Neurology, 55(12), 18541862.

Maas, D. W., van der Mast, R. C., \& de Craen, A. J. M. (2009). Increased C-reactive protein is not associated with apathy: the Leiden 85-Plus Study. International Journal of Geriatric Psychiatry, 24(11), 1177-1184.

Marin, R. S., Biedrzycki, R. C., \& Firinciogullari, S. (1991). Reliability and validity of the Apathy Evaluation Scale. Psychiatry Research, 38(2), 143-162.

Marshall, G., Fairbanks, L., Tekin, S., Vinters, H., \& Cummings, J. L. (2006). Neuropathologic correlates of apathy in Alzheimer's disease. Dementia and Geriatric Cognitive Disorders, 21(3), 144-147.

McKann, G., Drachman, D., Folstein, M., Katzman, R., Price, D., \& Dtadlan, E., M. (1984). Clinical diagnosis of Alzheimer's disease: report of the NINCDS-ADRDA Work Group under the auspices of Department of Health and Human Services Task Force on Alzheimer's Disease. Neurology, 34(7), 939-944.

McKinlay, A., Grace, R. C., Dalrymple-Alford, J. C., Anderson, T. J., Fink, J., \& Roger, D. (2008). Neuropsychiatric problems in Parkinson's disease: comparisons between self and caregiver report. Aging \& Mental Health, 12(5), 647-653.

Mitchell, R. A., Herrmann, N., \& Lanctôt, K. L. (2010). The role of dopamine in symptoms and treatment of apathy in Alzheimer's Disease. CNS Neuroscience and Therapeutics, 17(5), 411-427.

Mulin, E., Leone, E., Dujardin, K., Delliaux, M., Leentjens, A. F. G., Nobili, F., et al. (2011). Diagnostic criteria for apathy in clinical practice. International Journal Geriatric Psychiatry, 26(2), 158-165.

Politis, A. M., Vozzella, S., Mayer, L. S., Onyike, C. U., Baker, A. S., \& Lyketsos, C. G. (2004). A randomized, controlled, clinical trial of activity therapy for apathy in patients with dementia residing in long-term care. International Journal of Geriatric Psychiatry, 19(11), 1087-1094.

Raglio, A., Bellelli, G., Traficante, D., Gianotti, M., Ubezio, M. C., Gentile, S., et al. (2010). Effect of music therapy treatment based on cycles of sessions: a randomised controlled trial. Aging and Mental Health, 14(8), 900-904.

Reijnders, J. S. A. M., Ehrt, U., Weber, W. E. J., Aarsland, D., \& Leentjens, A. F. G. (2008). A systematic review of prevalence studies of depression in Parkinson's disease. Movement Disorders, 23(2), 183-189. 
Reijnders, J. S. A. M., Scholtissen, B., Weber, W. E. J., Aalten, P., Verhey, F. R. J., \& Leentjens, A. F. G. (2010). Neuroanatomical correlates of apathy in Parkinson's disease: a magnetic resonance imaging study using voxel-based morphometry. Movement Disorders, 25(14), 2318-2325.

Remy, P., Doder, M., Lees, A., Turjanski, N., \& Brooks, D. (2005). Depression in Parkinson's disease: loss of dopamine and noradrenaline innervation in the limbic system. Brain, 128(pt 6), 1314-1322.

Robert, P., Berr, C., Volteau, M., Bertogliati, C., Benoit, M., Sarazin, M., et al. (2006). Apathy in patients with mild cognitive impairment and the risk of developing dementia of Alzheimer's disease. A one-year followup study. Clinical Neurology and Neurosurgery, 108(8), 733-736.

Robert, P. H., Clairet, S., Benoit, M., Koutaich, J., Bertogliati, C., Tible, O., et al. (2002). The apathy inventory: assessment of apathy and awareness in Alzheimer's disease, Parkinson's disease and mild cognitive impairment. International Journal of Geriatric Psychiatry, 17(12), 1099-1105.

Robert, P. H., Onyike, C. U., Leentjens, A. F. G., Dujardin, K., Aalten, P., Starkstein, S. E., et al. (2009). Proposed diagnostic criteria for apathy in Alzheimer's disease and other neuropsychiatric disorders. European Psychiatry, 24(2), 98-104.

Scholtissen, B., Verhey, F. R., Adam, J. J., \& Leentjens, A. F. G. (2006). Challenging the serotonergic system in Parkinson's Disease patients: effects on cognition, memory, motor performance and mood. Clinical Neuropharmacology, 29(5), 276-285.

Schrag, A., Barone, P., Brown, R. G., Leentjens, A. F. G., McDonald, W. M., Starkstein, S. E., et al. (2007). Depression Rating Scales in Parkinson's Disease: Critique and Recommendations. Movement Disorders, 22(8), 1077-1092.

Sockeel, P., Dujardin, K., Devos, D., Deneve, C., Destee, A., \& Defebvre, L. (2006). The Lille apathy rating scale (LARS), a new instrument for detecting and quantifying apathy: validation in Parkinson's disease. Journal of Neurology, Neurosurgery and Psychiatry, 77(5), 579-584.

Starkstein, S. E., Jorge, R., Mizrahi, R., \& Robinson, R. G. (2006). A prospective longitudinal study of apathy in Alzheimer's disease. Journal of Neurology Neurosurgery and Psychiatry, 77(1), 8-11.

Tagariello, P., Girardi, P., \& Amore, M. (2009). Depression and apathy in dementia: Same syndrome or different constructs: a critical review. Archives of Gerontology and Geriatrics, 49(2), 246-249.

Temple, R. O., Stern, R. A., Latham, J., Ruffolo, J. S., Arruda, J. E., \& Tremont, G. (2004). Assessment of Mood State in Dementia by Use of the Visual Analog Mood Scales (VAMS). American Journal of Geriatric Psychiatry, 12(5), 527-530.

van der Mast, R. C., Vinkers, D. J., Stek, M. L., Bek, M. C., Westendorp, R. G. J., Gussekloo, J., et al. (2008). Vascular disease and apathy in old age. The Leiden 85-Plus Study. International Journal of Geriatric Psychiatry, 23(3), 266-271.

van Reekum, R., Stuss, D. T., \& Ostrander, L. (2005). Apathy: why care? Journal of Neuropsychiatry and Clinical Neurosciences, 17(1), 7-19.

Varanese, S., Perfetti, B., Ghilardi, M. F., \& Di Rocco, A. (2011). Apathy, but not depression, reflects inefficient cognitive strategies in Parkinson's Disease. Plos One, 6(3), e17846.

Verkaik, R., van Weert, J. C. M., \& Francke, A. L. (2005). The effects of psychosocial methods on depressed, aggressive and apathetic behaviors of people with dementia: a systematic review. International Journal of Geriatric Psychiatry, 20(4), 301-314.

Vicini Chilovi, B., Conti, M., Zanetti, M., Mazzu, I., Rozzini, L., \& Padovani, A. (2009). Differential impact of apathy and depression in the development of dementia in mild cognitive impairment patients. Dementia Geriatric Cognitive Disorders, 27(4), 390-398.

Winograd-Gurvich, C., Fitzgerald, P. B., Georgiou-Karistianis, N., Bradshaw, J. L., \& White, O. B. (2006). Negative symptoms: A review of schizophrenia, melancholic depression and Parkinson's disease. Brain Research Bulletin, 70(4-6), 312-321.

Wongpakaran, N., van Reekum, R., Wongpakaran, T., \& Clarke, D. (2007). Selective serotonin reuptake inhibitors associates with apathy among depressed elderly: a case-control study. Annals of General Psychiatry, 6,7 . 


\section{APPENDIX}

Systematic observation of apathy: the use of an ecological space 


\section{Introduction}

Apathy is one of the most common neuropsychiatric symptoms in dementia and other neurodegenerative diseases, such as Parkinson's disease (PD). It is defined as a disorder of motivation with a reduction in goal-directed behaviour, goal-directed cognitive activity and emotions (Robert et al., 2009). Apathy has a major impact on the quality of life of patients and caregivers (van Reekum et al., 2005).

The common method to assess apathy is through a structured interview and the use specific rating scales. Diagnostic criteria are recently proposed, but not yet structurally applied. Various rating scales are used, such as the Neuropsychiatric Inventory (NPI) (Cummings, 1994), the Apathy Evaluation Scale (AES) (Marin et al., 1991), the Apathy Inventory (IA) (Robert et al., 2002) and the Lille Apathy Rating Scale (LARS) (Sockeel et al., 2006). Recently, Clarke and colleagues evaluated the most frequently used apathy measures and concluded that the most psychometrically robust and widely used measures for assessing apathy are the AES and NPI (Clarke et al., 2011).

Nevertheless, questionnaires could be biased by the subjective evaluation of the patient or caregiver. Therefore, systematic observation is probably the best way to examine novelty seeking and spontaneous behaviour. This type of observation is common in the fields of mental handicap and child-psychiatric settings, but has been used to a much lesser extent in adult or geriatric psychiatry (Bowie \& Mountain, 1993). Most studies observing demented patients focus on the quality of life in nursing homes (Brooker, 1995). The observational methods used in these studies are mainly designed to measure aggressive or agitated behaviour in dementia patients (Cohen-Mansfield \& Libin, 2004). Little is known about the use of observation of apathetic behaviour. To improve the care and management of apathy, reliable assessment of apathy is very important. In this appendix we describe and discuss the method of a 15-minute observation period of spontaneous behaviour in an experimental ecological space, which was implemented in the studies described in chapter 5 and 6 of this thesis.

\section{Observation procedure}

Twelve AD patients, 23 PD patients and 23 healthy control subjects underwent a 15-minute observation period in an ecological space (for a detail subject description see the method section of chapter 5 and 6). This space consisted of an examination room of about $6 \mathrm{~m} 2$ in which different objects were placed on a table, such as a radio, various books and magazines, a newspaper, different puzzles and games, a bottle of water and a cookie jar. Before the observation period, in which the participants were left alone by the researcher, participants were told that they could use all objects available in the room. The observation was recorded by camera and videotaped, of which the participants were informed about and consented in advance. 
For 15 minutes the researcher continuously monitored the behaviour of the participant by video camera. Active time and newly initiated behaviour were systematically scored. Besides that, the participant's state, initiation and attention level were captured within 6 items that were partly developed from the Dutch version of the Bayley Scales of Infant Development, Second Edition (BSID-II-NL) (Bayley, 1993) and were based on the contents of the diagnostic criteria of apathy (Robert et al., 2009) (see observation form). Each item was scored on a 5-point Likert scale. Lower scores indicated more apathetic behaviour.

\section{Outcome}

In a post-hoc analysis, spearman correlations were calculated between the 6 items of the observation form, total active time, number of used objects and scores of the following apathy rating scales: Lille Apathy Rating Scale (LARS), Apathy Evaluation Scale (AES) and apathy item of the Neuropsychiatric Inventory (NPI) (Cummings, 1994; Marin et al., 1991; Sockeel et al., 2006). Although the items had good face validity, concurrent validity between the observation items, active time, number of used objects, and the existing apathy scales was low. A moderate correlation was found between the total score of the 6 observation items and the total active time ( $r$ o $=0.50, p<0.001$ ).

\section{Discussion}

Apathy is usually assessed by specific rating scales, using information from either the patient or the caregiver. However, as apathetic patients often have a lack of insight and caregivers are biased as well, the objectivity and reliability of these rating scales are questionable. Therefore, other, more objective methods to measure novelty seeking and spontaneous behaviour require attention. In the studies described in chapter 5 and 6 a systematic observation of 15 minutes in an ecological space was implemented to monitor apathy in AD, PD and healthy control subjects. To our knowledge such an experimental approach to assess apathy was never used before.

Besides the existing rating scales, in previous research only ambulatory actigraphy and its relationship with apathy was examined as an alternative and objective assessment method (David et al., 2010; Mulin et al., 2011; Muller et al., 2006). These studies, including patients with acquired brain damage and patients with mild $A D$, concluded that apathetic patients had lower daytime activity than non-apathetic patients. Furthermore, another potential method might be momentary assessment. This method, as it is already used in psychosis research with a new prototype device, may attribute to our knowledge of apathetic behaviour at home and identify certain 
symptom patterns (Myin-Germeys et al., 2011). However its applicability in apathetic patients has not have been examined yet.

A major advantage of systematic observation is to overcome the discrepancy between what people say and what they actually do, especially in patients with dementia. Moreover, it uncovers routines or behaviour of which the participants themselves may be unaware (Mays \& Pope, 1995). Furthermore, as observation at home can be quite intensive and interruptive of daily live, in the current experiment the observation, which took place in a clinical setting, was limited to 15 minutes. This approach is less burdensome, less time consuming and rather easy to implement e.g. in addition to neuropsychological testing. The participants who underwent the observation confirmed that they experienced the observation period, which followed on a neuropsychological examination, as little stressful and burdensome. Nevertheless, as described above, only total active time showed a correlation with the 6 items of the observation list, and no correlations were found with the other apathy assessment scales. This might indicate that the short observation list is not usable or sensitive as a surrogate marker of the observed behaviour, or it must be concluded that the 15-minute observation was not a valid tool for assessing apathy. Observation in such an experimental setting as described here has also some limitations. First of all, the situation and setting will never be the same as home. Besides that, because of ethical reasons participants were told in advance that they were being watched and videotaped. An unfamiliar surrounding and the knowledge of having a researcher observing actions may stimulate modifications in behaviour or action, e.g. people act more active than they would act at home. Furthermore, the diagnostic criteria for apathy divide behaviour in initiating behaviour and responsive behaviour (Robert et al., 2009). Systematic observation by video camera, while the participant is alone, measures only initiating behaviour and is not suitable to measure responsiveness. In addition, for the same reason, it is not possible to properly capture the sub domain emotion with this method of observation.

Concluding, objective measures to assess apathy could add value to the existing rating scales and therefore require more attention. A 15-minute systematic observation period in an ecological space as described in this appendix might be a valuable measure of spontaneous behaviour, especially for subjects in which existing rating scales are little reliable, such as demented patients. Future research should focus on refining and validation of a scoring system of the observation. Furthermore, combining systematic observation with actigraphy might strengthen the objective assessment of apathy. 


\title{
Observation form of spontaneous behaviour
}

\author{
Patient number: \\ Observed by: \\ Date: \\ Time of observation: from..............hour, till...............hour \\ Before or after the challenge: before / after
}

\section{Observations}

1. Degree of alertness

Score

- Drowsy or asleep all the time 1

- Drowsy most of the time; a few alert moments 2

- Half of the time drowsy and half of the time awake and alert 3

- Awake and alert most of the time, and some sleepy moments 4

- Awake and alert all the time $\quad 5$

Comments:

- Constant lack of vivacity and energy, tired and listless 1

- Tired and listless most of the time, one or two periods of vivification and energy 2

- Lively and energetic half of the time and tired and listless the other half of the time 3

- Lively and energetic most of the time, 1 or 2 periods of tiredness and listlessness 4

- Lively and energetic all the time

Comments: 


\section{Taking initiative}

Score

- Shows no initiative all the time 1

- Shows no initiative most of the time; one or two moments of initiation 2

- Shows initiative half of the time 3

- Shows initiative most of the time; one or two moments without initiation 4

- Shows initiative all the time 5

Comments:

4. Exploration of objects and/or setting

Score

- No exploration $\quad 1$

- One or two moments of exploration 2

- Average exploration 3

- Extensive exploration $\quad 4$

- Continuous exploration $\quad 5$

Comments:

\section{Attention to stimuli}

Score

- Distracted all the time, pays no attention to stimuli 1

- Distracted most of the time; pays attention once or twice 2

- Distracted half of the time 3

- Pays attention most of the time; distracted once or twice 4

- Pays attention to stimuli all the time 5

Comments: 
- Shows no persistence all the time 1

- Shows no persistence most of the time; one or two moments of persistence 2

- Shows no persistence half of the time 3

- Persistent most of the time; one or two moments without persistence 4

- Shows persistence all the time $\quad 5$

\section{Comments:}

\section{Total}

score.

Active time:.............................minutes
Inactive time:..........................minutes
Number of different activities/ used objects:.

Other details during observation 


\section{References}

Bayley, N. (1993). Manual for the Bayley Scales of Infant Development (2nd ed). San Antonio, TX: The Psychology Corporation.

Bowie, P., \& Mountain, G. (1993). Using direct observation to record the behaviour of long-stay patients with dementia. International Journal of Geriatric Psychiatry, 8(10), 857-864.

Brooker, D. (1995). Looking at them, looking at me: a review of observational studies into the quality of institutional care for elderly people with dementia. Journal of Mental Health, 4(2), 145-156.

Clarke, D. E., Ko, J. Y., Kuhl, E. A., van Reekum, R., Salvador, R., \& Marin, R. S. (2011). Are the available apathy measures reliable and valid? A review of the psychometric evidence. Journal of Psychosomatic Research, 70(1), 73-97.

Cohen-Mansfield, J., \& Libin, A. (2004). Assessment of agitation in elderly patients with dementia: correlation between informant rating and direct observation. International Journal Geriatric Psychiatry, 19(9), 881891.

Cummings, J. L., Mega, M., Gray, K., Rosenberg-Thompson, S., Carusi, D.A., Gornbein, J. (1994). The Neuropsychiatric Inventory: Comprehensive assessment of psychopathology in dementia. Neurology, 44(12), 2308-2314.

David, R., Rivet, A., Robert, P. H., Mailland, V., Friedman, L., Zeitser, J. M., et al. (2010). Ambulatory actigraphy correlates with apathy in mild Alzheimer's disease. Dementia, 9(4), 509-516.

Marin, R. S., Biedrzycki, R. C., \& Firinciogullari, S. (1991). Reliability and validity of the Apathy Evaluation Scale. Psychiatry Research, 38(2), 143-162.

Mays, N., \& Pope, C. (1995). Observational methods in health care settings. British Medical Journal, 311(6998), 182-184.

Mulin, E., Zeitser, J. M., Friedman, L., Le Duff, F., Yesavage, J., Robert, P. H., et al. (2011). Relationship between apathy and sleep disturbance in mild and moderate Alzheimer's disease: an actigraphic study. Journal of Alzheimer's Disease, 25(1), 85-91.

Muller, U., Czymmek, J., Thone-Otto, A., \& Von Cramon, D. (2006). Reduced daytime activity in patients with acquired brain damage and apathy: a study with ambulatory actigraphy. Brain Injury, 20(2), 157-160.

Myin-Germeys, I., Birchwood, M., \& Kwapil, T. (2011). From Environment to Therapy in Psychosis: A RealWorld Momentary Assessment Approach. Schizophrenia Bulletin, 37(2), 244-247.

Robert, P. H., Clairet, S., Benoit, M., Koutaich, J., Bertogliati, C., Tible, O., et al. (2002). The apathy inventory: assessment of apathy and awareness in Alzheimer's disease, Parkinson's disease and mild cognitive impairment. International Journal of Geriatric Psychiatry, 17(12), 1099-1105.

Robert, P. H., Onyike, C. U., Leentjens, A. F. G., Dujardin, K., Aalten, P., Starkstein, S. E., et al. (2009). Proposed diagnostic criteria for apathy in Alzheimer's disease and other neuropsychiatric disorders. European Psychiatry, 24(2), 98-104.

Sockeel, P., Dujardin, K., Devos, D., Deneve, C., Destee, A., \& Defebvre, L. (2006). The Lille apathy rating scale (LARS), a new instrument for detecting and quantifying apathy: validation in Parkinson's disease. Journal of Neurology, Neurosurgery and Psychiatry, 77(5), 579-584.

van Reekum, R., Stuss, D. T., \& Ostrander, L. (2005). Apathy: why care? Journal of Neuropsychiatry and Clinical Neurosciences, 17(1), 7-19. 


\section{Summary}

The research described in this thesis focuses on apathy in patients with Alzheimer's disease $(A D)$ and patients with Parkinson's disease (PD). Apathy is characterized by a lack of motivation, loss of initiative and in a flattening of emotions. It is one of the most prevalent and burdensome neuropsychiatric symptoms in neurodegenerative diseases that has a major impact on every day functioning and causes a decreased quality of life of both patient and caregiver. Nevertheless, the etiology of apathy remains poorly understood and no treatment is available yet.

Therefore, the aim of the research described in this thesis is to give more insight in the assessment, pathophysiology and treatment of apathy.

The main research questions are formulated as follows:

- Are the clinical diagnostic criteria for apathy valid compared to existing apathy assessments?

- What are the neuropsychological correlates of apathy?

- What is the role of the dopaminergic system in apathy?

- What is the evidence base for pharmacological treatment of apathy?

In chapter 2 an overview of the evolution of the concept of apathy is presented. There is convincing evidence that apathy should not be seen just as a symptom but as a syndrome. Apathy is a construct that consists of several aspects that occur in various diseases. It may occur as part of or independent of depressive disorder or cognitive decline. Over the years, the concept of apathy has been changed and adjusted till recently a consensus of diagnostic criteria for apathy as a syndrome has been published.

Subsequently, in chapter 3, a validation study of the clinical diagnostic criteria for apathy in PD is described. In this cross-sectional study, 122 outpatients with PD visited a movement disorders clinic and underwent a protocolized examination of motor functions, autonomy (ADL function), cognition and mood. Furthermore, the diagnostic criteria for apathy were evaluated on the basis of an interview and two rating scales for apathy were assessed; the Lille Apathy Rating Scale (LARS) and the Neuropsychiatric Inventory (NPI). The results showed that $17.2 \%$ of the included PD patients were diagnosed as apathetic according to the diagnostic criteria. Acceptability and internal 
consistency of the criteria were good, just as the convergent validity with the LARS and part of the NPI apathy. Discriminant validity of the criteria with depression was moderate. All domains of criterion B (behaviour, cognition, emotion) contributed to the diagnosis of apathy, of which "reduced goal-directed behaviour" was most frequently observed. We concluded that the recently proposed diagnostic criteria for apathy are useful for clinical practice and research with non-demented patients with PD.

Chapter 4 describes a study of the neuropsychological correlates of apathy in patients with mild cognitive impairment $(\mathrm{MCl})$ and $A D$. Four hundred and thirty-eight patients of the memory clinic of the Maastricht University Medical Centre were included, of which 260 were patients with $\mathrm{MCl}$ and 178 patients with AD. All these patients received a comprehensive neuropsychological assessment. Apathy was assessed using the NPI. The results showed that in the early stages of cognitive decline apathy was associated with executive dysfunction, particularly poor initiating, and impaired psychomotor tracking, but not in AD. Probably in a later stage of cognitive decline associations between apathy and neuropsychological correlates may be overshadowed by severe neuropathology. Awareness of apathy in the early stages of cognitive decline could help in early diagnosis of $A D$.

Chapter 5 describes a study on the relationship between dopaminergic mechanisms and apathy, mood and cognition. In a randomized, double-blind, placebo controlled cross-over design the effect of an acute challenge with methylphenidate on measures of apathy, mood and cognition was examined in 12 patients with AD. A trend was shown for improvement of mental speed after challenge with methylphenidate compared to placebo. Furthermore, observed differences on apathy, anger, vigour, initiative and reaction time showed a larger but non-significant improvement after challenge with methylphenidate than placebo. The study suggests that dopamine may be involved in the genesis of motivational deficits in AD. Further investigations into the dopaminergic mechanisms of motivation, mood and cognitive symptoms in AD, as well as into the clinical value of methylphenidate is needed, to provide more evidence base for potential treatment options, with the aim of improving quality of life of both patients as caregivers.

In chapter 6 a study on the role of the dopaminergic system on mood, motivation and cognition in patients with Parkinson's disease is described. Twenty-three PD patients and 23 age, education and sex matched healthy control subject underwent a direct and indirect acute challenge with pramipexole, methylphenidate and a placebo. Different measures on mood, motivation, executive functioning and mental speed were administered before and after the challenge. Methylphenidate but not pramipexole had a positive effect on anhedonia and vigour in PD patients. Pramipexole appeared not suited for an acute challenge because of a sedative effect, which might overshadow possible positive effects. No effects on cognition were observed after a direct and indirect dopaminergic challenge. The acute effects of a methylphenidate challenge on 
anhedonia and vigour in PD patients makes this drug an interesting choice for further studies of the treatment of mood and motivational disorders in PD patients.

In chapter 7 a systematic literature review of studies on the pharmacological treatment of apathy in neurodegenerative diseases is described. Thirty-five studies were included: two meta-analysis, 13 RCTs, 14 open-label studies and six case studies. In eight studies apathy was included as primary outcome measure. Twenty-four studies investigated a cholinesterase inhibitor, 5 studies were on methylphenidate and in 6 studies other medications were examined. The study showed that although some medications (e.g. methyphenidate and cholinesterase inhibitors) are promising candidates for further investigation, so far there is insufficient evidence for pharmacological treatment to improve symptoms of apathy. More large placebo-controlled studies with apathy as a primary outcome measure are needed to determine the potential benefit of pharmacological treatment on apathy.

In chapter 8 the results in this thesis are discussed on the basis of the research goals in chapter 1 . In addition, methodological issues and clinical implications of the findings are discussed. Finally, recommendations for future research are given. 



\section{Samenvatting}

Het onderzoek beschreven in dit proefschrift richt zich op apathie bij patiënten met de ziekte van Alzheimer (ZvA) en patiënten met de ziekte van Parkinson (ZvP). Apathie wordt gekenmerkt door een gebrek aan motivatie, verminderde initiatiefname en een afvlakking van emoties. Apathie is een van de meest voorkomende en belastende neuropsychiatrische symptomen in neurodegeneratieve ziektebeelden en leidt tot een verminderde kwaliteit van leven, meer beperkingen en een verminderde kwaliteit van leven voor zowel de patiënt als de mantelzorger. Desondanks is er nog weinig bekend over de etiologie van apathie en is er nog geen behandeling voor handen.

Het doel van het onderzoek dat beschreven staat in dit proefschrift is meer inzicht te geven in het meten, de pathofysiologie en de behandeling van apathie.

De belangrijkste onderzoeksvragen kunnen als volgt worden geformuleerd:

- Zijn de diagnostische criteria voor apathie valide in vergelijking met bestaande meetinstrumenten?

- Wat zijn de neuropsychologische correlaten van apathie?

- Welke rol speelt het dopaminerge systeem in apathie?

- Welk bewijs is er voor farmacologische behandeling van apathie?

In hoofdstuk 2 wordt een overzicht gegeven van de ontwikkeling van het concept apathie. Er zijn aanwijzingen dat apathie niet als symptoom, maar als syndroom moet worden gezien. Apathie is een construct dat uit meerdere aspecten bestaat en bij verschillende aandoeningen kan voorkomen. Het beeld kan voorkomen als onderdeel van of onafhankelijk van depressieve stoornissen of cognitieve achteruitgang. Door de jaren heen is het concept van apathie veranderd en aangepast tot recentelijk een consensus van diagnostische criteria voor het syndroom apathie zijn voorgesteld.

Aansluitend hierop wordt in hoofdstuk 3 een validatiestudie van de voorgestelde diagnostische criteria voor apathie bij de ZvP beschreven. In deze cross-sectionele studie, bezochten 122 poliklinische patiënten met de ZvP een bewegingsstoornissenpoli en ondergingen een geprotocolleerd onderzoek van de motorische functies, zelfredzaamheid (ADL functies), cognitie en stemming. Bovendien werden de diagnostische criteria voor apathie aan de hand van een interview beoordeeld en twee apathie beoordelingsschalen afgenomen; de Lille Apathy Rating Scale (LARS) en de 
Neuropsychiatric Inventory (NPI). De resultaten lieten zien dat $17,2 \%$ van de geïncludeerde patiënten met de ZvP werden gediagnosticeerd als apathisch volgens de criteria. Aanvaardbaarheid en de interne consistentie van de criteria waren goed, net als de convergente validiteit met de LARS en apathie gedeelte van de NPI. Discriminante validiteit van de criteria met depressie was matig. Alle domeinen van criterium B (gedrag, cognitie, emotie) droegen bij tot de diagnose van apathie, waarvan 'verminderd doelgericht gedrag' het meest frequent werd waargenomen. We concludeerden dat de onlangs voorgestelde diagnostische criteria voor apathie nuttig zijn voor gebruik in de klinische praktijk en voor onderzoek met niet-demente patiënten met de ZvP.

Hoofdstuk 4 beschrijft een onderzoek naar de neuropsychologische correlaten van apathie in patiënten met Mild Cognitive Impairment $(\mathrm{MCl})$ en de ziekte van Alzheimer (ZvA). Vierhonderdachtendertig patiënten van de geheugenpoli van het academisch ziekenhuis Maastricht werden geïncludeerd, waarvan 260 patiënten met de ZvA en 178 $\mathrm{MCl}$ patiënten. Al deze patiënten kregen een uitgebreid neuropsychologisch onderzoek. Apathie werd gemeten met de NPI. De resultaten toonde aan dat in de beginfase van cognitieve achteruitgang, maar niet in dementie, apathie samengaat met executief disfunctioneren en een verminderde psychomotoriek. Waarschijnlijk worden in een latere fase van cognitieve achteruitgang associaties tussen apathie en neuropsychologische correlaten overschaduwd door ernstigere neuropathologie. Bewustwording van apathie in de vroege fase van cognitieve achteruitgang zou kunnen helpen in de vroegdiagnostiek van de ZvA.

In hoofdstuk 5 wordt een onderzoek naar de relatie tussen dopaminerge mechanismen en apathie, stemming en cognitie beschreven. In een gerandomiseerd, dubbelblind, placebo-gecontroleerd cross-over design werd het effect van een acute challenge met methylfenidaat op apathie, stemming en cognitie onderzocht in 12 patiënten met de ZvA. Een trend werd aangetoond voor verbetering van mentale snelheid na de challenge met methylfenidaat in vergelijking met placebo. Bovendien lieten geobserveerde verschillen op maten van apathie, woede, het gevoel van kracht, initiatiefname en reactietijd een grotere, maar niet-significante verbetering zien na een challenge met methylfenidaat in vergelijking met placebo. De studie suggereert dat dopamine een rol zou kunnen spelen in het ontstaan van motivationele tekorten in de ZvA. Meer studies naar de dopaminerge mechanismen van motivatie, stemming en cognitieve symptomen bij de ZvA zijn nodig. Tevens is het nodig de klinische waarde van methylfenidaat verder te onderzoeken om meer potentiële behandelopties te kunnen bieden, en de kwaliteit van leven van zowel patiënten als mantelzorgers te vergroten.

In hoofdstuk 6 wordt een studie naar de rol van het dopaminerge systeem op stemming, motivatie en cognitie bij patiënten met de ziekte van Parkinson beschreven. Drieëntwintig patiënten met de ZvP en 23 leeftijd, opleiding en geslacht gekoppelde gezonde controles ondergingen een directe en indirecte acute challenge met 
pramipexol, methylfenidaat en een placebo. Verschillende maten voor stemming, motivatie, executief functioneren en mentale snelheid werden afgenomen voor en na de challenges. Methylfenidaat, maar niet pramipexol, had een positief effect op anhedonie en het gevoel van kracht in patiënten met de ZvP. Pramipexol bleek niet geschikt voor een acute challenge vanwege een versuffend effect, dat mogelijke positieve effecten zou kunnen overschaduwen. Er werden geen effecten op cognitie waargenomen na een directe en indirecte dopaminerge challenge. Vanwege de acute effecten van de methylfenidaat challenge op anhedonie en het gevoel van kracht in patiënten met de ZvP zou dit middel een interessante keuze kunnen zijn voor verder onderzoek van behandeling van stemmings- en motivationele stoornissen bij patiënten met de ZvP.

In hoofdstuk 7 wordt een systematisch literatuuroverzicht gegeven van studies naar de farmacologische behandeling van apathie in neurodegeneratieve ziektebeelden. Vijfendertig studies werden geïncludeerd: 2 meta-analyses, 13 RCTs, 14 open-label studies, en 6 case studies. In 8 studies was apathie meegenomen als primaire uitkomstmaat. Een cholinesteraseremmer werd onderzocht in 24 studies, methylfenidaat in 5 en andere medicatie in 6 studies. Het overzicht laat zien dat, hoewel sommige medicijnen veelbelovende kandidaten zijn voor verder onderzoek, er tot nu toe onvoldoende bewijs is voor een bepaalde farmacologische behandeling. Meer grote, placebo-gecontroleerde studies met apathie als primaire uitkomstmaat zijn nodig om het voordeel van een farmacologische behandeling op apathie te bepalen.

In hoofdstuk 8 worden de resultaten beschreven in dit proefschrift nogmaals kort besproken aan de hand van de in hoofdstuk 1 gestelde onderzoeksdoelen. Daarnaast worden methodologische aspecten besproken en klinische implicaties van de bevindingen gegeven. Ten slotte worden er aanbevelingen voor toekomstig onderzoek gegeven. 



\section{Curriculum Vitae}

Rosa Drijgers werd geboren op 24 december 1982 te Middelburg. In 2001 behaalde zij haar gymnasiumdiploma aan de Stedelijke Scholengemeenschap Nehalennia in Middelburg. Hierna begon zij haar studie Psychologie aan de Universiteit Maastricht. Zij koos voor de afstudeerrichting Biologische Psychologie met als specialisatie Neuropsychologie. Tijdens haar studie heeft zij extra keuzevakken gevolgd aan de Universiteit van Lund (Zweden) en een praktijkstage gevolgd bij de geheugenpoli van het academisch ziekenhuis Maastricht. Haar onderzoeksstage vond plaats binnen de vakgroep Psychiatrie en Neuropsychologie van de Universiteit Maastricht, alwaar zij na het behalen van haar diploma in 2007 startte met haar promotieonderzoek. Het onderzoek uit deze periode is beschreven in dit proefschrift. Momenteel is zij als psycholoog werkzaam bij de Vitalis Behandelgroep in Eindhoven. Daarnaast is zij werkzaam als docent aan de Fontys Hogescholen in Eindhoven. 



\section{Publications}

- $\quad$ Drijgers, R.L., Aalten, P., Leentjens, A.F.G., Verhey, F.R.J. (2010). Apathy: from symptom to syndrome, Tijdschrift voor Psychiatrie, 52, 397-405.

- $\quad$ Drijgers, R.L. Dujardin, K., Reijnders, S.A.M., Defebvre, L., Leentjens, A.F.G. (2010). The validation of diagnostic criteria for apathy in Parkinson's disease, Movement disorders, 16, 656-60.

- Drijgers, R.L., Verhey, F.R.J., Leentjens, A.F.G., Köhler, S., Aalten, P. (2011). Neuropsychological correlates of apathy in mild cognitive impairment and Alzheimer's disease: the role of executive functioning, International Psychogeriatrics, 23, 1327-33.

- Drijgers, R.L., Verhey, F.R.J., Leentjens, A.F.G., Aalten, P. (2011). Methylphenidate and the pathogenesis of apathy in Alzheimer's disease: a randomized controlled trial. Submitted.

- Drijgers, R.L., Verhey, F.R.J., Aalten, P., Leentjens, A.F.G. (2012). Apathy and the role of the dopaminergic system in Parkinson's disease and Alzheimer's disease: an experimental approach. Journal of Neurological Sciences, 320, 121126.

- Drijgers, R.L., Aalten, P., Winogrodzka, A., Verhey, F.R.J., Leentjens, A.F.G. (2009). Pharmacological treatment of apathy in neurodegenerative diseases: a systematic review. Dementia and Geriatric Cognitive Disorders, 28, 13-22. 



\section{Dankwoord}

Onwerkelijk maar waar, het boekje is af! lets waar ik lang naar heb uitgekeken en enorm trots op ben, maar wat niet was gelukt zonder de hulp en steun van velen.

Allereerst wil ik alle deelnemers die hebben meegedaan aan mijn onderzoek hartelijk bedanken. Jullie hebben me laten zien waarvoor we het doen. Bedankt voor jullie inzet en de veelal interessante en warme contacten.

Mijn promotieteam; promotor Frans Verhey en co-promotores Albert Leentjens en Pauline Aalten. Beste Frans, bedankt voor de mogelijkheden die je me gegeven hebt, je betrokkenheid en alle leerzame gesprekken tijdens ons wekelijks uurtje overleg. Albert, bedankt voor je begeleiding, je snelle en gedegen commentaren op mijn stukken en de deur die altijd open stond. Pauline, ik ben je dankbaar voor de fijne begeleiding tijdens de afgelopen jaren, het vertrouwen dat je me gaf en de persoonlijke touch aan ons contact.

Ron, Nico, Elsa en Els, zonder jullie is iedereen verloren. Bedankt dat jullie altijd klaarstonden als het nodig was!

Beste collega's van het Riagg Maastricht, dank voor jullie gastvrijheid en jullie inzet.

Gerrit Tissingh, dank voor de hulp bij het includeren van Parkinson patiënten.

Laura, bedankt voor je enthousiasme en hulp met het onderzoek tijdens je stage!

Lieve Renée, Juliette, Ivo, Geert, Ine en mevrouw Johanna Swinkels-van Wekberg, bedankt voor jullie hulp met de voorkant en de lay-out van dit boekje. Het is erg mooi geworden, al zeg ik het zelf!

Inez en Lia, mijn twee paranimfen. Lieve Inez, van stagiairebegeleider, naar kamergenoot, naar dierbare collega en goede vriendin. Ik kan oprecht zeggen dat zonder jou dit boekje er niet gelegen had. Al het meedenken, je altijd enorme vertrouwen in mij, en niet te vergeten de gezelligheid en de vriendschap; ik ben blij dat je vandaag, naast figuurlijk, ook letterlijk achter me staat.

Lieve Lia, mijn klankbord, altijd beschikbaar voor de nodige relativering en natuurlijk het uitwisselen van de laatste nieuwtjes ;) Bedankt dat je zo'n goed vriendinnetje bent, en bedankt dat je vandaag mijn paranimf wil zijn! 
Het is dat je maar twee paranimfen mag hebben...

Lieve Jennifer, mijn Parkinsonmaatje en een van de allerliefste collega's die je maar kan wensen. Bedankt dat je er altijd was en bent om me te helpen, mee te denken, of gewoon even gezellig te kletsen! Lieve Deliane en Rosa, bedankt voor het delen van al het lief en leed op de werkvloer en daarbuiten!

Alle (oud) collega's van de afdeling Psychiatrie en Neuropsychologie en met name mijn mede Aio's: bedankt voor de fijne sfeer op de afdeling, alle gezellige lunches, feestjes en uitjes! Zonder jullie zou het werk lang zo leuk niet zijn geweest. In het bijzonder, lieve aio-meisjes, een mingle dag, pizza-meetings; samen met jullie vergaderen en organiseren was een verrijking en vooral enorm gezellig.

Lieve wijze meisjes uit het Oosten, wat hadden we het leuk daar in ons eigen hoekje! Jeroen, jammer genoeg maar twee jaar collega's geweest, maar gelukkig worden alle roddels nog regelmatig uitgewisseld. Bedankt voor je gezelligheid op de werkvloer en alle relaxatie borrels en etentjes!

Lieve collega's van de Vitalis Behandelgroep. Het afgelopen jaar hebben jullie van dichtbij de laatste loodjes mee mogen maken. Bedankt voor het meeleven en de kansen die jullie mij gegeven hebben. En natuurlijk ook bedankt voor de enorm gezellige en collegiale werksfeer!

Beste collega's van de Fontys Hogeschool. Sinds enkele maanden ben ik bij jullie werkzaam voor 1 dag in de week, iets wat me enorm goed bevalt. Ook jullie bedankt voor het bieden van zo'n leuke en leerzame werkplek en het meeleven met de afronding van mijn proefschrift!

Mijn lieve vrienden en vriendinnen, bedankt voor alle gezellige en ontspannende momenten samen. Alle etentjes, terrasjes, stapavondjes, wijntjes op de bank, carnavalszondagen... Bedankt voor jullie vriendschap!

Lief WIAN, lieve Mieke, Michelle, Sandra, Lia, Rosa, Fleur en Deliane. Al meer dan 10 jaar zijn jullie mijn uitlaatklep, mijn ontspanning, mijn 'tweede familie'. Meiden, alle goede gesprekken, geruststellende woorden, maar vooral ook de hilarische lachmomenten en andere welkome afleiding.... jullie zijn goud waard! Op naar het volgende lustrum!

En Mieke, mijn allerliefste (reis)maatje, bijna kunnen we ontspannen! Heb enorm veel zin om er samen met jou weer een topvakantie van te maken.

Lieve Rosalin, Kirsten en Ellen, mijn Zeeuwse vriendinnetjes. Onze vriendschap die al zo lang teruggaat is me enorm dierbaar. Ik hoop dat we nog veel mooie momenten met elkaar zullen beleven! 
Lieve oma, ondanks dat het je niet altijd meevalt om ouder te worden ben jij mijn voorbeeld van hoe het kan. Bedankt voor de fijne zondagse bezoekjes, onze gesprekken en je interesse in wat ik doe.

Lieve Eva, wat ben ik trots dat jij mijn zus bent! Dat we nog maar veel leuke zussendingen mogen doen samen.

Lieve papa en mama, bedankt voor het altijd meeleven en meedenken met mij, het luisterend oor en jullie oprechte interesse in wat ik doe. Maar bovenal bedankt voor jullie liefde en grote vertrouwen in mij. Lieve mama, niemand voelt mij zo goed aan als jij, bedankt dat je er altijd voor mij bent. En lieve papa, welke vader leest er elk wetenschappelijk artikel van zijn dochter, stuurt er krantenartikelen op ter informatie en inspiratie en denkt mee over stellingen? Leuk hè, dat er ook eentje van jou bij staat!

En dan zijn de laatste woorden voor degene die ik het kortst ken...

Lieve Pieter, net op tijd om een plekje in het dankwoord te bemachtigen ;) Wat ben ik blij dat ik jou heb leren kennen. Bedankt voor jouw liefde, het samenzijn en het geluk van de afgelopen maanden. Dat het nog maar heel lang mag duren! 